Nova Southeastern University

NSUWorks

$1-1-2015$

\title{
Mindfulness In Parenting Questionnaire (MIPQ): Development and validation of a measure of mindful parenting
}

Stacey McCaffrey

Nova Southeastern University, drstaceymccaffrey@gmail.com

This document is a product of extensive research conducted at the Nova Southeastern University College of Psychology. For more information on research and degree programs at the NSU College of Psychology, please click here.

Follow this and additional works at: https://nsuworks.nova.edu/cps_stuetd

Part of the Psychology Commons

\section{Share Feedback About This Item}

\section{NSUWorks Citation}

McCaffrey, S. (2015). Mindfulness In Parenting Questionnaire (MIPQ): Development and validation of a measure of mindful parenting. .

Available at: https://nsuworks.nova.edu/cps_stuetd/81 
Mindfulness In Parenting Questionnaire (MIPQ): Development and Validation of a Measure of Mindful Parenting

\section{by}

\section{Stacey A. McCaffrey, M.S.}
A Dissertation Presented to the School of Psychology of Nova Southeastern University in Partial Fulfillment of the Requirements for the Degree of Doctor of Philosophy

NOVA SOUTHEASTERN UNIVERSITY 


\section{DISSERTATION APPROVAL SHEET}

This dissertation was submitted by Stacey McCaffrey under the direction of the Chairperson of the dissertation committee listed below. It was submitted to the School of Psychology and approved in partial fulfilment of the requirements for the degree of Doctor of Philosophy in Clinical Psychology at Nova Southeastern University.

Approved:

Date of Defense

David Reitman, Ph.D., Chairperson

Ryan Black, Ph.D.

Barry Nierenberg, Ph.D.

Date of Final Approval

David Reitman, Ph.D., Chairperson 


\section{ACKNOWLEDGEMENTS}

First, I need to thank my dissertation chair, Dr. David Reitman, for his commitment and support during this challenging research endeavor. Thank you for your time, insight, and belief in me as I worked through this multiphase project. I would also like to thank my committee members, Dr. Ryan Black and Dr. Barry Nierenberg, for their guidance. Dr. Black, your enthusiasm for measure development is contagious, and I sincerely appreciate all the time you spent with me trying out new programs and running syntax.

Aside from my dissertation committee, I would like to thank my family for their unwavering support. Kelly — although we are many states away, I am grateful that we were able to work through the stages of our dissertations simultaneously and experience the challenge together. Last but not least, I want to thank my husband, Dr. Kevin McCaffrey, for his incredible patience, encouragement, love and support. 


\section{TABLE OF CONTENTS}

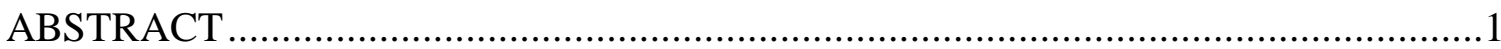

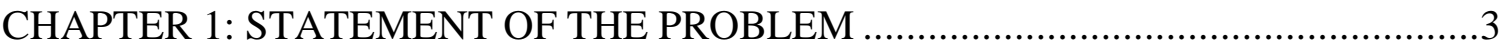

Benefits of Quantifying Mindful Parenting.........................................................

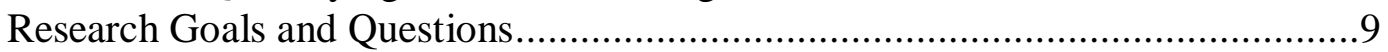

CHAPTER II: REVIEW OF THE LITERATURE ...................................................

History and Development of Mindfulness ....................................................10

Common Mindfulness Definitions and Conceptualizations..................................11

Mindfulness-Based Interventions for Adults................................................15

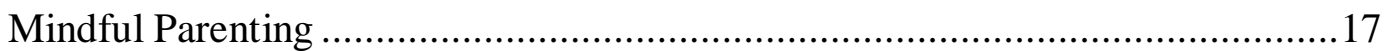

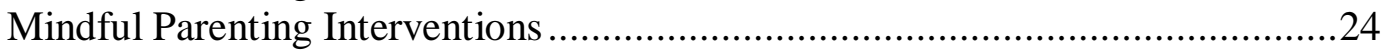

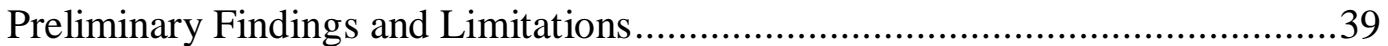

The Interpersonal Mindfulness in Parenting Scale ……....................................49

Measure Development Following from Modern Test Theory ..............................53

Modern Test Theory and Mindfulness Measures ………....................................57

Modern Test Theory and Mindful Parenting ...................................................58

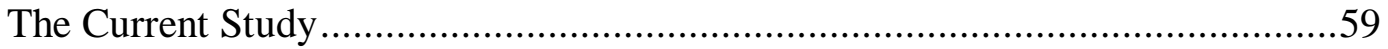

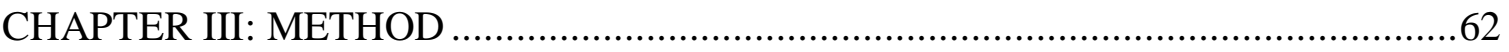

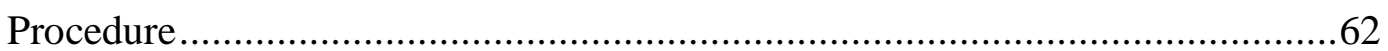

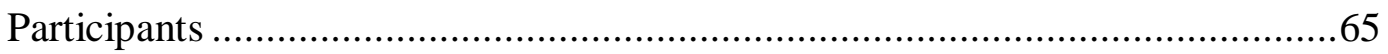

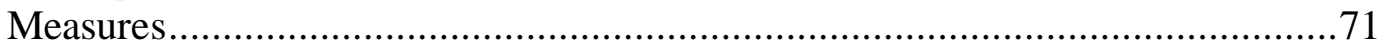

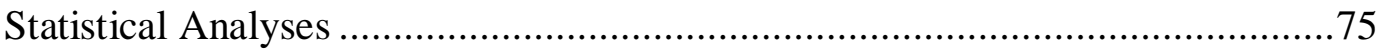

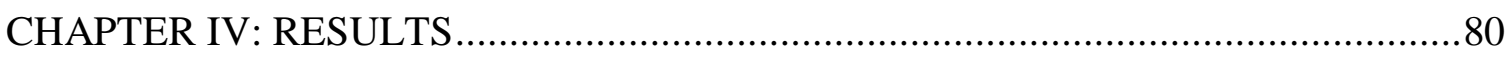

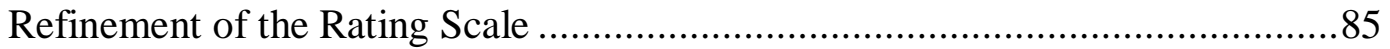

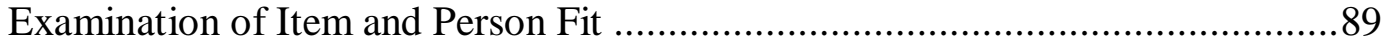

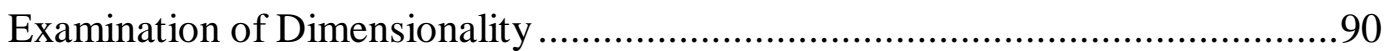

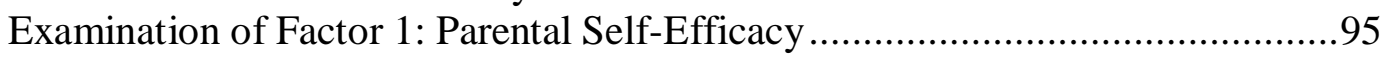

Examination of Factor 2: Being in the Moment with the Child ...........................95

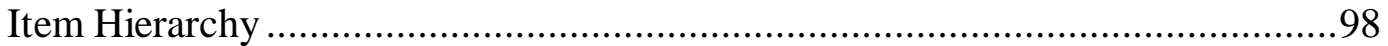

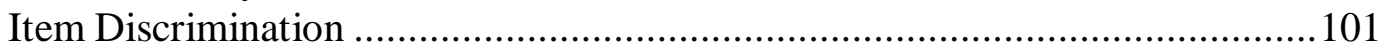

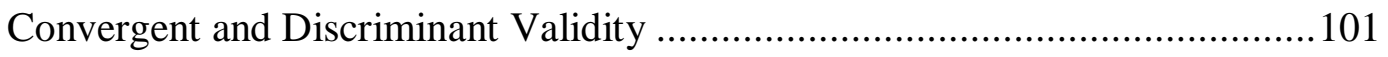

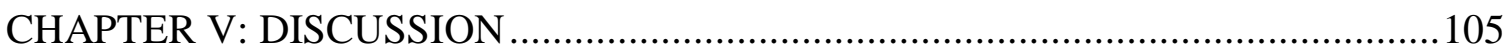

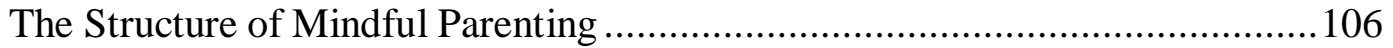

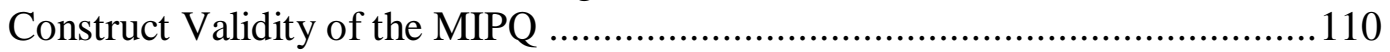

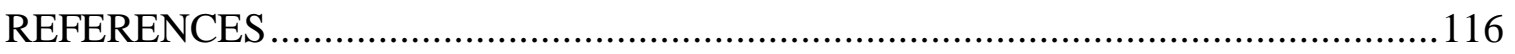

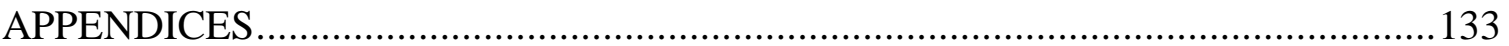


Appendix A: Initial MIPQ Created During Phase 1 ..................................... 133

Appendix B: Measures Used During Phase 3 …............................................ 138

Appendix C: Mindfulness In Parenting Questionnaire ................................... 148

Appendix D1: Eigenvalues from Factor Analysis ......................................... 150

Appendix D2: Scree Plot of MIPQ Positively Worded Items following PCA.... 152 


\section{LIST OF TABLES}

Table 1: Differential Conceptualizations of Mindfulness........................................... 12

Table 2: Application of Mindfulness to Youth and Parents ........................................25

Table 3: Application of Mindfulness to Parents.................................................28

Table 4: Results Following from the Application of Mindfulness to Youth and Parents .42

Table 5: Results Following from the Application of Mindfulness to Parents ................45

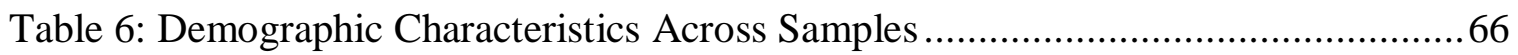

Table 7: Reliability Estimates of Study Measures .............................................. 75

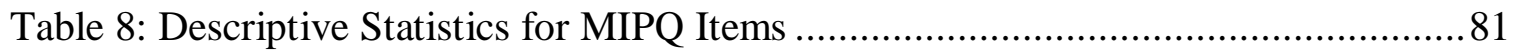

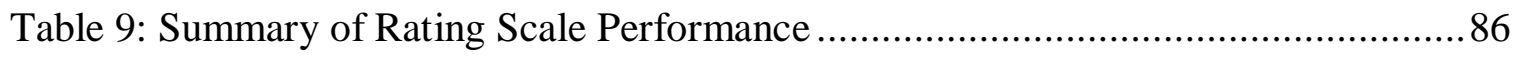

Table 10: Item Infit and Outfit .................................................................... 91

Table 11: Standardized Residual Loadings for Item .............................................93

Table 12: Item Fit by Factor and Discrimination Values .......................................96

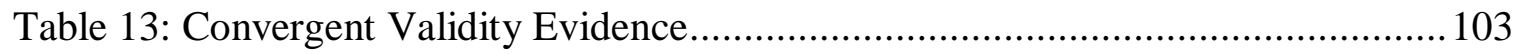

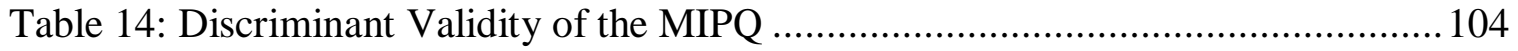




\section{LIST OF FIGURES}

Figure 1: Standardized Residual Contrast Plot ......................................................99

Figure 2: Person to Item Map for Factor 1 .......................................................... 99

Figure 3: Person to Item Map for Factor 2 .......................................................... 100 


\section{ABSTRACT \\ Mindfulness In Parenting Questionnaire (MIPQ): \\ Development and Validation of a Measure of Mindful Parenting \\ by}

\section{Stacey A. McCaffrey, M.S. \\ Nova Southeastern University}

Mindful parenting has been defined as "paying attention to your child and your parenting in a particular way: intentionally, here and now, and non-judgmentally" (Kabat-Zinn \& Kabat-Zinn, 1997). Although it is hypothesized that increasing mindful parenting improves parent and child functioning, the development of a measure of mindful parenting is needed to support this assumption. The aim of the present study was to develop and psychometrically evaluate a measure of mindful parenting (the Mindfulness In Parenting Questionnaire: MIPQ) for use with mothers and fathers of both children and adolescents, ranging in age from 2- to 16-years-old. The current study contained three phases. First, content experts in the area of mindfulness and parenting provided content for preliminary items. Second, parents participated in cognitive interviewing in order to reduce measurement error and increase the psychometrics of the measure. The third and final phase consisted of large-scale data collection to explore the psychometrics of the new MIPQ. Two-hundred and three parents recruited from academic and after-school programs in South Florida completed the MIPQ, along with measures of intrapersonal mindfulness, parenting behavior, parenting style, and a demographics questionnaire. The Partial Credit Model, which evidenced significantly better fit than the Rating Scale Model, was used to evaluate the MIPQ using WINSTEPS 3.74.01. The MIPQ was 
iteratively refined based on statistical and clinical considerations, resulting in a 28 -item measure with 4 response categories. Further, results supported a 2 factor mindful parenting construct. The first factor (Parental Self-Efficacy) reflects a parent's selfefficacy, as well as nonreactivity and awareness within the parenting role, while the second factor (Being in the Moment with the Child) pertains to the child, and reflects present-centered attention, empathic understanding, and acceptance of the child. Factors were correlated $(r=.67)$ and explained $42.3 \%$ and $43.4 \%$ of the variance, respectively. Correlations between the MIPQ and parenting style, parenting practices, practice of mindfulness, and participant demographics provided support for convergent and discriminant validity. The MIPQ exhibited a positive and weak correlation with the MAAS, indicating that interpersonal and intrapersonal mindfulness are related, but separate and distinct constructs. Limitations and directions for future research are discussed. 


\section{CHAPTER 1}

\section{Statement of the Problem}

Mindful parenting has been defined as "paying attention to your child and your parenting in a particular way: intentionally, here and now, and non-judgmentally" (Kabat-Zinn \& Kabat-Zinn, 1997). Authors have conceptualized mindful parenting as a "higher order construct that encompasses parent social cognitions, meta-cognition, emotions, and meta-emotion taking place in the parenting context" (Duncan, 2007, p. 15, unpublished dissertation). This practice of extending mindfulness to the social context of parent-child relationships has been described as an important tool in the development of secure attachment (Siegel \& Hartzell, 2003) and touted as a fundamental parenting skill (e.g., Kabat-Zinn \& Kabat-Zinn, 1997; Steinberg, 2004). Mindful parenting is hypothesized to result in a reduction of parental reactivity and to increase patience, parenting flexibility, responsiveness, consistency, and parenting that is in accordance with parents' goals and values (Duncan, Coatsworth, \& Greenberg, 2009a). Mindful parenting provides parents the ability to disrupt the automatic destructive cycle of negativity and disengagement and to choose more effective parenting strategies (Dishion, Burraston, \& Li, 2003; Dumas, 2005; Duncan et al., 2009a). Further, mindful parenting is believed to enhance the parent-child relationship by improving trust and emotional sharing, decreasing parenting stress, and increasing youth-well-being (Duncan et al., 2009a).

Given the hypothesized benefits of engaging in mindful parenting, researchers have begun developing and investigating the effectiveness of mindful parenting and mindfulness interventions for parents. Some of the studies utilized mindful parenting 
interventions (e.g., Coatsworth, Duncan, Greenberg, \& Nix, 2009), while others provided mindfulness to parents (a distinction that will be elucidated in Chapter 2). To date, over two dozen clinical studies have investigated the application of mindfulness with parents, or mindfulness with the combination of parents and their youth. These mindfulness-based interventions have been utilized with clinical and nonclinical populations, and they have targeted a variety of both parent and child symptoms and behaviors, as well as parentchild relationship variables. In general, studies have reported numerous positive outcomes, including improvement in parental functioning, such as reductions in stress, anxiety (Benn, Akiva, Arel, \& Roeser, 2012), parental distress, child abuse potential (Dawe, Harnett, Rendalls, \& Staiger, 2003; Dawe \& Harnett, 2007; Frye \& Dawe, 2008), and improvements in self-compassion and personal growth (Benn et al., 2012). Further, research has demonstrated a decrease in parents' HIV risk-taking behavior and methadone maintenance (Dawe et al., 2003), lower parenting stress (Dawe \& Harnett, 2007; Frye \& Dawe, 2008; Harnett \& Dawe, 2008; Singh et al., 2007), a more positive parent child relationship (Dawe et al., 2003; Harnett \& Dawe, 2008), and greater parenting satisfaction (Singh et al., 2007) following mindfulness-based interventions for parents. Empirical evidence suggests that children's behavior may also improve after their parents engage in a mindfulness intervention; authors have reported a decrease in children's externalizing behavior problems, such as noncompliance, hyperactivity, aggression, self-injury (Dawe \& Harnett, 2007; Singh et al., 2006; Singh et al., 2010; Srivastava et al., 2011), a reduction in anxious behavior (Srivastava et al., 2011), and an increase in social skills (Singh et al., 2007). 
Some authors have attributed these positive outcomes to changes in parents' mindfulness (e.g., Benn et al., 2012). However, Harnett and Dawe (2012) emphasize the problem with focusing on mindfulness without considering other variables which inextricably influence child development and family functioning, as well as their possible mediating role in treatment. Indeed, a variety of mindfulness-based interventions were implemented in the abovementioned studies, several containing multiple treatment components (e.g., concentration meditation, bibliotherapy), as well as numerous nonspecific factors (e.g., supportive environment, social contact with other parents who are experiencing similar difficulties, etc.) that could be responsible for changes in dependent variables. However, there is little evidence that parents' mindfulness is responsible for the treatment effect, as mindfulness is rarely evaluated directly. Among the few studies that have evaluated mindfulness, the vast majority have assessed parents' mindfulness (intrapersonal mindfulness; Benn et al., 2012, Saltzman \& Goldin, 2009, van der Oord, Bogels, \& Peijnenburg 2012, van de Weijer-Bergsma, Formsma, de Bruin, \& Bogels, 2012) as opposed to mindful parenting (interpersonal mindfulness). Only one clinical study has assessed mindful parenting (Coatsworth et al., 2009). A failure to measure mindful parenting is particularly problematic, as interpersonal mindfulness is often the target of mindful parenting training interventions and is presumably responsible for treatment effects.

While measures of mindfulness typically assess an individual's intrapersonal mindfulness, they fail to evaluate mindfulness within social interactions (e.g., the parentchild relationship). According to Duncan (2007; unpublished dissertation), knowing an individual's level of intrapersonal mindfulness does not necessarily strongly predict their 
reactivity, judgment, and awareness in social interactions. Currently, one measure of mindful parenting exists. The Interpersonal Mindfulness in Parenting (IEM-P; Duncan, 2007, unpublished dissertation) scale was developed for use with parents of at-risk adolescents (10-14 years), and contains 8-items IEM-P which comprise four factors. However, little psychometric information for this measure is available. When utilizing the original 10-item IM-P in a clinical study (the acronym IEM-P was changed to IM-P in all research after the initial scale development), Coatsworth and colleagues (2009) reported an internal consistency of $\alpha=0.61$. More recently, the IM-P was expanded from 10 items to 31 items and translated into Dutch. This validation study (de Bruin et al., 2012), utilizing a general population sample of Dutch mothers of adolescents (12-15 years), yielded a 29-item measure with a six factor structure, with subscale internal consistencies of .54 to .83 . Authors also reported some evidence for convergent validity in this sample through partial correlations (controlling for parent age) with the Dutch IM$\mathrm{P}$ and a measure of optimism and depression. In a separate sample that included the Parenting Scale, the Five Facet Mindfulness Questionnaire, and the World Health Organization Quality of Life-Short Version (WHOQOL-BREF), convergent validity was also confirmed through correlations. Additionally, convergent and factorial validity of the Dutch IM-P held in a sample of mothers of adolescents with type 1 diabetes mellitus (de Bruin et al., 2012). Although this study provides some psychometric support for the use of the Dutch IM-P with Dutch mothers of adolescents with and without type 1 diabetes, use of the Dutch IM-P may be limited to these populations. That is, the Dutch IM-P is not intended for use with parents of children or older adolescents, psychiatric populations, or 
for parents of youth who are not considered at-risk, and no psychometric information for these populations exists.

As mindful parenting interventions are presumed to lead to improvements in parent and child functioning as a consequence of increasing parents' interpersonal mindfulness, having an adequate measure of mindful parenting is essential to effectively assess this hypothesis. Further, this hypothesis rests on the assumption that mindfulness within the parent-child relationship is a skill that can be fostered or taught. For instance, in the intrapersonal mindfulness literature, some researchers view mindfulness as a skill that can be taught or a fluctuating state, while others view it more similarly to a dispositional trait (e.g., Baer et al., 2009; Miners, 2008). Having the ability to assess parents' mindful parenting before and after an intervention would provide information as to the stability or "teach-ability" of this construct.

\section{Benefits of Quantifying Mindful Parenting}

Although numerous benefits are theorized to be associated with mindful parenting, these hypotheses remain largely untested. A psychometrically adequate measure of mindful parenting would allow researchers to investigate the relation between mindful parenting and various parenting styles and behaviors, parental psychopathology, etc., further elucidating the dynamic relationship between parental factors and child wellbeing. If mindful parenting is found to be related (i.e., correlated) to various positive characteristics (e.g., low parenting stress, a positive parent-child relationship, low child psychopathology), it may be fruitful to further investigate the nature of the relationship. When two variables are related, more information (e.g., temporal precedence, nonspuriousness) is needed to understand whether one variable is causally related to the 
other, which variable leads to change in the other variable (i.e., does mindful parenting lead to improvements in parenting behaviors or does changing parenting behaviors lead to an increase in mindful parenting?), or whether a separate variable can account for the associated relationship. For example, examination of temporal precedence may reveal that mindful parenting functions as a protective factor against maternal stress as she has more children. Alternatively, it may be that family income, social support, or living in a two-parent household accounts for this relationship. With this information, researchers can determine what variables to target during intervention.

If research demonstrates that mindful parenting mediates, or is responsible for, improvement in parent functioning, child functioning, and the parent-child relationship, then a measure of mindful parenting could allow clinicians to identify parents who may be "at risk" due to low levels of mindful parenting and would benefit from intervention. Screening parents to identify who is most likely to benefit from intervention would increase the efficiency and cost-effectiveness of clinical work. Finally, studying how mindful parenting changes across various intervention components would allow investigators to identify the most effective (or active) components, and create more efficient mindful parenting interventions.

Based on hypotheses regarding the benefits of mindful parenting, clinical studies that attempt to deliver mindful parenting interventions are premature without an adequate measure of mindful parenting. That is, it is not possible to determine whether the intervention is actually increasing parents' intrapersonal mindfulness, or whether such an increase in responsible for treatment effects. A measure of mindful parenting is a prerequisite for clinical studies and research of mindful parenting. Consequently, the 
purpose of the current study is to develop and psychometrically evaluate a measure of mindful parenting.

\section{Research Goals and Questions}

The primary goal of the study is to develop a measure of mindful parenting for parents of children and adolescents (i.e., the Mindfulness In Parenting Questionnaire; MIPQ). Development and psychometric evaluation of the MIPQ will follow modern test theory approaches, which are considered more rigorous than classical approaches to psychometric evaluation. In conjunction with developing the MIPQ, the following research questions will be addressed:

(1) What is the structure of the mindful parenting construct?

(2) Is mindful parenting distinct from intrapersonal mindfulness?

(3) How is mindful parenting related to parenting style and behaviors? 


\section{CHAPTER II}

\section{Review of the Literature}

\section{History and Development of Mindfulness}

The first generation of behavior therapy, born in the 1950s, developed as a rejection against existing clinical psychoanalytic theory and focused on direct symptom relief through the application of well-established basic principles (Hayes, Follette, \& Linehan, 2004). Cognitive- behavior therapy, considered the "second generation" behavior therapy, grew out of the first generation by expanding the scope, models, and methods. Specifically, thoughts and feelings were dealt with in a more direct and central way by identifying and correcting cognitive errors (Hayes et al., 2004). Overall, behavioral therapies (comprising the first and second generations) "dominate lists of empirically supported treatments and practice guidelines" as effective approaches (Hayes et al., 2004, p. 3).

According to Hayes, mindfulness and acceptance are "third generation" behavior therapies (Hayes et al., 2004; Hayes, 2004). First gaining empirical support through dialectical behavior therapy (DBT; Linehan, 1993), mindfulness and acceptance are said to carry behavior and cognitive behavior therapy forward by questioning the universal applicability of first-order change strategies, emphasizing contextualistic assumptions, utilizing experiential and indirect change strategies along with direct strategies, and broadening the focus of change (Hayes et al., 2004). However, these ideas are hardly new. Historically, mindfulness has been the fundamental attentional stance, or "the heart”, underlying all streams of Buddhist meditative practice (Thera, 1962; as cited in Kabat-Zinn, 2005). While mindfulness has undergone its greatest development over the 
past 2,500 years (Kabat-Zinn, 2005), it is not uniquely Buddhist and is also fundamental to other ancient traditions. Mindfulness is therefore regarded as "culture free," "universal," and "timeless" (Kabat-Zinn, 2005).

\section{Common Mindfulness Definitions and Conceptualizations}

In the mindfulness literature, the vast majority of authors define mindfulness by invoking Kabat-Zinn's popular definition: "paying attention in a particular way: on purpose, in the present moment, and nonjudgmentally" (1994, p. 4). However, several authors have noted the discrepancy in descriptions of mindfulness across investigators (e.g., Bishop et al., 2004). As noted by Hayes and Wilson (2003), some of this confusion may arise from the various ways in which authors treat the concept of mindfulness. That is, mindfulness has been viewed as a technique, as a general method or collection of techniques, as an independent variable (i.e., a psychological process that can produce outcomes), and as a dependent variable (an outcome in and of itself; see Table 1). Given the lack of an operational definition of mindfulness (see below), it is not surprising that recent review articles struggle to draw conclusions about mindfulness and its assessment (e.g., Bergomi, Tschacher, \& Kupper, 2012; Burke, 2010).

For instance, Linehan (1993) defined mindfulness as a method or collection of techniques. Specifically, she discusses a set of "what" skills (i.e., observing current experiencing, describing/labeling experiences with words, and participating) and "how" skills (i.e., being nonjudgmental, one-minded, and effective). Baer and colleagues offer a similar conceptualization. They describe this particular type of attending (i.e., mindful attending) as “acceptance, openness, allowing, nonjudging, willingness, kindness, and curiosity" (Baer, Walsh, \& Lykins, 2009, p. 155). Frequently, mindfulness is described as 
an awareness that results from paying attention (e.g., Brown \& Ryan, 2004; Kabat-Zinn, 2003; Williams, Teasdale, Segal, \& Kabat-Zinn, 2007). From this perspective, mindfulness may be viewed as an outcome.

Table 1

Differential Conceptualizations of Mindfulness

\begin{tabular}{ll}
\hline Conceptualization of Mindfulness & \multicolumn{1}{c}{ Examples } \\
\hline Technique(s) or method & $\begin{array}{l}\text { "What" skills (i.e., observing current experiencing, } \\
\text { describing/labeling experiences with words, and } \\
\text { participating) and "how" skills (i.e., being } \\
\text { nonjudgmental, one-minded, and effective; Linehan, } \\
\text { 1993) }\end{array}$ \\
\hline $\begin{array}{l}\text { Independent variable } \\
\text { (psychological process that can } \\
\text { produce outcomes) }\end{array}$ & $\begin{array}{l}\text { et al., 2004) } \\
\text { m This creative state of mind or "wakefulness" } \\
\text { results in an increased sensitivity to the environment, }\end{array}$ \\
& $\begin{array}{l}\text { a greater capacity for creativity and broadening } \\
\text { perspectives in problem solving (Langer \& } \\
\text { Moldoveanu, 2002) }\end{array}$ \\
\hline $\begin{array}{l}\text { Dependent variable } \\
\text { (outcome in and of itself) }\end{array}$ & (e.g., Brown \& Ryan, 2004; Kabat-Zinn, 2003; \\
& Williams, Teasdale, Segal, \& Kabat-Zinn, 2007) \\
\hline
\end{tabular}

Note. This concept underlying this table was taken from Hayes and Wilson (2003)

While the preponderance of mindfulness definitions emphasize attention, some authors stress thought over attention. Langer describes mindfulness as "an open, assimilative 'wakefulness' to cognitive tasks, in which thought is used flexibly to create new categories, draw distinctions, and seek multiple perspectives" (Langer, 1989, as cited in Brown et al., 2011, p. 1023). From this perspective, this creative state of mind results in an increased sensitivity to the environment, a greater capacity for creativity, and broadening perspectives in problem solving (Langer \& Moldoveanu, 2002). Kabat-Zinn (2003) discusses mindfulness as "insight meditation”, where individuals engage in “deep, penetrative nonconceptual seeing into the nature of mind and world" which requires constant inquiry and curiosity ("what is this?"; 2003, p. 146). From this perspective, 
conceptualizing inquiry is necessary and fundamental to mindfulness. Because of the emphasis on attention, awareness, thought, and action, many authors highlight mindfulness' universality and describe it as a "natural propensity" for humans (Baer et al., 2009; Kabat-Zinn, 2003).

The distinction between mindfulness and related constructs. Further complicating the definitional issue, researchers disagree as to the distinction between mindfulness, acceptance, decentering, defusion, interoceptive exposure and values; some attempt to distinguish these constructs while others use them interchangeably. According to Hayes and Wilson (2003), these concepts are similar in that they all emphasize contextual targets, seek to increase flexibility, and focus on the impact of language. Others view these constructs as elements of mindfulness (Block-Lerner et al., 2005; Dimidjian \& Linehan, 2003), while others view them as mindfulness outcomes (Bishop et al., 2004) or as skills that aid in fostering mindfulness (Brown, Ryan, \& Creswell, 2007; see Baer et al., 2009 for a discussion). Mindfulness approaches are however, typically regarded as more than simply relaxation or mood management techniques (Naranjo \& Ornstein, 1971). On the other hand, mindfulness has been described by some as a "form of mental training to reduce cognitive vulnerability to reactive modes of mind that might otherwise heighten stress and emotional distress, or that may otherwise perpetuate psychopathology" (Bishop et al., 2004, p. 231).

The search for an operational definition of mindfulness. Operationally defining a variable entails stating the construct in measurable terms so that validity testing can be conducted and its theoretical structure (e.g., stability, number of factors) confirmed empirically (Bishop et al., 2004). In 2004, Bishop and colleagues attempted to 
develop such an operational definition. Through a series of meetings, researchers arrived at consensus regarding the components of mindfulness, developed an operational definition, and provided testable predictions for validation. According to Bishop and colleagues (2004), mindfulness is a metacognitive process which consists of: 1) selfregulation of attention and 2) experiential openness and acceptance. For example, if mindfulness is an increased recognition of mental events in the present moment, it should be related to sustained attention, switching (e.g., standard vigilance tests), and improvements in cognitive inhibition/level of stimulus selection (e.g., emotional Stroop; Bishop et al., 2004). Additionally, authors maintain that holding an open, accepting and curious attitude towards experience should be associated with reductions in experiential avoidance (e.g., a repressive coping style as measured by the Miller Behavioral Style Scale; Miller, 1980), and positively related to emotional awareness (e.g., measured by the Levels of Emotional Awareness Scale; Lane, Quinlan, Schwartz, Walker, \& Zeitlin, 1990) and psychological mindedness (e.g., Psychological Mindedness Scale; Conte \& Ratto, 1997).

Brown and Ryan (2004) refined Bishop's operational definition by distinguishing between attention and awareness, and also critiqued other aspects of the proposed definition. Specifically, the authors assert that mindfulness is distinct from cognition and cannot be described as a metacognitive skill; "if mindfulness involves observing thought, including thoughts about thoughts, it cannot be thought" (Brown \& Ryan, 2004, p. 243). Moreover, authors highlight a contradiction in Bishop and colleagues' assertion that mindfulness involves maintaining focus while at the same time allowing the curious mind to wander. As a resolution, Brown and Ryan suggest that concentration and 
awareness/insight are forms of meditative practice that play a part in how mindfulness is obtained. Based on their own research, authors emphasize that acceptance is rooted in the capacity to sustain attention and experiential awareness, and should not be construed as a second component of mindfulness (Brown \& Ryan, 2003). In sum, these structural differences in the theoretical underpinnings of mindfulness led authors to an alternative operational definition of mindfulness as a receptive awareness and attention to ongoing events and experience (e.g., Brown \& Ryan, 2003; 2004).

The unresolved issues in the operational definition of mindfulness presented above are not comprehensive but are representative of challenges associated with describing the structure of this elusive construct. While many of the definitions share similar features and core components, these discrepancies have implications for measure development and refinement. For example, different definitions of mindfulness suggest different expectations about stability of mindfulness measures. For example, Miners (2008) describes mindfulness as containing both state and trait characteristics, arguing that it is an enduring disposition as well as a fluctuating state. Conversely, Bishop et al. (2004) contend that mindfulness is closer to a state (or mode) than a trait due to its dependence upon the maintenance of attention regulation (2004). Further, there is some evidence to suggest that mindfulness can be enhanced through training, and therefore may be considered a skill (e.g., Baer et al., 2009; Kabat-Zinn, 2003; Miners 2008).

\section{Mindfulness-Based Interventions for Adults}

Mindfulness-based interventions have been used for decades with a variety of adult populations to promote psychological health and well-being. The predominant mindfulness-based approaches for use with adults (Burke, 2010) include mindfulness- 
based stress reduction (MBSR; Kabat-Zinn, 1990), mindfulness-based cognitive therapy (MBCT; Segal, Williams, \& Teasdale, 2002), dialectical behavior therapy (DBT; Linehan, Armstrong, Suarez, Allmon, \& Heard, 1991) and acceptance and commitment therapy (ACT; Hayes, Strosahl, \& Wilson, 1999). In clinical studies with adult populations, mindfulness-based interventions have demonstrated efficacy for treatment of chronic pain, stress, anxiety, psoriasis, eating disorders, substance abuse, generalized anxiety disorder, mood disorders, bipolar disorder, and to improve outcomes with cancer patients (see Baer, 2006). Meta-analyses have estimated an overall medium effect size for mindfulness-based intervention on physical and psychological health (Baer, 2003;

Grossman, Niemann, Schmidt, \& Walach, 2004).

Following the successful application and outcomes of utilizing mindfulness interventions with adult populations, researchers began investigating the application of these interventions for use with parents and children (see Burke, 2010 and Harnett \& Dawe, 2012 for reviews of mindfulness-based approaches with children and families). Indeed, interest in the area of mindfulness with parents and children has grown rapidly in the last several years. A search on the PsycInfo database for the keywords "mindfulness" and "child" or "adolescent" before 2003 reveals 5 results, and a search for "mindfulness" and "parents" or "parenting" reveals only 1 result (a dissertation). In the last decade alone, PsycInfo produces 188 results for the keywords "mindfulness" and "child" or “adolescent," and a search for "mindfulness" and "parents" or "parenting" reveals 63 results. 


\section{Mindful Parenting}

In the literature, mindful parenting is commonly defined as "paying attention to your child and your parenting in a particular way: intentionally, in the present moment, and non-judgmentally" (Kabat-Zinn \& Kabat-Zinn, 1997). Mindful parenting is hypothesized to result in a reduction of parental reactivity and to increase patience, parenting flexibility, responsiveness, consistency, and parenting that is in accordance with goals and values (Duncan et al., 2009a). Mindful parenting may allow parents to disrupt the automatic destructive cycle of negativity and disengagement and choose more effective parenting strategies (Dishion et al., 2003; Dumas, 2005; Duncan et al., 2009a). Further, mindful parenting is believed to enhance the parent-child relationship by improving trust and emotional sharing, decreasing parenting stress, and increasing youthwell-being (Duncan et al., 2009a). According to Duncan and colleagues (2009a), "parents who can remain aware and accepting of their child's needs through using mindfulness practices can create a family context that allows for more enduring satisfaction and enjoyment in the parent-child relationship" (p. 256).

Mindful parenting has been described as "attributes, skills, and practices" (Duncan et al., 2009a, p. 259). Importantly, mindful parenting is believed to be malleable, or a skill that can be fostered through practice and intervention (e.g., Dumas, 2005). Dumas (2005) describes mindfulness in parenting as a skill that essentially can be "turned on" or "turned off" consciously by parents when needed. For example, Dumas discusses how mindfulness can be used purposefully by parents to change automatic dysfunctional interactions and choose more adaptive alternative behaviors; "When this is successful, it replaces old, mindless habits with more effective ways of coping that should become just 
as mindless with practice” (Dumas, 2005, p. 789). Indeed, authors have hypothesized about the utility in providing interventions to parents that are aimed at increasing parents' mindful parenting, and numerous interventions have been created and tested (see below).

However, the hypothesis that interpersonal mindfulness is conceptually separate or unique from intrapersonal mindfulness has not been adequately tested. Duncan (2007, unpublished dissertation) assessed the relation between the 8-item IEM-P and a measure of intrapersonal mindfulness and found that intrapersonal mindfulness accounted for approximately half of the variance in mindful parenting. However, the intrapersonal mindfulness instrument was created for purposes of the study, and psychometric information for this instrument is unknown (e.g., is it a reliable and valid measure of intrapersonal mindfulness?). Further research is needed to clarify this relationship.

Additionally, the conceptual structure of mindful parenting is unclear. That is, while researchers have hypothesized several different structural models, a paucity of research supporting any one structure exists. As discussed below, Duncan (2007) first hypothesized that mindful parenting consisted of three factors. However, data her dissertation supported a four factor structure (i.e., present-centered attention, emotional awareness, non-judgmental receptivity, non-reactivity). In 2009, Duncan, Coatsworth, and Greenberg (2009a) presented a five factor model of mindful parenting in a theoretical paper. Dimensions included: (a) listening with full attention, (b) nonjudgmental acceptance of self and child, (c) emotional awareness of self and child, (d) self-regulation in the parenting relationship, and (e) compassion for self and others. In 2012, a validation study of the 29-item Dutch IM-P suggested a six factor structure (de Bruin et al., 2012). These six factors included listening with full attention, compassion for child, non- 
judgmental acceptance of parental functioning, emotional non-reactivity in parenting, emotional awareness of child, and emotional awareness of self. In sum, the discrepancies in factor structure in mindful parenting (as assessed through different versions of the IMP) leave the structure of mindful parenting unclear.

Mechanisms underlying mindful parenting. Several authors have hypothesized about the mechanisms underlying mindful parenting. Bogels, Lehtonen, and Restifo (2010) assert that mindful parenting may bring about change in parent-child interaction by: (1) decreasing parental stress and reactivity; (2) reducing parental preoccupation resulting from parental and/or child psychopathology; (3) improving parental executive functioning; (4) interrupting the transmission of dysfunctional parenting schemes and habits; (5) increasing self-nourishing attention; and (6) improving marital functioning and co-parenting. Importantly, Bogels and colleagues assert that these changes occur as a result of mindfulness' impact on parental attention (2010). Indeed, results from several studies have suggested that attention is related (i.e., correlated) with mindfulness, and that mindfulness may improve aspects of attention; specifically, the ability to disengage from unexpected and emotional stimuli and attention conflict monitoring (e.g., see Galla, Hale, Shrestha, Loo, \& Smalley, 2012; Jha, Krompinger, \& Baime, 2007; Ortner, Kilner, \& Zelazo, 2007; Tang et al., 2007; Valentine \& Sweet, 1999).

According to Duncan, Coatsworth and Greenberg (2009a), interpersonal mindfulness allows a parent to have clearer awareness of their immediate experience, allowing for greater choice in responding and providing alternatives to engaging in automatic cognitions and behaviors. Based on their five-dimensional model (described above), authors theorize how mindful parenting promotes effective parenting behaviors. 
For example, listening with full attention is anticipated to lead to accurately discerning the child's behavioral cues and the child's verbal communication. Similarly, selfregulation in the parenting relationship would be expected to result in better emotion regulation in the parenting context and parenting in accordance with goals and values (see Duncan et al., 2009a). In their model, Duncan and colleagues view mindful parenting as directly impacting parenting and parental well-being, which in turn influences child management practices and parent-child affection, and lead to youth positive or problematic outcomes (e.g., conduct problems, substance use, child wellbeing and self-regulation). Because of mindful parenting's direct path to parenting and parental well-being, Duncan's model fundamentally differs from Bogels and colleagues (2010) who view mindfulness as having an indirect impact on parenting-child relationship and parenting through parental attention.

Similar models have been proposed by other authors. For instance, Benn, Akiva, Arel, and Roeser (2012) hypothesized that mindful parenting improves parents' emotion regulation and problem solving through listening, increased awareness of internal reactions, and responding with greater skill and calm when confronted with emotional events. Akin to Duncan's dimensions of nonjudgmental acceptance of self/child and compassion of self/child, both O'Brien, Larson, and Murrell (2008) and Kabat-Zinn and Kabat-Zinn (1997) conclude that sovereignty (honoring the child's "true selves"), empathy (attempting to see the world from their child's perspective), and acceptance form the foundation for mindful parenting.

Offering a unique perspective on the function of mindful parenting, Dumas (2005) theorized that three methods of fostering mindfulness (facilitative listening, distancing, 
and motivated action plans) could be used as a "stepping stone to a different, more productive mindfulness between parents and children" (p. 783). From Dumas' perspective, increasing a parents' trait mindfulness or increasing mindfulness in the longterm is not the goal; instead, mindfulness strategies should be employed in a short-term intervention to move a parent from dysfunctional automatized interactions to more productive ones. Other authors have also suggested that mindfulness reduces reactivity (e.g., Bluth \& Wahler, 2011) and may lead to reduced automatized reactions or parenting behaviors. Indeed, research has demonstrated that intrapersonal mindfulness may attenuate prolonged reactivity to negative stimuli (Ortner et al., 2007), supporting the possibly that mindfulness may be responsible for a reduction in parental reactivity. However, whether these findings can be extended to interpersonal relationships is not clear (see Eyberg \& Graham-Pole, 2005, for an argument against the inclusion of mindfulness with behavioral parent training).

From a relational frame theory perspective, Coyne and Wilson (2004) alternatively suggest that the effectiveness of mindfulness and acceptance (ACT) may improve parenting by breaking patterns of cognitive fusion. That is, parents may react to their own thoughts of failure (e.g., "I am not able to control my child's behavior," "my child is trying to irritate me") as opposed to what their child is experiencing in the present moment, leading to escalation of ineffective parenting efforts (Coyne \& Wilson, 2004). Through ACT, parents are taught to be more mindful and accepting of their child's experience as unique from their own, allowing them to respond more effectively.

Another key mechanism identified in the literature is insight. That is, Williams and Wahler (2010) cite that mindful parenting alters parenting style through insight. 
According to these authors, when a mother notices how her style impacts her child's behavior, she will choose more authoritative interactions. Indeed, Williams and Wahler's (2010) research supports the hypothesis that parenting style mediates the connection between mothers' mindfulness and their perception of child behavior. Similar to insight, Bogels and colleagues suggest that mindful parenting may allow parents to take a more objective approach to their interactions with their children, or observe what is happening more accurately (Bogels, Hoogstad, van Dun, de Schutter, \& Restifo, 2008). This "reperceiving" in turn leads to improved self- and emotion-regulation, according to authors (Bogels et al., 2008).

Wahler, Rowinski, and Williams (2008) have studied parents' responsiveness and sensitivity (what authors refer to as "synchrony") to their child. According to authors, parents must maintain synchrony with their child over time and have the ability to remain flexible in how and when they respond to their children. Mindfulness meditation teaches parents how to sustain this flexibility and facilitates maintenance of effective parenting over time (Wahler et al., 2008).

In multiple single-case design studies, Singh and colleagues taught mothers mindfulness strategies and asked them to apply the strategies to interactions with their children. Although unable to explain how it occurs, authors attributed mothers' observations of change (i.e., improvements) in their child's behavior to fundamental, transformational changes in the way that the mothers related to events in their environments (e.g., Singh et al., 2006). Mindfulness "changes the very nature of the individual", and "opens up a developmental pathway that produces positive, bidirectional parent-child transactions", according to authors (Singh et al., 2006, p.175). Further, 
authors assert that teaching skills (e.g., such as those parenting skills taught in behavioral parent training) is not necessary to produce changes in the child's behavior. Yet, as authors note, further research is needed to investigate exactly how mindfulness brings about these transformational changes.

Based on the literature described above, the reader is left with an extensive list of possibilities for the mechanisms underlying mindful parenting, including: changes in attention, listening, acceptance, emotional awareness, self-regulation/reactivity, compassion, empathy, dysfunctional automatized interactions, cognitive fusion, insight, synchrony, and transformational changes in parents. Despite the variety of models and hypothesized key mechanisms reviewed, common themes can be distilled from these studies. As identified by Harnett and Dawe (2012), what seems to be the consistent view is that "heightened parental awareness of their own and their child's emotional states and enhanced parental emotional regulation skills allow the parent to respond more flexibly to the child, as opposed to responding with a "'mindless' automated negative reactivity" ( $\mathrm{p}$. 11). Importantly, a limitation for many of the models proposed above is that they suggest mindfulness outcomes (e.g., improving acceptance of self and child and reducing reactivity), but do not explain how (i.e., the mechanisms) teaching parents mindfulness or mindful parenting specifically leads to these outcomes. Notably, there is some preliminary evidence proposing that attention is affected by mindfulness (see Bogels et al. 2010), suggesting it may be a key mechanism of intervention effects. However, further research is needed before any particular model can be supported. 


\section{Mindful Parenting Interventions}

Over the past decade, a variety of mindfulness interventions with parents have been investigated in clinical studies. These interventions vary along a number of factors, including the core mindfulness strategy utilized (e.g., MBCT, MBSR, DBT, ACT, etc.), their length, their setting, and whether parents alone or parents and their children both are involved in the intervention. The population for which each intervention was created and evaluated also varies across studies, and is closely related to the unique goals of the interventions; some of these goals include improving the parent's well-being (e.g., parenting satisfaction, reducing parental stress) and functioning within the parenting role, improving the parent-child relationship, and improving the child's psychological functioning and well-being. Further, several of these mindfulness-based interventions for parents target parents' mindfulness, while others call themselves "mindful parenting interventions" and focus on a parent's interpersonal mindfulness within the context of the parent-child relationship specifically. For purposes of the current dissertation, all clinical studies utilizing mindful parenting as well as mindfulness with parents are included to provide the reader with a comprehensive picture of the existing mindfulness literature. First, an overview of the clinical studies that have utilized mindful parenting is provided, including discussion of the particular intervention types and populations that have been targeted through this research. Specific information about each clinical study is contained in Tables 2 and 3. Second, preliminary findings extrapolated from this research are highlighted. Finally, limitations of the current evidence base are identified. 
Table 2

Application of Mindfulness to Youth and Parents

\begin{tabular}{|c|c|c|c|c|c|c|c|c|}
\hline $\begin{array}{l}\text { Authors/ } \\
\text { Date }\end{array}$ & $\begin{array}{l}\text { Age of } \\
\text { Youth }\end{array}$ & $\mathrm{N}$ & $\begin{array}{c}\text { Clinical/ } \\
\text { Nonclinical }\end{array}$ & DV & $\begin{array}{l}\text { Intervention } \\
\text { Provided } \\
\end{array}$ & Intervention Provided by & Intervention Length & $\begin{array}{c}\text { Intervention } \\
\text { Setting }\end{array}$ \\
\hline $\begin{array}{l}\text { Bogels } \\
(2008)\end{array}$ & \begin{tabular}{|l|}
$11-18$ \\
years
\end{tabular} & $\begin{array}{l}14 \text { youth; } \\
12 \text { with } \\
\text { mom and/ } \\
\text { or dad }\end{array}$ & $\begin{array}{l}\text { Clinical } \\
\text { (ADHD, ODD } \\
\text { and/or CD, and } \\
\text { ASD with } \\
\text { externalizing } \\
\text { problem bx) }\end{array}$ & $\begin{array}{l}\text { Youth-report of personal } \\
\text { goals, internalizing and } \\
\text { externalizing complaints, } \\
\text { attention problems, } \\
\text { happiness, mindful } \\
\text { awareness; sustained } \\
\text { attention on performance } \\
\text { test; parent-report of youth } \\
\text { goals, externalizing and } \\
\text { attention problems, self- } \\
\text { control, social behavior }\end{array}$ & $\begin{array}{l}\text { Group MBCT } \\
\text { adapted for youth; } \\
\text { the child program } \\
\text { was adapted to } \\
\text { create mindful } \\
\text { parenting for } \\
\text { parents }\end{array}$ & \begin{tabular}{|l|} 
Experienced therapists \\
who received \\
mindfulness training and \\
were experienced in \\
mindfulness and \\
meditation techniques.
\end{tabular} & \begin{tabular}{|l|} 
Eight 90 -minute \\
weekly sessions with \\
daily home practice; \\
parents and youth met \\
in separate groups
\end{tabular} & Not stated \\
\hline $\begin{array}{l}\text { Singh et } \\
\text { al. (2009) }\end{array}$ & $\begin{array}{l}10-12 \\
\text { years }\end{array}$ & 2 dyads & $\begin{array}{l}\text { Clinical } \\
\text { (ADHD) }\end{array}$ & $\begin{array}{l}\text { Compliance, satisfaction } \\
\text { with self in interactions with } \\
\text { my child (SSIMC) and } \\
\text { subjective units of happiness } \\
\text { with my child (SUHMC) }\end{array}$ & $\begin{array}{l}\text { mindfulness } \\
\text { training for } \\
\text { mothers; child } \\
\text { training was } \\
\text { modeled after the } \\
\text { mother's training } \\
\text { and included } \\
\text { children's } \\
\text { mindfulness books }\end{array}$ & $\begin{array}{l}\text { Experienced } \\
\text { mindfulness trainer }\end{array}$ & $\begin{array}{l}12 \text { weeks of mother } \\
\text { training followed by } \\
12 \text { weeks of child } \\
\text { training }\end{array}$ & Not stated \\
\hline \begin{tabular}{|l} 
Saltzman \\
$\&$ Goldin \\
$(2009)$
\end{tabular} & $\begin{array}{l}\text { Grades 4- } \\
6 \text {; dyad } \\
\text { and family } \\
\text { formats }\end{array}$ & $\begin{array}{l}31 \\
\text { children, } \\
27 \text { parents }\end{array}$ & $\begin{array}{l}\text { Self-referred, } \\
\text { non-clinical }\end{array}$ & $\begin{array}{l}\text { Child and adult report of } \\
\text { attention, emotional } \\
\text { reactivity and regulation, } \\
\text { anxiety and depression sx, } \\
\text { metacognitive functioning; } \\
\text { parent's mindfulness, } \\
\text { computer- administered } \\
\text { cognitive/affective tasks }\end{array}$ & Modified MBSR & Authors & \begin{tabular}{|l|}
8 weeks of group that \\
included children and \\
parents in the same \\
group; requires home \\
practice
\end{tabular} & Not stated \\
\hline
\end{tabular}




\begin{tabular}{|c|c|c|c|c|c|c|c|c|}
\hline \begin{tabular}{|l} 
Duncan et al. \\
$(2009)$
\end{tabular} & $\begin{array}{l}\text { Sixth } \\
\text { grade }(x= \\
11.5 \text { years }\end{array}$ & $\begin{array}{l}5 \text { families } \\
(5 \\
\text { children } 9 \\
\text { parents })\end{array}$ & Nonclinical & $\begin{array}{l}\text { Qualitative parent-report } \\
\text { data of receptivity to the } \\
\text { program, perceived changes } \\
\text { in parenting behaviors }\end{array}$ & MSFP & $\begin{array}{l}\text { Graduate students } \\
\text { trained in SFP } \\
\text { curriculum }\end{array}$ & $\begin{array}{l}\text { Seven 2-hour sessions; } 1^{\text {st }} \text { hour } \\
\text { parents and youth meet } \\
\text { separately and } 2^{\text {nd }} \text { hour together } \\
\text { home practice }\end{array}$ & school \\
\hline $\begin{array}{l}\text { Coatsworth et } \\
\text { al. (2009) }\end{array}$ & $\begin{array}{l}10-14 \\
\text { years }\left(5^{\text {th }}-\right. \\
7^{\text {th }} \text { grade } \\
\text { students })\end{array}$ & $\begin{array}{l}65 \\
\text { families } \\
(80 \% \\
\text { dual- } \\
\text { parents) }\end{array}$ & Nonclinical & $\begin{array}{l}\text { Parent-report of mindful } \\
\text { parenting, child management } \\
\text { strategies, maternal anger } \\
\text { and affect toward child; } \\
\text { youth-report of discipline } \\
\text { consistency }\end{array}$ & MSFP & $\begin{array}{l}\text { Facilitators were } \\
\text { trained by author, } \\
\text { had BA or MA } \\
\text { degrees and } \\
\text { completed SFP } \\
\text { training. }\end{array}$ & $\begin{array}{l}\text { Seven 2-hour sessions; } 1^{\text {st }} \text { hour } \\
\text { parents and youth meet } \\
\text { separately and } 2^{\text {nd }} \text { hour together } \\
\text { home practice }\end{array}$ & school \\
\hline $\begin{array}{l}\text { Singh, } \\
\text { Lancioni, } \\
\text { Singh, et al. } \\
(2011)^{*}\end{array}$ & $\begin{array}{l}13-18 \\
\text { years }\end{array}$ & 3 dyads & $\begin{array}{l}\text { Clinical } \\
\text { (Asperger } \\
\text { Syndrome) }\end{array}$ & aggression & SoF & $\begin{array}{l}\text { Experienced } \\
\text { trainers taught } \\
\text { mother SoF and } \\
\text { mothers taught } \\
\text { children SoF }\end{array}$ & $\begin{array}{l}1^{\text {st }} 5 \text { days mother taught child } \\
\text { procedures for } 15 \text { min; youth- } \\
\text { mother practice } 2 \text { xday for } 17-24 \\
\text { weeks (i.e., until } 3 \text { weeks w/out } \\
\text { aggression occurred) }\end{array}$ & home \\
\hline $\begin{array}{l}\text { Singh, } \\
\text { Lancioni, } \\
\text { Manikam, et } \\
\text { al. }(2011)^{*}\end{array}$ & $\begin{array}{l}14-17 \\
\text { years }\end{array}$ & 3 dyads & $\begin{array}{l}\text { Clinical } \\
\text { (autism) }\end{array}$ & aggression & SoF & $\begin{array}{l}\text { Singh taught } \\
\text { mothers SoF and } \\
\text { mothers taught } \\
\text { children SoF }\end{array}$ & $\begin{array}{l}\text { Mothers practiced for } 1 \text { month } \\
\text { during their child's baseline. } \\
\text { Youth training: } 30 \text { minute } \\
\text { sessions for } 5 \text { days w/ practice } \\
\text { 2xday. Practice phase: } 2 \text { xday } \\
\text { with mother for } 23-30 \text { weeks } \\
\text { (i.e., until } 4 \text { consecutive weeks } \\
\text { w/out aggressive behavior) }\end{array}$ & home \\
\hline
\end{tabular}




\begin{tabular}{|c|c|c|c|c|c|c|c|c|}
\hline \begin{tabular}{|l} 
Van de \\
Weijer- \\
Bergsma et \\
al. (2012)
\end{tabular} & $\begin{array}{l}11-15 \\
\text { years }\end{array}$ & $\begin{array}{l}10 \text { adolescents, } \\
19 \text { parents, and } \\
7 \text { tutors }\end{array}$ & $\begin{array}{l}\text { Clinical } \\
\text { (ADHD) }\end{array}$ & $\begin{array}{l}\text { self-report of behavior } \\
\text { problems, attention, } \\
\text { mindfulness; computerized } \\
\text { sustained attention tasks; } \\
\text { parent and tutor report of } \\
\text { adolescent attention, } \\
\text { behavior problems, } \\
\text { executive functioning; } \\
\text { parent-report of parenting, } \\
\text { parenting stress, mindful } \\
\text { awareness }\end{array}$ & $\begin{array}{l}\text { Mindfulness } \\
\text { intervention for } \\
\text { youth; mindful } \\
\text { parenting for } \\
\text { parents }\end{array}$ & $\begin{array}{l}\text { Experienced } \\
\text { therapists who } \\
\text { were experienced } \\
\text { mindfulness } \\
\text { practitioners and } \\
\text { trainers. Received } \\
\text { weekly supervision }\end{array}$ & $\begin{array}{l}\text { Eight 90-minute group } \\
\text { sessions for adolescents } \\
\text { and parents separately }\end{array}$ & $\begin{array}{l}\text { Academic } \\
\text { treatment } \\
\text { center }\end{array}$ \\
\hline $\begin{array}{l}\text { Van der } \\
\text { Oord et al. } \\
(2012)\end{array}$ & $\begin{array}{l}8-12 \\
\text { years }\end{array}$ & $\begin{array}{l}22 \text { parents and } \\
\text { their children } \\
(N \text { not given })\end{array}$ & $\begin{array}{l}\text { Clinical } \\
(\mathrm{ADHD})\end{array}$ & $\begin{array}{l}\text { Parent-rated child } \\
\text { ADD/ODD sx, own ADHD } \\
\text { sx, parenting stress, parental } \\
\text { overreactivity, } \\
\text { permissiveness, mindful } \\
\text { awareness; teacher-reported } \\
\text { child ADHD/ODD bx }\end{array}$ & $\begin{array}{l}\text { Child mindfulness } \\
\text { and mindful } \\
\text { parenting (adapted } \\
\text { MBSR/MBCT for } \\
\text { children with } \\
\text { ADHD and their } \\
\text { parents) }\end{array}$ & $\begin{array}{l}\text { Experienced } \\
\text { cognitive-behavior } \\
\text { therapists with } \\
\text { mindfulness } \\
\text { experience or } \\
\text { experienced } \\
\text { mindfulness } \\
\text { trainers. Received } \\
\text { weekly supervision }\end{array}$ & $\begin{array}{l}\text { Eight 90-minute group } \\
\text { sessions; parents and } \\
\text { children met separately; } \\
\text { includes HW and home } \\
\text { practice }\end{array}$ & $\begin{array}{l}\text { Outpatient } \\
\text { mental } \\
\text { health clinic }\end{array}$ \\
\hline
\end{tabular}

$\mathrm{ADHD}=$ attention-deficit/hyperactivity disorder; MAAS $=$ mindful attention and awareness scale; ODD = oppositional defiant disorder; bx $=$ behavior; $\mathrm{sx}=$

symptom; $\mathrm{MBSR}=$ mindfulness based stress reduction; $\mathrm{MBCT}=$ mindfulness based cognitive therapy; $\mathrm{SoF}=$ soles of the feet $\mathrm{CD}=$ conduct disorder; $\mathrm{ASD}=$

Autism spectrum disorder; HW = homework; SFP = strengthening families program; MSFP = mindfulness enhanced strengthening families program 
Table 3

Application of Mindfulness to Parents

\begin{tabular}{|c|c|c|c|c|c|c|c|c|}
\hline $\begin{array}{l}\text { Authors/ } \\
\text { Date }\end{array}$ & $\begin{array}{l}\text { Age of } \\
\text { Youth }\end{array}$ & $\mathrm{N}$ & $\begin{array}{c}\text { Clinical/ } \\
\text { Nonclinical }\end{array}$ & DV & $\begin{array}{l}\text { Intervention } \\
\text { Provided } \\
\end{array}$ & $\begin{array}{l}\text { Intervention } \\
\text { Provided by }\end{array}$ & Intervention Length & $\begin{array}{l}\text { Intervention } \\
\text { Setting }\end{array}$ \\
\hline $\begin{array}{l}\text { Dawe et al. } \\
2003\end{array}$ & $\begin{array}{l}M=45.6 \\
\text { months, SD } \\
=15.4 \\
\text { months }\end{array}$ & $\begin{array}{l}9 \text { children; } \\
9 \text { parents }\end{array}$ & $\begin{array}{l}\text { Families on } \\
\text { methadone } \\
\text { maintenance }\end{array}$ & $\begin{array}{l}\text { Parent-report of parenting } \\
\text { stress, child abuse potential, } \\
\text { child behavior problems, } \\
\text { drug use, alcohol use, risk } \\
\text { taking bx }\end{array}$ & $\begin{array}{l}\text { Parents Under } \\
\text { Pressure (PuP) }\end{array}$ & $\begin{array}{l}\text { Psychologist and } \\
\text { psychiatric nurse } \\
\text { trained in PuP; } \\
\text { received weekly } \\
\text { supervision }\end{array}$ & $\begin{array}{l}\text { Twelve 90-minute } \\
\text { sessions }\end{array}$ & Clinic or home \\
\hline $\begin{array}{l}\text { Minor et al. } \\
(2006)\end{array}$ & 3-18 years & $\begin{array}{l}45 \\
\text { caregivers } \\
(42 \text { were } \\
\text { parents }) \\
\end{array}$ & $\begin{array}{l}\text { Children with } \\
\text { various chronic } \\
\text { conditions; } \\
\text { outpatients }\end{array}$ & $\begin{array}{l}\text { Symptoms of stress and } \\
\text { mood }\end{array}$ & $\begin{array}{l}\text { MBSR plus } \\
\text { Joint Freeing } \\
\text { Yoga }\end{array}$ & $\begin{array}{l}\text { Social worker and } \\
\text { family physician }\end{array}$ & $\begin{array}{l}\text { Eight } 2 \text { hour group } \\
\text { sessions }\end{array}$ & Hospital \\
\hline $\begin{array}{l}\text { Singh et al. } \\
(2006)\end{array}$ & 4-6 years & 3 dyads & Clinical (autism) & $\begin{array}{l}\text { Aggression, } \\
\text { noncompliance, self-injury; } \\
\text { parenting satisfaction } \\
\text { (SUPS), interaction } \\
\text { satisfaction (SUIS), use of } \\
\text { mindfulness (SUUM) }\end{array}$ & $\begin{array}{l}\text { Mindful parent } \\
\text { training with } \\
\text { bibliotherapy }\end{array}$ & Singh & $\begin{array}{l}\text { Twelve 2-hour } \\
\text { weekly Individual } \\
\text { sessions with home } \\
\text { practice; } 52 \text { week } \\
\text { practice (no } \\
\text { instruction given) }\end{array}$ & $\begin{array}{l}\text { Practice and } \\
\text { data collection } \\
\text { were conducted } \\
\text { in the home }\end{array}$ \\
\hline $\begin{array}{l}\text { Blackledge } \\
\& \text { Hayes } \\
\text { (2006) }\end{array}$ & $\begin{array}{l}\text { Not } \\
\text { specified }\end{array}$ & 20 parents & Clinical (autism) & $\begin{array}{l}\text { Depression, Global Severity } \\
\text { Index, Brief Symptom } \\
\text { Inventory, general health, } \\
\text { automatic thoughts }\end{array}$ & $\mathrm{ACT}$ & Not specified & $\begin{array}{l}\text { 2-day (14 hours total) } \\
\text { group workshop }\end{array}$ & \\
\hline $\begin{array}{l}\text { Singh et al. } \\
(2007)\end{array}$ & 4 to 6 years & 4 dyads & $\begin{array}{l}\text { Clinical } \\
\text { (developmental } \\
\text { disabilities) }\end{array}$ & $\begin{array}{l}\text { Social interaction, } \\
\text { aggression, satisfaction with } \\
\text { parenting and interactions } \\
\text { with child, parenting stress }\end{array}$ & $\begin{array}{l}\text { mindful parent } \\
\text { training with } \\
\text { bibliotherapy }\end{array}$ & Singh & $\begin{array}{l}\text { Twelve 2-hour } \\
\text { weekly individual } \\
\text { sessions with home } \\
\text { practice; } 52 \text { week } \\
\text { practice (no } \\
\text { instruction given) }\end{array}$ & $\begin{array}{l}\text { Practice and } \\
\text { data collection } \\
\text { were conducted } \\
\text { in the home }\end{array}$ \\
\hline
\end{tabular}




\begin{tabular}{|c|c|c|c|c|c|c|c|c|}
\hline \begin{tabular}{|l|} 
Dawe \& \\
Harnett, \\
2007
\end{tabular} & $2-8$ years & 64 & $\begin{array}{l}\text { Families on } \\
\text { methadone } \\
\text { maintenance }\end{array}$ & $\begin{array}{l}\text { Parent-report of } \\
\text { parenting stress, mood, } \\
\text { child abuse potential, } \\
\text { child behavior, } \\
\text { methadone dose }\end{array}$ & $\mathrm{PuP}$ & \begin{tabular}{|l} 
Clinicians \\
trained in PuP \\
manuals
\end{tabular} & $\begin{array}{l}\text { Ten modules conducted } \\
\text { over 7-14 sessions }\end{array}$ & Home \\
\hline $\begin{array}{l}\text { Frye \& } \\
\text { Dawe, } \\
2008\end{array}$ & $2-12$ years & 12 mothers & $\begin{array}{l}\text { Women } \\
\text { offenders in low } \\
\text { security or just } \\
\text { released }\end{array}$ & $\begin{array}{l}\text { Parent-report of } \\
\text { parenting stress, mood, } \\
\text { child abuse potential, } \\
\text { child bx }\end{array}$ & $\mathrm{PuP}$ & $\begin{array}{l}\text { Psychologists } \\
\text { trained in PuP } \\
\text { program }\end{array}$ & $\begin{array}{l}10 \text { modules completed } \\
\text { over } 11-38 \text { sessions; } \\
\text { session length varied } \\
\text { with mother's needs } \\
\text { ( } x=86 \text { minutes })\end{array}$ & $\begin{array}{l}\text { In home or in } \\
\text { low security } \\
\text { prison }\end{array}$ \\
\hline $\begin{array}{l}\text { Harnett } \\
\text { \& Dawe } \\
\text { (2008) }\end{array}$ & $\begin{array}{l}x=4.4 \\
\text { years } \\
(\mathrm{SD}=2.2)\end{array}$ & 10 families & $\begin{array}{l}\text { Families } \\
\text { referred by } \\
\text { child protection } \\
\text { services }\end{array}$ & $\begin{array}{l}\text { Parent report of } \\
\text { parenting stress, mood, } \\
\text { child abuse potential, } \\
\text { child bx, social support }\end{array}$ & $\mathrm{PuP}$ & $\begin{array}{l}\text { Psychologists } \\
\text { trained in PuP }\end{array}$ & $\begin{array}{l}10 \text { modules completed } \\
\text { over } 9-13 \text { sessions, } \\
\text { approximatly1.5 hours } \\
\text { each }\end{array}$ & Home or clinic \\
\hline \begin{tabular}{|l|} 
Vieten \& \\
Astin \\
$(2008)$
\end{tabular} & Fetus & 31 mothers & $\begin{array}{l}\text { Mothers in their } \\
\text { second or third } \\
\text { trimester }\end{array}$ & $\begin{array}{l}\text { Perceived stress, } \\
\text { depression, anxiety, } \\
\text { positive/negative affect, } \\
\text { affect regulation, } \\
\text { mindfulness }\end{array}$ & $\begin{array}{l}\text { The Mindful Motherhood } \\
\text { Intervention }\end{array}$ & $\begin{array}{l}\text { Clinical } \\
\text { psychologist } \\
\text { and yoga } \\
\text { instructor }\end{array}$ & $\begin{array}{l}8 \text { weekly } 2 \text { hour } \\
\text { meetings }\end{array}$ & Hospital \\
\hline \begin{tabular}{|l} 
Singh et \\
al. (2010)
\end{tabular} & $9-18$ years & $\begin{array}{l}3 \\
\text { caregivers/ } \\
\text { mothers }\end{array}$ & nonclinical & noncompliance & $\begin{array}{l}\text { Mindfulness training } \\
\text { (concentration meditation, } \\
\text { insight meditation, } \\
\text { discussion on how to apply } \\
\text { mindfulness to caregiving } \\
\text { work) with bibliotherapy }\end{array}$ & $\begin{array}{l}\text { Experienced } \\
\text { mindfulness } \\
\text { trainer }\end{array}$ & $\begin{array}{l}12 \text { training sessions } \\
\text { across } 8 \text { weeks; } 16 \text { weeks } \\
\text { of practice }\end{array}$ & $\begin{array}{l}\text { Practice and } \\
\text { s data collection } \\
\text { were } \\
\text { conducted in } \\
\text { the home }\end{array}$ \\
\hline
\end{tabular}




\begin{tabular}{|c|c|c|c|c|c|c|c|c|}
\hline \begin{tabular}{|l|} 
Duncan \& \\
Bardacke \\
$(2010)$
\end{tabular} & $\begin{array}{l}\text { Fetus in } \\
3^{\text {rd }} \\
\text { trimester }\end{array}$ & 27 women & $\begin{array}{l}\text { Women in their } 3^{\text {rd }} \\
\text { trimester of pregnancy } \\
\text { plus a partner }\end{array}$ & $\begin{array}{l}\text { Mindfulness, } \\
\text { positive/negative affect, } \\
\text { pregnancy anxiety, } \\
\text { depression; qualitative } \\
\text { report of perceived benefits }\end{array}$ & MBCP & Not specified & $\begin{array}{l}3 \text { hours for } 9 \text { weeks } \\
\text { plus a } 7 \text { hour } \\
\text { weekend retreat and } \\
\text { reunion class; } 30 \\
\text { minutes of } \\
\text { meditation daily }\end{array}$ & $\begin{array}{l}\text { University clinic or } \\
\text { off-site location } \\
\text { more } \\
\text { "geographically } \\
\text { proximal" to } \\
\text { participants }\end{array}$ \\
\hline $\begin{array}{l}\text { Srivastava } \\
\text { et al. } \\
(2011)\end{array}$ & $3-6$ years & 60 & $\begin{array}{l}\text { Children who presented to } \\
\text { the pediatric OPD or } \\
\text { psychiatric OPD for } \\
\text { behavioral problems (low } \\
\text { learning, poor memory, } \\
\text { vertigo, speech problems, } \\
\text { stress and headache, } \\
\text { depression, adjustment } \\
\text { problems) }\end{array}$ & Disturbed behavior & $\begin{array}{l}\text { Mindful } \\
\text { Parenting }\end{array}$ & Not specified & $\begin{array}{l}24 \text { individual } \\
\text { sessions }\end{array}$ & Medical institute \\
\hline \begin{tabular}{|l} 
Benn et al. \\
(2012)
\end{tabular} & $5-23$ years & $\begin{array}{l}35 \\
\text { educators } \\
\text { and } 25 \\
\text { parents }\end{array}$ & $\begin{array}{l}\text { Parents and educators of } \\
\text { children with disabilities } \\
\text { (ASD, ADHD, cognitive } \\
\text { or health impairment) }\end{array}$ & $\begin{array}{l}\text { Mindfulness, stress, anxiety, } \\
\text { depression, positive and } \\
\text { negative affect, personal } \\
\text { growth, self-compassion, } \\
\text { forgiveness, empathic } \\
\text { concern, teaching self- } \\
\text { efficacy, parenting self- } \\
\text { efficacy, quality of parent- } \\
\text { child interaction }\end{array}$ & $\begin{array}{l}\text { SMART- } \\
\text { in- } \\
\text { education }\end{array}$ & \begin{tabular}{|l|} 
Instructors had \\
formal \\
professional \\
training in MBSR \\
or MBCT and \\
received 2 days of \\
training in the \\
SMART \\
curriculum
\end{tabular} & $\begin{array}{l}\text { Parents and } \\
\text { educators met in } \\
\text { their own groups } \\
\text { twice a week for } 5 \\
\text { weeks (didactic and } \\
\text { group discussion } \\
\text { activities, } \\
\text { mindfulness } \\
\text { practices, and HW } \\
\text { assignments) }\end{array}$ & Not specified \\
\hline \begin{tabular}{|l|} 
Ferraioli \& \\
Harris \\
$(2012)$
\end{tabular} & $\begin{array}{l}\text { Under } 18 \\
\text { years, } \\
\text { specifics } \\
\text { not } \\
\text { provided }\end{array}$ & $\begin{array}{l}10 \\
\text { mothers } \\
\text { and } 5 \\
\text { fathers of } \\
15 \text { youth }\end{array}$ & $\begin{array}{l}\text { Parents of children } \\
\text { diagnosed with Autism (5), } \\
\text { Asperger's (5), and PDD- } \\
\text { NOS (5) }\end{array}$ & $\begin{array}{l}\text { Parenting Stress, general } \\
\text { health }(M A A S \text { used for a } \\
\text { manipulation check but was } \\
\text { not } a \text { DV) }\end{array}$ & $\begin{array}{l}\text { Adapted } \\
\text { from DBT } \\
\text { and MBCT }\end{array}$ & Doctoral students & $\begin{array}{l}8 \text { weekly } 2 \text { hour } \\
\text { meetings }\end{array}$ & University Clinic \\
\hline $\begin{array}{l}\text { Dunn et al. } \\
(2010)\end{array}$ & Fetus & \begin{tabular}{|l|}
19 \\
pregnant \\
mothers
\end{tabular} & $\begin{array}{l}\text { Pregnant women (between } \\
12-28 \text { weeks gestation at } \\
\text { program commencement) }\end{array}$ & $\begin{array}{l}\text { Depression, anxiety, stress, } \\
\text { mindfulness, self- } \\
\text { compassion }\end{array}$ & $\begin{array}{l}\text { Modified } \\
\text { MBCT for } \\
\text { pregnant } \\
\text { women }\end{array}$ & $\begin{array}{l}\text { Psychiatrist and } \\
\text { counselor }\end{array}$ & 8 weeks & Hospital \\
\hline
\end{tabular}




\begin{tabular}{|c|c|c|c|c|c|c|c|}
\hline $\begin{array}{l}\text { Perez-Blasco } \\
\text { et al. (2013) }\end{array}$ & $\begin{array}{c}\text { Infants } 26 \text { breast } \\
\text { feeding } \\
\text { mothers }\end{array}$ & $\begin{array}{l}\text { Breast- } \\
\text { feeding } \\
\text { mothers }\end{array}$ & $\begin{array}{l}\text { Maternal self-efficacy, mindfulness, self- } \\
\text { compassion, satisfaction with life, subjective } \\
\text { happiness, psychological distress }\end{array}$ & $\begin{array}{l}\text { Based on MBSR, MBCT, and } \\
\text { Mindful Self-compassion and } \\
\text { adapted to the population }\end{array}$ & $\begin{array}{l}\text { Not } \\
\text { specified }\end{array}$ & $\begin{array}{l}8 \\
\text { weeks }\end{array}$ & $\begin{array}{l}\text { Health } \\
\text { Center }\end{array}$ \\
\hline
\end{tabular}

$\mathrm{ACT}=$ acceptance and commitment therapy; MBSR= mindfulness based stress reduction; $\mathrm{MBCT}=$ mindfulness based cognitive therapy; $\mathrm{PuP}=$ parenting under

pressure; $\mathrm{DBT}=$ dialectical behavior therapy; $\mathrm{ADHD}=$ attention-deficit/hyperactivity disorder; $\mathrm{ASD}=$ autism spectrum disorder; $\mathrm{PDD}-\mathrm{NOS}=$ pervasive

developmental disorder not otherwise specified; SMART= stress management and relaxation techniques; $\mathrm{MBCP}=\mathrm{Mindfulness-Based} \mathrm{Childbirth}$ and Parenting;

$\mathrm{HW}=$ homework 
A total of 25 studies have provided mindfulness to parents (see Tables 2 and 3). Nine of these studies also provided mindfulness to youth in addition to their parents as part of the intervention (Table 2). To provide the reader with an integrated overview of the mindful parenting intervention research, the studies will be discussed along a variety of dimensions, including the type of intervention utilized, the populations targeted by the interventions, and intervention goals.

Mindfulness interventions utilized in clinical research. Thirteen of the interventions delivered to parents in the clinical literature were specifically considered “mindful parenting” interventions (Benn et al., 2012; Bogels et al., 2008; Coatsworth et al., 2009; Dawe \& Harnett, 2007; Dawe et al., 2003; Duncan \& Bardacke, 2010; Duncan et al, 2009b; Frye \& Dawe, 2008; Harnett \& Dawe, 2008; Singh et al., 2006; 2007; Srivastava et al., 2011; van der Oord et al., 2012; van de Weijer-Bergsma et al., 2012). The remaining studies included a variety of intrapersonal mindfulness interventions. For example, Singh, Lancioni, and Singh et al. (2011), Singh, Lancioni, and Manikam, et al. (2011), and Singh et al. (2009) provided a mindfulness training to parents that was comprised of popular mindfulness and meditation exercises (see Singh et al. 2009 for a list of the exercises), as opposed to mindful parenting. Although during the final session (session 12) parents discussed how mindfulness could be applied to family life, the intervention was primarily aimed at improving a parents' intrapersonal mindfulness. Several other studies similarly utilized mindfulness-based interventions as opposed to mindful parenting interventions. Both Saltzman and Goldin (2009) and Minor, Carlson, Mackenzie, Zernicke, \& Jones (2006) provided a modified MBSR to parents, while Blackledge and Hayes provided ACT, Ferraioli \& Harris (2012) utilized an intervention 
adapted from DBT and MBCT, and Perez-Blasco and colleagues' intervention was based on a combination of MBSR, MBCT, and Mindful self-compassion (Perez-Blasco, Viguer, \& Rodrigo, 2013).

The mindful parenting interventions utilized in the aforementioned studies include the Mindfulness-enhanced Strengthening Families Program (MSFP; Duncan et al., 2009b; Coatsworth et al., 2009), the stress management and relaxation techniques (SMART-in-education; Benn et al., 2012), Parenting Under Pressure (PuP; Dawe \& Harnett, 2007; Dawe et al., 2003; Frye \& Dawe, 2008; Harnett \& Dawe, 2008), Mindfulness-Based Childbirth and Parenting (MBCP; Duncan \& Bardacke, 2010), and Mindful Parenting (MP; Srivastava et al., 2011). Bogels et al. (2008), van der Oord et al. (2012), and van der Weijer-Bergsma (2012) each provided the same mindful parenting (MP) training. This intervention is based on MBCT and was adapted for use with parents. Finally, Singh and colleagues $(2006 ; 2007)$ provided what they called "mindful parenting" to parents, which included meditation methods to enhance both intrapersonal mindfulness and interpersonal mindfulness. Each of these interventions is described below.

The MSFP, utilized in Duncan et al. (2009b) and Coatsworth et al. (2009), was created by incorporating mindfulness concepts and practices related to parenting into an empirically validated family-focused skills training preventive intervention (SFP; Molgaard, Spoth, \& Redmond, 2000). The MSFP is intended for families (youth and their parents) of at-risk youth in order to prevent adolescent substance use and problem behaviors. The purpose of adding mindfulness components to the SFP was to "improve 
parent mindfulness, mindful parenting, psychological well-being, coping, emotional and metacognitive awareness, and self-regulation" (Duncan et al., 2009b, p. 608).

To create the SMART-in-education (unpublished manual by Cullen \& Wallace, 2010) program, "emotion theory and regulation, forgiveness, kindness and compassion, and the application of mindfulness to parenting and teaching" was incorporated into MBSR (Benn et al., 2012). This adapted MBSR program (i.e., SMART-in-education) was specifically tailored for parents and teachers of children with ASD, ADHD, cognitive or health impairments.

Four studies were conducted by Dawe and colleagues to examine the utility of the Parents Under Pressure (PuP) program (Dawe \& Harnett, 2007; Dawe et al., 2003; Frye \& Dawe, 2008; Harnett \& Dawe, 2008). The PuP program is a primarily cognitive behavioral program that draws from literature on emotion regulation and behavioral family therapy (Dawe et al., 2003). It includes mindfulness strategies to help parents improve emotion regulation during child-focused play and managing difficulty child behavior.

The Mindfulness-Based Childbirth and Parenting (MBCP) Education program (Duncan \& Bardacke, 2010) was developed from MBSR and aims to promote family health and well-being during pregnancy, childbirth, and early parenting. Women and their partners are provided with mindfulness skills for coping with mind-body pain and stress in daily life. MBCP incorporates mindfulness into "current knowledge of the psychobiological processes of pregnancy, labor, birth, breastfeeding, postpartum adjustment, and the psychobiological needs of the infant" (p.190, Duncan \& Bardacke, 2010). 
Srivastava et al. (2011) and colleagues reported that they utilized a mindful parenting intervention based off of Duncan, Coatsworth, and Greenberg's conceptualization of mindful parenting (2009a). According to this model, mindful parenting includes five dimensions; listening with full attention, nonjudgmental acceptance of self and child, emotional awareness of self and child, self-regulation in the parenting relationship, and compassion for self and child. However, further information regarding content of the intervention was not provided by Srivastava and colleagues (2011).

Singh and colleagues delivered mothers of children (4- to 6-years-old) with autism and developmental disabilities what they called "mindful parent training." This program included individual sessions with Dr. Singh where mothers were taught meditation methods and exercises to help them incorporate mindfulness during parentchild interactions (Singh et al., 2006; Singh et al., 2007). Additionally, in both studies mothers were required to read a mindful parenting book by Kabat-Zinn and Kabat-Zinn (Everyday Blessings: The Inner Work of Mindful Parenting). Singh et al. (2010) provided an interpersonal mindfulness training to caregivers ("Mindful Caregiving") of individuals with profound multiple disabilities that parents later applied to interactions with their own children. This intervention was comprised of insight and concentration meditation exercises, discussion and application of mindfulness with others (coworkers, individuals with profound disabilities), and bibliotherapy.

Intervention populations. Mindfulness with parents and mindful parenting interventions have been investigated for use with both clinical and nonclinical populations. Populations have included various at-risk families, such as families on 
methadone maintenance (Dawe et al., 2003; Dawe \& Harnett, 2007), women offenders (mothers) in low security prisons or who were recently released (Frye \& Dawe, 2008), and families referred by child protection services (Harnett \& Dawe, 2008). Additionally, clinical populations have included parents of children with autism (Blackledge \& Hayes, 2006; Singh et al., 2006), developmental disabilities (Ferraioli \& Harris, 2012; Singh et al., 2007), special needs (Benn et al., 2012), various behavioral problems (Srivastava et al., 2011) and chronic conditions (Minor et al., 2006). Further, these interventions have been used with nonclinical populations, such as mothers of typically developing children who are caregivers of individuals with profound multiple disabilities (Singh et al., 2010), women in their third trimester of pregnancy (Duncan \& Bardacke, 2010), and breastfeeding mothers (Perez-Blasco et al., 2013). The age range of parents' children in these studies included neonates and infants (Duncan \& Bardacke, 2010; Perez-Blasco et al., 2013) to young adults (Benn et al., 2012; Ferraioli \& Harris, 2012; Minor et al., 2006; Singh et al., 2010).

Of the mindfulness interventions that include both parents and youth as participants, the majority were intended for clinical populations. Specifically, six of the nine studies were conducted with clinical youth populations, and include youth with ADHD (Singh et al., 2009; van der Oord et al., 2012; van de Weijer-Bergsma et al., 2012), youth with developmental disabilities (Singh, Lancioni, and Manikam, et al., 2011; Singh, Lancioni, and Singh et al., 2011), or youth with a variety of developmental and externalizing difficulties (Bogels et al., 2008). The remaining three provided mindfulness to dyads and families of nonclinical youth (Coatsworth et al., 2009; Duncan et al., 2009b; Saltzman \& Goldin, 2009). Further, all of the parent and youth mindfulness 
interventions were provided to pre-adolescent and adolescent youth. That is, none of these interventions included youth younger than 8 years old.

Intervention goals. Several of the studies that provided mindfulness-based interventions to parents were intended to impact adult variables as well as to improve child behavior (Dawe et al., 2003; Dawe \& Harnett, 2007; Frye \& Dawe, 2008; Harnett \& Dawe, 2008; Srivastava et al., 2011). The purpose of many of the interventions was to target parents whose children may be at-risk, and to provide early intervention and prevention for children by improving parental functioning and mindfulness. For example, children of families on methadone maintenance, women offenders, and families referred by child protection services (populations targeted by the PuP program) are at-risk for child abuse and other adverse outcomes (e.g., see Dawe et al., 2003; Dawe \& Harnett, 2007; Frye \& Dawe, 2008; Harnett \& Dawe, 2008). Consequently, the PuP intervention is aimed at reducing parental stress, child abuse potential, drug and alcohol use and risk taking behavior in parents, which is likely to have an adverse impact on children. In addition, the PuP intervention is intended to reduce child behavior problems (e.g., Dawe et al., 2003). Other child behaviors that were targeted through mindfulness interventions included aggression, self-injury, noncompliance (Singh et al., 2006; Singh et al., 2010), and social interaction (Singh et al., 2007). Parent variables included stress (Minor et al., 2006), mood (Blackledge \& Hayes, 2006; Duncan \& Bardacke, 2010; Frye \& Dawe, 2008), general health (Blackledge \& Hayes, 2006; Ferraioli \& Harris, 2012), forgiveness (Benn et al., 2012), personal growth (Benn et al., 2012), self-compassion (Benn et al., 2012), satisfaction with life (Perez-Blasco et al., 2013), psychological distress (PerezBlasco et al., 2013), and perceived social support (Harnett \& Dawe, 2008). Specific 
parenting variables that were targeted through intervention included parenting selfefficacy (Benn et al, 2012; Perez-Blasco et al., 2013), parenting stress (Dawe \& Harnett, 2007; Ferraioli \& Harris, 2012; Singh et al., 2007), parenting satisfaction (Singh et al., 2006), and quality of parent-child interaction (Benn et al., 2012).

Goals of studies that applied mindfulness to both parents and youth were primarily to improve child functioning and the parents' functioning within the parentchild relationship. Dependent variables included youth's personal goals (Bogels et al., 2008), internalizing and externalizing symptoms (Bogels et al., 2008; Saltzman \& Goldin, 2009; van der Oord et al., 2012; van de Weijer-Bergsma et al., 2012), attention (Bogels et al., 2008; Saltzman \& Goldin, 2009; van de Weijer-Bergsma, 2012), executive functioning (van de Weijer-Bergsma et al, 2012), happiness (Bogels et al., 2008), mindful awareness (Bogels et al., 2008; van de Weijer-Bergsma et al., 2012), metacognitive functioning (Saltzman \& Goldin, 2009), self-control (Bogels et al., 2008), emotional regulation (Saltzman \& Goldin, 2009), aggression (Singh, Lancioni, Singh, et al., 2011; Singh, Lancioni, Manikam, et al., 2011), social behavior (Bogels et al., 2008), and compliance (Singh et al., 2009). These studies also focused on improving the parents' functioning within the parent-child relationship. Specifically, these variables included satisfaction during child-interaction (Singh et al., 2009), happiness with the child (Singh et al., 2009), mindful parenting (Coatsworth et al., 2009), child management strategies (Coatsworth et al., 2009), maternal anger and affect toward the child (Coatsworth et al., 2009), parenting stress (van der Oord et al., 2012; van de Weijer-Bergsma et al., 2012), mindful awareness (van der Oord et al., 2012; van de Weijer-Bergsma et al., 2012), 
parenting behavior (Duncan et al., 2009b; van der Oord et al., 2012; van de WeijerBergsma, et al., 2012), and discipline consistency (youth report; Coatsworth et al., 2009). Preliminary Findings and Limitations

In 2010, Burke conducted a review of the 15 published and unpublished research studies that had examined the application of MBSR/MBCT interventions with children and adolescents. In this review, Burke concluded that while there is support for feasibility, there is a lack of empirical evidence supporting efficacy. Burke recommended that research shift from feasibility to large methodologically robust studies that utilize standardized interventions to facilitate replication and comparison studies. Practical issues with the implementation of mindfulness interventions identified by Burke (2010) include time demands (e.g., home practice), treatment fidelity (i.e., training and experience for mindfulness teachers), and collaborating with the schools for school-based interventions. Further, Burke called for "careful attention to research aims and hypotheses...design, methodology, selection of appropriate and objective outcome measures," analysis of moderating variables, and valid measures for children and adolescents (p. 143). Following Burke's review (2010), Harnett and Dawe conducted an updated review in 2012. Authors identified 24 studies that had been published since Burke's review that were related to the application of mindfulness-based interventions to children and families. Authors concluded that while a diversity of mindfulness interventions (differing in content and dose) appear to have a positive impact on a variety of outcome variables, large-scale methodologically rigorous studies are lacking as well as research investigating mechanisms of change. Finally, authors concluded that 
mindfulness-based interventions may be more useful as part of a larger treatment approach as opposed to being used in isolation (Harnett \& Dawe, 2012).

This current discussion builds upon previous reviews by including more recent studies. Overall, results listed in Tables 4 and 5 suggest that the application of mindful parenting and mindfulness with parents lead to improvements across a range of domains, including child (e.g., symptom severity, executive functioning, stress self-esteem, selfcare, reactivity, sleep, relaxation, rumination, compliance, weight loss, social skills, academic performance, ego resiliency, and quality of life), parent (well-being, cognitive control of attention, stress, overreactivity, psychological symptoms, substance use), and parent-child relationship variables (relationship, satisfaction with the interactions with their children, happiness with parenting, parenting behaviors, discipline consistency). Yet, findings are not consistent across studies. For example, several studies reported no change in parenting stress (Harnett \& Dawe, 2008; van der Oord et al., 2012), while others reported a significant reduction in stress (Benn et al., 2012; Dawe \& Harnett, 2007; Dunn et al., 2012; Frye \& Dawe, 2008). A similar discrepancy exists regarding parental symptoms of depression and anxiety, with some studies reporting a decrease (e.g., Benn et al., 2012; Dunn et al., 2012) and others reporting no change (e.g., Harnett \& Dawe, 2008; Perez-Blasco et al., 2013). Interestingly, in one study (van de WeijerBergsma et al., 2012), fathers reported an increase in overreactivity at post-test, while mothers reported a significant decrease. However, these effects attenuated over time and were no longer significant at follow-up. Conversely, van der Oord et al. (2012) found no change in parenting style (overreactivity or permissiveness) from pre- to post-test, yet reported a decrease in parental overreactivity from pre-test to follow-up. Discrepant 
findings were also found for child variables, such as sustained attention (e.g. Bogels et al., 2008; van de Weijer-Bergsma et al., 2012).

Finally, findings were discrepant as to whether the intervention resulted in changes in parents' intrapersonal mindfulness. Ferraioli and Harris (2012) and Dunn and colleagues (2012) reported a significant increase on the MAAS, while van de WeijerBergsma and colleagues (2012) and Vieten and Astin (2008) did not find a significant change in parents' MAAS scores. While Van der Oord et al. (2012) reported an increase in mindfulness (MAAS) from pre- to post-test, no significant change was observed from pre-test to follow-up (van der Oord et al., 2012). Three studies utilized the FFMQ to track parents' mindfulness (Benn et al., 2012; Duncan \& Bardacke, 2010; Perez-Blasco et al., 2013). Two studies reported improvements on some (yet different) scales of the FFMQ (Duncan \& Bardacke, 2010; Perez-Blasco et al., 2013). The third study collapsed the five scales and reported improvements on the total FFMQ score from pre- to post-test and from pre-test to follow-up (Benn et al., 2012).

Using the MAAS, an adult measure of mindfulness, Bogels and colleagues (2008) reported an increase in child-rated mindfulness while van de Weijer-Bergsma found no change in adolescent-rated mindfulness following the intervention. However, Bogels and colleagues (2008) found that increased child-reported mindfulness at post-test did not predict improvements in child's self-report of their symptoms.

These discrepancies could be the result of several factors, including differences among interventions, different samples, and/or the different measures utilized across studies. However, before new mindful parenting interventions are developed and more 
Table 4

Results Following from the Application of Mindfulness to Youth and Parents

\begin{tabular}{|c|c|c|c|}
\hline Authors/Date & Study Type & Control Group & Findings \\
\hline Bogels et al. (2008) & $\begin{array}{l}\text { Within participant } \\
\text { pre-post, intent to } \\
\text { treat, } 8 \text { week f/up }\end{array}$ & $\begin{array}{l}\text { Non-random } \\
\text { waitlist }\end{array}$ & $\begin{array}{l}\text { Children self-reported substantial } \\
\text { improvement on personal goals, internalizing and externalizing complaints, attention problems, } \\
\text { happiness, and mindful awareness, and performed better on a sustained attention test }(d=.5-1,4) \\
\text { Parents reported improvement on children's goals }(d=1.6) \text { and self-control }(d=0.8) \text { at post-test. } \\
\text { Parents did not report improvement in child behavior }(\mathrm{CBCL}) \text { or child social behavior at post-test } \\
\text { Parents reported improvement on their own goals }(d=1.7) \\
\text { Improvement was maintained at f/up } 8 \text { weeks after the training }(d=-.02-1.5) \\
\text { Increased child-reported mindfulness at post-test predicted longer-term improvement in parent- } \\
\text { rated } \\
\text { child symptoms, but not child-report. } \\
36 \% \text { of children (primary diagnosis ODD) and } 25 \% \text { of parents dropped out }\end{array}$ \\
\hline Singh et al. (2009) & $\begin{array}{l}\text { Multiple baseline } \\
\text { across participants }\end{array}$ & No & $\begin{array}{l}\text { Mother mindfulness training enhanced compliance } \\
\text { to requests by her child and decreased mother's frequency of requests } \\
\text { Following child mindfulness training, compliance to commands continued to increase and was } \\
\text { maintained during f/up } \\
\text { Mothers reported associated increases in satisfaction with the interactions with their children and } \\
\text { happiness with parenting }\end{array}$ \\
\hline $\begin{array}{l}\text { Saltzman \& Goldin } \\
(2009)\end{array}$ & $\begin{array}{l}\text { Between groups } \\
\text { pre-post, wait list } \\
\text { control }\end{array}$ & Waitlist & $\begin{array}{l}\text { Data analysis incomplete and no quantitative data was reported } \\
\text { MBSR participants showed greater improvement on cognitive control of attention (ANT) than } \\
\text { waitlist; children and parents in MBSR demonstrated the same pattern of improvement } \\
\text { MBSR participants reported less negative emotion in response to threat; this effect was stronger for } \\
\text { parents } \\
\text { No change in positive or negative self-view or reduction of anxiety or depression in children } \\
\text { Parents reported a reduction in anxiety and depression } \\
\text { Parents and children in MBSR group showed improvement on some measures of metacognitive } \\
\text { functioning (e.g., self-judgment and self-compassion). }\end{array}$ \\
\hline
\end{tabular}




\begin{tabular}{|c|c|c|c|}
\hline Duncan et al. (2009) & $\begin{array}{l}\text { Pilot study of } \\
\text { acceptability }\end{array}$ & No & $\begin{array}{l}\text { - Qualitative support for feasibility, acceptability, and positive benefits for family functioning } \\
\text { (parenting behaviors) and parent psychological well-being. }\end{array}$ \\
\hline $\begin{array}{l}\text { Coatsworth et al. } \\
\text { (2009) }\end{array}$ & $\begin{array}{l}3 \text { group RCT pre- } \\
\text { post }\end{array}$ & Waitlist and SFP & $\begin{array}{l}\text { - Increase in parental report of mindful parenting } \\
\text { in MSFP group } \\
\text { - Increased use of effective child management practices in both SFP and MSFP groups. } \\
\text { - Increase in youth report of parental discipline consistency in MSFP group. } \\
\text { - Mediation analyses indicated that the mindful } \\
\text { parenting program operated indirectly on the quality of parent-youth relationships through changes } \\
\text { in mindful parenting. }\end{array}$ \\
\hline $\begin{array}{l}\text { Singh, Lancioni, } \\
\text { Singh, et al. (2011) }\end{array}$ & $\begin{array}{l}\text { Multiple baseline } \\
\text { across participants }\end{array}$ & No & $\begin{array}{l}\text { - Decrease in aggressive incidents from baseline to training and practice phases } \\
\text { - No incidents of aggression occurred during } 4 \text { year f/up }\end{array}$ \\
\hline $\begin{array}{l}\text { Singh, Lancioni, } \\
\text { Manikam, et al. } \\
\text { (2011) }\end{array}$ & $\begin{array}{l}\text { Multiple baseline } \\
\text { across participants }\end{array}$ & No & $\begin{array}{l}\text { - Decrease in aggressive incidents from baseline to training phase (across } 35 \text { weeks) } \\
\text { - Maintained over } 3 \text { year f/up }\end{array}$ \\
\hline $\begin{array}{l}\text { Van de Weijer- } \\
\text { Bergsma et al. } \\
(2012)\end{array}$ & $\begin{array}{l}\text { Pre-post, } 8 \text { week } \\
\text { and } 16 \text { week f/up }\end{array}$ & No & $\begin{array}{l}\text { - At post-test, fathers reported a significant reduction in externalizing behavior, in parenting stress, } \\
\text { and overreactivity. Mothers reported an increase in overreactivity. No other significant changes were } \\
\text { observed at post-test. } \\
\text { - At } 8 \text { week f/up, fathers reported a significant reduction in attention problems, externalizing } \\
\text { problems, metacognition, behavioral regulation, and parenting stress. Adolescents reported a } \\
\text { reduction in attention problems. } \\
\text { - Adolescents demonstrated significant improvement on some scales of sustained attention on } \\
\text { performance tasks from pre- to post-test and from pre-test to } 8 \text { week f/up. } \\
\text { - No significant changes were observed from pre-test to } 16 \text { week f/up. } \\
\text { - No significant changes in mindfulness were observed }\end{array}$ \\
\hline
\end{tabular}




\begin{tabular}{|c|c|c|c|}
\hline $\begin{array}{l}\text { Van der Oord et al. } \\
(2012)\end{array}$ & $\begin{array}{l}\text { Pre-post, } 8 \text { week } \\
\text { f/up }\end{array}$ & $\begin{array}{l}\text { Within group } \\
\text { waitlist control }\end{array}$ & $\begin{array}{l}\text { - From pre- to post-test, parents reported a decrease in child ADHD symptoms as well as a reduction } \\
\text { in their own ADHD symptoms. } \\
\text { - No change in parenting stress or parenting style was reported from pre- to post-test by parents } \\
\text { - Parents reported an increase in mindful awareness from pre- to post-test; no significant change in } \\
\text { mindfulness was reported from pre-test to f/up } \\
\text { - Parents reported a significant reduction in child and self-report of ADHD symptoms and a decrease } \\
\text { in parenting stress and overreactivity from pre-test to } 8 \text { week f/up, } \\
\text { - No significant change in teacher ratings was observed }\end{array}$ \\
\hline
\end{tabular}

f/up= follow-up; ADHD= Attention-Deficit/Hyperactivity Disorder; SFP= Strengthening Families Program; MSFP= Mindfulness-Enhanced Strengthening Families Program; RCT= Randomized Control Trial; MBCT= Mindfulness-Based Cognitive Therapy; ANT= Attention Network Task; $d=$ Cohen's d, a measure of effect size; ODD= Oppositional Defiant Disorder; $\mathrm{CBCL}=$ Child Behavior Checklist 
Table 5

Results Following from the Application of Mindfulness to Parents

\begin{tabular}{|c|c|c|c|}
\hline Authors/Date & Study Type & Control Group & Findings \\
\hline Dawe et al. 2003 & $\begin{array}{l}\text { Case study, pre- } \\
\text { post, } 3 \text { month f/up }\end{array}$ & No & $\begin{array}{l}\text { - } 9 \text { of } 12 \text { completed program } \\
\text { - Each family reported significant improvements in three domains: parental functioning, parent - child } \\
\text { relationship and parental substance use and risk behavior at post-test } \\
\text { - Majority of families showed a significant improvement in parental functioning (parental distress, } \\
\text { child abuse potential), parent-child relationship, concurrent alcohol use, and child functioning at f/up } \\
\text { - Three families reported a decrease in HIV risk-taking behavior and maintenance dose of methadone } \\
\text { at f/up } \\
\text { - Families reported satisfaction with the program }\end{array}$ \\
\hline Minor et al. (2006) & Pre-post design & No & $\begin{array}{l}\text { - Reduction in stress and mood disturbance } \\
\text { - Qualitative support for acceptability of the intervention }\end{array}$ \\
\hline Singh et al. (2006) & $\begin{array}{l}\text { Multiple baseline } \\
\text { across participants }\end{array}$ & No & $\begin{array}{l}\text { - Children's aggression, noncompliance, and self-injury decreased from baseline to training and } \\
\text { practice periods } \\
\text { - Mothers' reported satisfaction with their parenting skills and interactions with their children } \\
\text { following intervention } \\
\text { - Mothers' reported use of mindfulness decreased from baseline to the training phase and increased } \\
\text { during practice. For one mother, mindfulness was highest during baseline. }\end{array}$ \\
\hline $\begin{array}{l}\text { Blackledge \& Hayes } \\
(2006)\end{array}$ & $\begin{array}{l}\text { Pre-post design; } \\
\text { assessments } \\
\text { conducted } 3 \\
\text { weeks before, } 1 \\
\text { week before, } 1 \\
\text { week after, and } 3 \\
\text { months after the } \\
\text { workshop }\end{array}$ & No & $\begin{array}{l}\text { - Reduction in depression and general psychological distress from pre- to post-treatment } \\
\text {-Significant pre- to follow-up improvements on depression, brief symptom inventory, and psychiatric } \\
\text { problems. } \\
\text { - A measure of parenting ability was dropped from analysis given high scores at baseline } \\
\text { - Authors report "some evidence" that process measures of experiential avoidance and cognitive fusion } \\
\text { mediated the intervention effect }\end{array}$ \\
\hline Singh et al. (2007) & $\begin{array}{l}\text { Multiple baseline } \\
\text { across participants }\end{array}$ & No & $\begin{array}{l}\text { - From the baseline to training and practice phases, children demonstrated a decrease in aggressive } \\
\text { behavior and increase their children's social skills, based on mother observation. } \\
\text { - Children showed increased positive and decreased negative social interactions with their siblings } \\
\text { based on mother observation; Mothers reported a greater practice of mindfulness, increased } \\
\text { satisfaction with parenting, more social interactions with their children, and lower parenting stress. }\end{array}$ \\
\hline
\end{tabular}




\begin{tabular}{|c|c|c|c|}
\hline $\begin{array}{l}\text { Dawe \& Harnett, } \\
2007\end{array}$ & $\begin{array}{l}3 \text { group RCT, } 6 \\
\text { month f/up from } \\
\text { pretest }\end{array}$ & $\begin{array}{l}\text { TAU, } 2 \text { sessions } \\
\text { parenting } \\
\text { education } \\
\text { intervention }\end{array}$ & $\begin{array}{l}\text { - The PuP group demonstrated a significant reduction in parenting stress, child abuse potential, } \\
\text { parental methadone dose, and child behavior problems, and a significant increase in child prosocial } \\
\text { scores. } \\
\text { - High retention in PuP program; } 20 \text { of } 22 \text { families continued to } 6 \text { month f/up } \\
\text { - No changes on alcohol use for any group } \\
\text { - Significant reduction in child abuse potential across all } 3 \text { groups } \\
\text { - Clinically significant reduction in the risk status of } 36 \% \text { of the PUP group and of } 17 \% \text { of the brief } \\
\text { intervention group. } \\
\text { - } 42 \% \text { of TAU families moved into the high-risk category and a further } 37 \% \text { remained in the high- } \\
\text { risk group. None of the families receiving PuP moved into the high-risk category }\end{array}$ \\
\hline Frye \& D & $\begin{array}{l}\text { Single case, pre- } \\
\text { post with } 3 \text { month } \\
\text { f/up }\end{array}$ & No & $\begin{array}{l}\text { - } 8 \text { of } 12 \text { completed treatment } \\
\text { - Significant reduction on all measures (child abuse potential, parenting stress, symptoms inventory, } \\
\text { parenting-child dysfunction, and child difficult behavior at } 3 \text { month f/up } \\
\text { - Authors report evidence for feasibility }\end{array}$ \\
\hline $\begin{array}{l}\text { Harnett \& Dawe } \\
\text { (2008) }\end{array}$ & $\begin{array}{l}\text { Single case, pre- } \\
\text { post }\end{array}$ & No & $\begin{array}{l}\text { - All } 10 \text { families completed treatment } \\
\text { - Significant improvement in parent functioning (stress and distress), child-functioning (child } \\
\text { problem behavior), parent-child relationships, social contextual measures (support, problems with } \\
\text { others, intensity rating of daily hassles) } \\
\text { - No significant change in parents' report of depression, anxiety, and stress and one subscale of the } \\
\text { child abuse potential inventory (child and self) } \\
\text { - Majority of families showed clinically significant improvement; } 2 / 10 \text { showed no change or } \\
\text { deteriorated } \\
\text { pre-post }\end{array}$ \\
\hline $\begin{array}{l}\text { Vieten \& Astin } \\
(2008)\end{array}$ & $\begin{array}{l}\text { RCT with } 3 \text { month } \\
\text { f/up (postpartum) }\end{array}$ & Waitlist control & $\begin{array}{l}\text { - The intervention group demonstrated a significant reduction in state anxiety (effect size, } 0.89 \text { ) and } \\
\text { negative affect (effect size, } 0.83 \text { ) compared to the control group } \\
\text { - Measures of perceived stress, positive affect, depressed and anxious mood, affect regulation, and } \\
\text { mindfulness were in the expected direction, but not significantly different across groups at post-test } \\
\text { and follow-up }\end{array}$ \\
\hline
\end{tabular}




\begin{tabular}{|c|c|c|c|}
\hline Singh et al. (2010) & $\begin{array}{l}\text { Alternating } \\
\text { treatment within a } \\
\text { multiple baseline } \\
\text { across participants }\end{array}$ & No & $\begin{array}{l}\text { - Decrease in non-compliance during mindfulness training of the caregivers and further decreases } \\
\text { following the completion of training. } \\
\text { - Overall, regardless of their baseline rate, the children showed a reduction in non-compliance } \\
\text { between } 45 \text { and } 78 \% \text {. } \\
\text { - Authors conclude that their findings provide preliminary evidence of transfer of mindfulness } \\
\text { training from caregiving to parent-child interactions. } \\
\text { - Parental informal interview provided support for the acceptability and increased mindfulness }\end{array}$ \\
\hline $\begin{array}{l}\text { Duncan \& Bardacke } \\
(2010)\end{array}$ & $\begin{array}{l}\text { Pre-post pilot } \\
\text { study }\end{array}$ & No & $\begin{array}{l}\text { - Increases in mindfulness ( } 3 \text { factors from the FFMQ) and positive affect, decreases in pregnancy } \\
\text { anxiety, depression, and negative affect from pre- to post-test. } \\
\text { - Perceived stress and the attention/awareness scale of the FFMQ did not show significant change } \\
\text { from pre- to post-intervention } \\
\text { - Effect sizes for changes in mindfulness, the hypothesized intervention mediator, were large ( } d= \\
\text { 74) } \\
\text { - Participants reported using mindfulness more frequently to cope with salient stressful aspects of } \\
\text { pregnancy and family life post-intervention (from } 37 \% \text { to } 85 \% \text { at post-test) } \\
\text { - Qualitative evidence suggests that mother perceived benefits from the intervention }\end{array}$ \\
\hline $\begin{array}{l}\text { Srivastava et al. } \\
\text { (2011) }\end{array}$ & Pre-post & No & $\begin{array}{l}\text { - Mean difference of total disturbed behavior was found to be significant } \\
\text { - Specifically, there was a significant decline in hostile/aggressive behavior, anxious behavior, and } \\
\text { hyperactive/distractible behavior }\end{array}$ \\
\hline Benn et al. (2012) & $\begin{array}{l}\text { RCT with } 2 \text { month } \\
\text { f/up }\end{array}$ & Waitlist & $\begin{array}{l}\text { - MT participants showed significant reductions in stress and anxiety and increased mindfulness, } \\
\text { self-compassion, and personal growth at post-test }(d=-0.40,-0.52,0.52,0.40,0.48) \text { and at } 2 \text { month } \\
\text { f/up }(d=-0.79,-0.75,0.57,0.37,0.64) \\
\text { - Depression was significantly lower in MT group at post-test }(d=-0.51) \text {, but changes were not } \\
\text { maintained at f/up } \\
\text { - Relational competence also showed significant positive changes (empathic concern and } \\
\text { forgiveness) at f/up }(d=0.49,1.23) \\
\text { - Mindfulness changes at program completion mediated outcomes at f/up }\end{array}$ \\
\hline
\end{tabular}




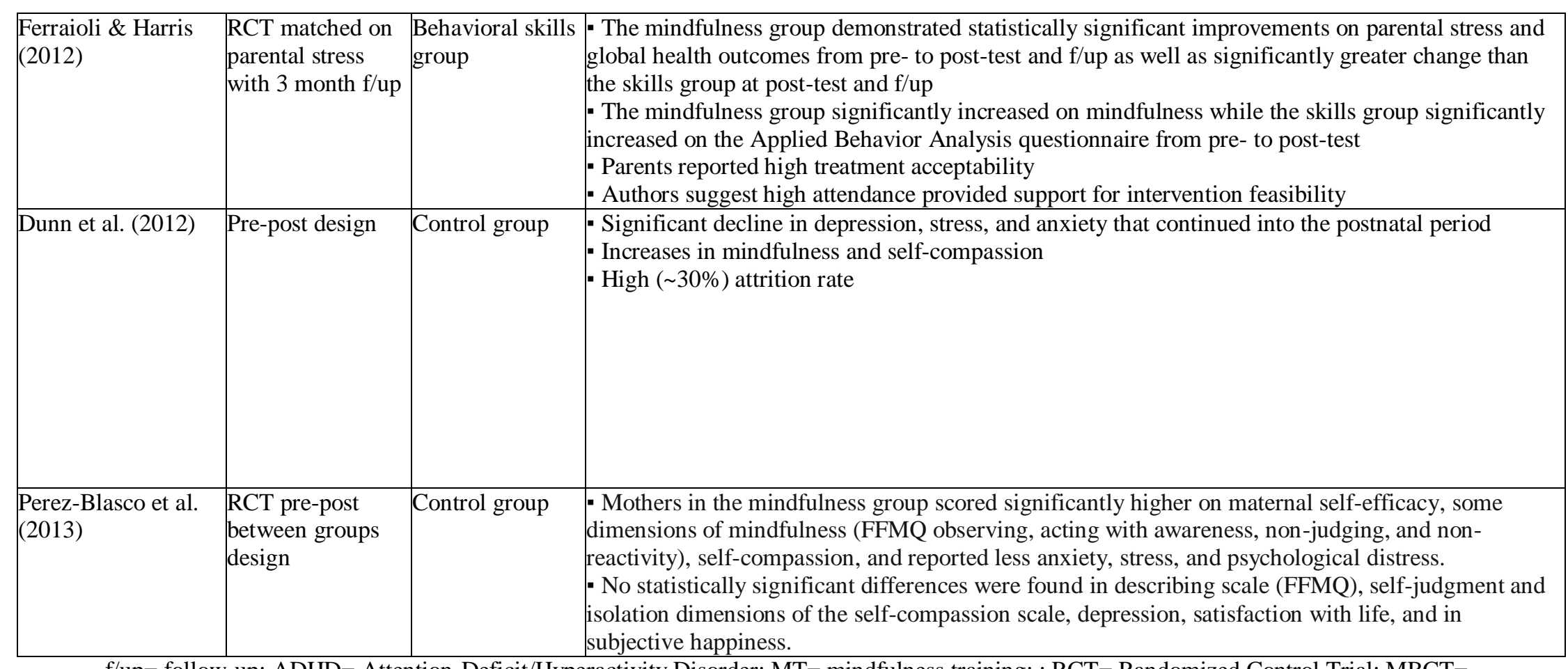

f/up= follow-up; ADHD= Attention-Deficit/Hyperactivity Disorder; MT= mindfulness training; $; \mathrm{RCT}=$ Randomized Control Trial; MBCT=

Mindfulness-Based Cognitive Therapy; PuP= Parenting Under Pressure; TAU = treatment as usual; FFMQ = five factor mindfulness questionnaire; $d=\mathrm{Cohen}$ 's d, a measure of effect size; ODD= Oppositional Defiant Disorder; $\mathrm{CBCL}=$ Child Behavior Checklist 
resources are spent trying to assess their efficacy and effectiveness, a psychometricallysound instrument of mindful parenting is needed.

\section{The Interpersonal Mindfulness in Parenting Scale}

Currently, one measure of mindful parenting exists - the Interpersonal Mindfulness in Parenting (IEM-P; Duncan, 2007, unpublished dissertation) scale. This measure targets mindfulness within the parent-child relationship, while other measures of mindfulness for adults assess intrapersonal mindfulness. That is, other mindfulness scales neglect to assess mindfulness within social interactions (i.e., interpersonal mindfulness). According to Duncan, knowing an individual's level of intrapersonal mindfulness does not necessarily strongly predict their reactivity, judgment, and awareness in social interactions.

The IEM-P scale was developed for use with parents of early adolescents (10-14 years $)$, and initial items $(N=10)$ were created from existing measures of intrapersonal mindfulness. As part of her dissertation, Duncan (2007) evaluated her hypothesis that interpersonal mindfulness is a related but distinct construct from intrapersonal mindfulness. A simple structural model revealed that intrapersonal mindfulness explained a moderate amount of the relationship of the variance in mindful parenting $\left(R^{2}=0.489\right)$. Duncan concluded that mindful parenting is distinct from mothers' intrapersonal mindfulness. However, the measure of intrapersonal mindfulness used in the study was constructed for the study, and its psychometric properties are unknown. Research exploring the relationship between mindful parenting and intrapersonal mindfulness that utilizes validated measures of intrapersonal mindfulness is needed before any conclusions can be drawn regarding the distinctiveness of these two constructs. 
Another purpose of Duncan's dissertation was to investigate the structure of the mindful parenting construct (2007). The apriori model of mindful parenting consisted of three factors: low reactivity $(n=3)$, awareness/present-centered attention $(n=4)$, and non-judgmental receptivity $(n=3)$. The initial 10 -item version of the IEM-P was reduced to 8 items following factor analysis. Two items comprised each of the four first-order factors (present-centered attention, present-centered emotional awareness, nonjudgmental acceptance, and non-reactivity). Internal consistency for the full 8-item scale was estimated at $\alpha=.72$. More recently, when utilizing a 10 -item IM-P in a clinical study (the acronym for the measure was changed from IEM-P to IM-P after Duncan's original study in 2007), Coatsworth and colleagues (2009) reported an internal consistency of $\alpha=$ 0.61 .

In 2012, the IM-P was expanded from 10 items to 31 items and translated into Dutch. The validation study (de Bruin et al., 2012), utilizing a general population sample of Dutch mothers of adolescents (12-15 years), found the Dutch IM-P to have a six-factor structure. Twenty-nine of the 31 items were retained. Subscale internal consistencies ranged from .54 to .83 . Authors also reported some evidence for convergent validity in this sample with measures of optimism, depression, quality of life, mindfulness, and parenting. Construct validity of the Dutch IM-P also held in a sample of mothers of adolescents with type 1 diabetes mellitus (de Bruin et al., 2012). Although there is growing psychometric support for the use of the Dutch IM-P with Dutch mothers of atrisk adolescents, use of the Dutch IM-P may be limited to this population. That is, the Dutch IM-P is not intended for use with parents of children or older adolescents, clinical 
populations, or for parents of youth who are not considered at-risk, and no psychometric information for these populations exists.

Clinical uses of the IM-P. To date, versions of the IM-P have been utilized clinically in one intervention study and two correlational studies. In the clinical intervention study, Coatsworth et al. (2009) measured parents' interpersonal mindfulness using the initial 10-item version of the IM-P. At post-test, mothers in the mindfulnessenhanced intervention evidenced a significant difference on mindful parenting compared to the control condition. However, mindful parenting was not significantly different between the two intervention conditions (Coatsworth et al., 2009). Interestingly, mediation analyses provided support that the mindful parenting intervention operated indirectly on the quality of parent-youth relationships through changes in mindful parenting.

In a correlational study investigating fathers of children with intellectual disabilities, MacDonald and Hastings (2010) found a positive relation between fathers' mindful parenting scores (two items from the IM-P that measured Present-Centered Attention) and involvement in child-related parenting tasks and roles related to child socialization. Yet, mindful parenting scores were not related to daily caregiving tasks. Additionally, measuring mindful parenting with only two items decreases reliability and validity, making the study's finding difficult to interpret. Conversely, another correlational study conducted by Beer, Ward and Moar (2013) found that mindful parenting (measured by a 31-item version of the Dutch IM-P) did not mediate the relationship between child behavior problems and parental distress. 
Of the versions of the IM-P (the 8-item, the 10-item, 29-item Dutch version, and a 31-item version that was used by Beer et al., 2013), the 29-item Dutch IM-P may have the most psychometric support. However, it is premature to draw conclusions regarding this measure's reliability, validity, or appropriateness for use with various populations. While the Dutch IM-P has shown psychometric promise in a Dutch community sample of mothers of adolescents, it was not built with the intention of being used with other populations, and its psychometric functioning in other populations (e.g., with fathers, or with parents of children) is unknown. As the structure of the IM-P has varied across samples, further research is needed before conclusions regarding the factor structure of the mindful parenting construct can be made.

Mindful parenting interventions are being utilized with mothers and fathers of infants, children, and adolescents. A psychometrically-sound measure of mindful parenting is needed to understand the results of mindful parenting intervention studies. For example, is the intervention increasing mindful parenting, and is mindful parenting responsible for treatment effects? Being able to measure mindful parenting would also function to maximize the efficiency of mindful parenting interventions by identifying active components of treatment. The first step toward creating a mindful parenting measure is to invest resources in initial item development in order to increase the likelihood of adequate psychometrics. The next section presents an approach to measure development from modern test theory (MTT). MTT analyses of current mindfulness measures are reviewed and the application of MTT to mindful parenting is discussed. 


\section{Measure Development Following from Modern Test Theory}

Beyond classical test theory (CTT), based in traditional ideas of reliability and validity, are modern test theories, including Item Response Theory (IRT). IRT approaches assume that an individual's response to an item is influenced by qualities of the individual (ability level) and qualities of the item. Item qualities include item difficulty (essentially, the trait level required for a respondent to have a probability of .5 of answering the item correctly) and item discrimination (the degree to which an item can differentiate individuals who have various trait levels; see Crocker \& Algina, 2008 or Fraley, Waller, \& Brennan, 2000). In contrast, CTT views a test score as the sum of the true score and error. As the exact value of the true score and error can never be defined, CTT rests on several assumptions. Specifically, CTT operates under the assumption that (a) true scores and error scores are uncorrelated; (b) the average error score in the population of examinees is zero; and (c) error scores on parallel tests are uncorrelated (Hambleton \& Jones, 1993). In fact, if the assumptions of CTT hold, then CTT and IRT will yield the same results. However, this is often not the case.

According to An and Yung (2014), IRT is widely used in the field of education to develop tests, calibrate and evaluate test items, and to score subjects on their abilities (or other latent traits). All major educational tests (SAT, GRE) are developed from IRT because it increases accuracy and reliability, while reducing assessment time (i.e., the individual does not have to complete an entire test to locate their ability; An \& Yung, 2014). IRT is becoming more popular in health outcomes, quality of life research, and in clinical research. A search on PsychInfo for "Item Response Theory" from 1990 to 1999 
reveals 938 results, while the same search from only 2010 to 2015 (current) reveals 2125 results.

Benefits of choosing an IRT approach. There are several important differences between CTT and IRT. First, CTT models generally focus on test-level data, while IRT approaches rely primarily on item-level analyses (Hambleton \& Jones, 1993). Further, item level analyses conducted in CTT are limited in that they are sample dependent. Consequently, the test is most useful when the sample used for measurement development is very similar to the population for which the test is intended (Hambleton \& Jones, 1993). Generalizability is limited in CTT research, where characteristics of the sample (e.g., homogeneity of participants, sample size, variability) directly influence $r$ and $p$ values and limit findings. Not only are items sample dependent in CTT, but scores are test dependent. For example, different tests of depression based on CTT approaches arrive at different scores, suggesting different levels of depression. Conversely, in IRT, item and person parameters are sample independent, meaning that both the person characteristics are independent of test items and item parameters are independent of the set of examinees and their ability levels (Hambleton, Swaminathan, \& Rogers, 1991). Because IRT permits "test free measurement", this allows for comparison of individuals who were administered different forms of the same test (i.e., different items) or different subtests (Crocker \& Algina, 2008). This property of IRT underlies modern testing adaptations, such as Computerized Adaptive Testing (CAT), and is considered a primary benefit of choosing an IRT approach (Hambleton \& Jones, 1993).

Another benefit of choosing IRT is that IRT provides a basis for matching items to ability levels. Item Characteristics Curves (ICCs) reflect the probabilities with which 
individuals across a range of traits levels are likely to answer each item "correctly," allowing one to estimate the likelihood that an individual at a specific trait level would answer a particular item correctly (Crocker \& Agina, 2008). For example, a mother with a low level of mindfulness is unlikely to answer the item "I always listen when my child is talking to me" correctly (i.e., endorse "yes") because her mindfulness "ability" is below that items' level of "difficulty." In this example, the ICC would indicate a low probability, based on the mother's ability and the item's difficulty, that she would endorse this item.

IRT approaches also provide more specific information regarding test reliability. According to CTT, a test has a single reliability estimate (e.g., coefficient alpha). However, from an IRT perspective, a test does not have a single reliability score because a test may provide better information at some trait levels than others (Crocker \& Algina, 2008). This concept is referred to as test information. For example, individual A is extremely low on mindfulness, individual B is slightly higher on mindfulness than person A (but still very low), individual C is extremely high on mindfulness, and individual D is slightly higher on mindfulness than individual C. A test may be able to differentiate person A from B (it can detect differences only at low trait levels), but not from person C and D. A test with good information is able to accurately discriminate between individuals at various trait levels. The reader can also refer to Fraley et al. (2000) or Hambleton et al. (1991) for further discussions regarding advantages of IRT over CTT.

IRT models. A variety of models have been developed from the IRT perspective. These include the one parameter (1PL), two parameter (2PL), and three parameter models (3PL; Bond \& Fox, 2007). The 1PL model assumes that all items have equivalent 
discrimination (an equal ability to differentiate among examinees). The 2PL allows items to differentially discriminate, while the 3PL allows for guessing. The Rasch model is a 1PL logistic model used to examine binary response items. This model is expressed as

$$
P\left(X_{i s}=1 \mid \theta_{s}, \beta_{i}\right)=\frac{e^{(\theta s-\beta i)}}{1+e^{(\theta s-\beta i)}}
$$

Or the probability that an individual with a trait level $\left(\theta_{\mathrm{s}}\right)$ will correctly answer an item with a particular difficulty level $\left(\beta_{i}\right)$. Consequently, an individual's response is determined by their trait level and item difficulty. Along with assuming that items are equally discriminating, assumptions of the Rasch model include unidimensionality (the covariance among the items can be explained by a single latent factor), conditional/local independence (there is no additional systematic covariance among the items), and monotonicity (response probability increases with higher ability level; Embretson \& Reise, 2000; Rosenbaum, 1984). According to Embretson and Reise (2000), "because only the Rasch model can be justified by conjoint additivity and other fundamental measurement properties, many psychometricians reject the other IRT models as not providing objective measurement" (p. 151). That is, the Rasch permits additivity (person and item differences contribute additively to the probability of a positive response; as opposed to ordinal level data. Interval level data is particularly useful as it allows for reliable comparisons of change among and within subjects (Avery, Russell, Raina, Walter, \& Rosenbaum, 2003). Further, it permits estimation of a total score without having to administer all items (the foundation of computerized adaptive testing; Avery et al., 2003). Indeed, research generally indicates that computerized adaptive testing can reduce test lengths up to $50 \%$, while maintaining equal or actually increasing reliability and validity (e.g., Weiss \& Kingsbury, 1984). 


\section{Modern Test Theory and Mindfulness Measures}

MTT models have been used to assess several adult mindfulness instruments. One MTT concept that is frequently employed in test development and improvement is the analysis of differential item function (DIF). DIF provides an assessment of differential response bias or demand. That is, DIF occurs when an item's properties in one group are different from the item's properties in another group (Reise \& Waller, 2009). There are several reasons to suspect that mindfulness scales may be vulnerable to DIF.

For instance, accurate self-assessment of attention or awareness inherently requires metacognitive awareness of awareness (Schooler, 2002). If an individual is low on mindfulness, or metacognitive awareness of awareness, they may be unable to accurately report on their mindfulness. Said differently, reporting upon an "experience one was potentially unaware of in the first place likely increases error and bias" (van Dam, Earleywine, \& Danoff-Burg, 2009, p. 516). Indeed, Singh and colleagues found that mothers reported their mindfulness to be higher pre-intervention than postintervention. Additionally, research suggests that impulsive individuals may be less likely to endorse negatively-worded items because of the way they are worded (DiStefano \& Motl, 2009).

Based on this research, van Dam and colleagues (2009) examined DIF of the FFMQ across meditators and nonmeditators. Indeed, results indicated that non-meditators were more likely than meditators to reject (i.e., rate lower on a Likert scale) negativelyworded items than accept (i.e., rate highly) positively-worded items. Consequently, DIF across meditators and nonmeditators threatens the construct validity of the FFMQ as a pre-post measure of mindfulness. Similarly, in 2010 van Dam, Earleywine, and Borders 
examined the response patterns of adults on the MAAS using IRT. Consistent with findings of DIF and the FFMQ, authors reported that negatively-worded items challenge the construct validity of the MAAS. Taken together, these results suggest that negativelyworded items may not be appropriate for mindfulness instruments.

In addition to incorporating DIF analyses, IRT can be used to increase the sensitivity of mindful parenting measurement by taking into account the difficulty (or severity) of items. Indeed, brief examination of the IM-P suggests that items may range in difficulty. Overall, subjecting mindful parenting instruments to the more stringent analyses employed in IRT may improve accuracy and utility.

\section{Modern Test Theory and Mindful Parenting}

As mentioned previously, few studies of mindful parenting have incorporated a measure of interpersonal mindfulness. In the one clinical study that utilized the IM-P, the purpose of assessment was to determine whether parents increased in their level of mindfulness following participation in the mindfulness-enhanced intervention and to discern its mediating role in intervention outcomes (Coatsworth et al., 2009). In light of recent findings suggesting DIF for negatively-worded items on intrapersonal mindfulness scales across meditators and nonmeditators (suggesting these scales may not be appropriate for pre-post interventions assessment of mindfulness; van Dam et al., 2009; van Dam et al., 2010), it would be beneficial to examine DIF of the IM-P, as it included negatively-worded items and is being used as a pre-post measure. Given the scarcity of validation studies examining various versions of the IM-P, more research is needed to examine the psychometric qualities of these instruments across a variety of populations. 
Dimensions of mindful parenting as measured by various versions of the IM-P have not been consistent across studies. These different findings may be due to characteristics of the sample, or may suggest poor psychometrics. Previous research examining the IM-P relied on factor analytic methods to explore and validate the factor structure of the instrument. According to Bond and Fox (2007), reliance on factor analytic strategies is limited in that it is based on correlations of sample-dependent ordinal-level data. As factor analysis does not require the construction of linear, intervallevel measures of factor scores, the factor sizes and loadings are "rarely" reproduced across samples (Bond \& Fox, 2007, p. 252). While factor analysis identifies correlations with the underlying variable, it does not provide information regarding locations on it (Schumacker \& Linacre, 1996; as cited in Bond \& Fox, 2007). Further, although a factor structure is typically considered "confirmed" once it is reproduced, the confirmation procedures do not provide fit statistics (Wright, 1996, as cited in Bond \& Fox, 2007). Another benefit of using IRT modeling as opposed to factor analysis in evaluating data is that factor analysis requires complete data matrices for analyses. Eliminating missing data by deleting cases or data imputation can result in data loss or distortions in the data. Research would likely benefit from an IRT evaluation of mindful parenting to better understand the structure of this construct.

\section{The Current Study}

A psychometrically-sound measure of mindful parenting for parents of children and adolescents is needed. This measure would facilitate clinical research by allowing researchers to assess mindful parenting in relation to other variables (e.g., parenting), track changes in mindful parenting during intervention, and increase the efficiency and 
effectiveness of interventions. Consequently, the aim of the present study is to develop a measure of mindful parenting. Specifically, this measure will be developed for use with mothers and fathers of both children and adolescents, ranging in age from 2- to 16-yearsold.

In order to develop a measure that is maximally effective, modern test theory will be utilized to guide measure development and psychometric analysis. As previously discussed, if the assumptions of classical test theory hold true, then classical test theory and modern test theory will yield the same results. However, as true scores are not known, modern test theory provides a more conservative and perhaps accurate approach to measure development and validation.

Study goals and hypotheses. The primary goal of the current study is to develop a measure of mindful parenting for parents of children and adolescents. As part of measure development, the structure of mindful parenting will be explored. Specifically, it is hypothesized that mindful parenting, as measured by the new Mindfulness in Parenting Questionnaire (MIPQ), will be:

(a) distinct but positively related to intrapersonal mindfulness (Mindful Attention and Awareness Scale [MAAS]; Brown \& Ryan, 2003) and meditation experience

(b) positively related to authoritative parenting style (Parental Authority Questionnaire [PAQ-R]; Reitman, Rhode, Hupp, \& Altobello, 2002)

(c) negatively related to permissive and authoritarian parenting styles (PAQ-R; Reitman et al., 2002) 
(d) negatively related to both laxness and overreactivity in parents' discipline practices (Parenting Scale [PS]; Arnold, O’Leary, Wolff, \& Acker, 1993)

(e) unrelated to parents' socioeconomic status and ethnicity 


\section{CHAPTER III}

\section{Method}

\section{Procedure}

The following study was conducted in three phases, where (a) phase 1 included item development through interviewing cognitive experts; (b) phase 2 consisted of cognitive interviewing with parents; and (c) phase 3 included large-scale data collection to evaluate psychometrics of the measure. Institutional Review Board (IRB) approval was obtained prior to each phase of data collection.

Phase 1: Item development. In order to develop items for the initial Mindfulness In Parenting Questionnaire (MIPQ), content experts were asked to provide statements describing a parent who is extremely high in mindful parenting, a parent who is extremely low in mindful parenting, and characteristics of a parent who has moderate levels of mindful parenting. Specifically, content experts in the areas of mindfulness, mindful parenting and related fields were identified from a literature search of recent publications in these content areas. A formal request to participate in the item development phase was emailed to 19 content experts, along with the "brainstorm worksheet." A total of four content experts completed the brainstorm worksheet. Content experts' descriptive statements were translated into questions by the primary investigator, and these questions $(\mathrm{N}=84)$ were compiled to create the initial MIPQ (see Appendix A).

Phase 2: Cognitive interviewing. Cognitive interviewing is an important, yet often overlooked, stage of measurement development. Frequently, researchers assume that the respondent understands the questions and terminology in the way that the researcher intended them to interpret the material, is able to accurately recall information, 
and accurately formulate answers (Jobe, 2003). Yet, numerous variables may impact a respondent's ability to accurately report information. Variables can include the instructions, response strategy, response options, reference period (period of time to which the question refers), order of the questions, etc. (Jobe, 2003). Consequently, utilizing cognitive interviewing strategies to reduce measurement error associated with these variables can increase the psychometrics of a measure.

Four parents ( $75 \%$ female), recruited through fliers posted around a private university, participated in the cognitive interviewing sessions. Procedures for cognitive interviewing were as follows:

1. Following consent, the parent completed a brief demographic form.

2. The parent was given the MIPQ and asked to read the directions and complete all items. Completing the MIPQ took approximately 10-15 minutes.

3. The interviewer (principal investigator) queried the parent about the item responses. Specifically, the interviewer asked the parent:

(a) if he/she experienced any difficulties while completing the items (e.g., “was this item hard to answer? If yes, why?")

(b) for his/her interpretation of the meaning of each item (e.g., "what did this question mean to you?")

(c) his/her basis for the response of each item (e.g., "What did you think of when answering this question? How did you choose your answer?")

(d) his/her opinion regarding whether any content is missing from the measure ("are there things that we forgot to ask about that you think are important?") 
(e) his/her opinion regarding the response options (5-point likert scale)

(e.g., "how would you make the response choices easier to understand?")

(f) the clarify of the directions (e.g., "how would you make the directions more clear?’)

This interview lasted approximately 30 to 45 minutes. Parents' responses were written down verbatim.

After completing the cognitive interviews, parents' responses were compiled. Comments were reviewed to determine issues with formatting, instructions, response format, and item comprehension and tense. Items deemed problematic were revised for clarity or eliminated. Items identified by more than one parent as measuring the same or very similar content also reviewed and considered for removal. Following revision and item elimination, 61 items remained. The directions were also modified to emphasize the time frame (i.e., the last two weeks) for which parents were to reflect when providing responses. This revised MIPQ was used for the final phase of data collection (see Appendix B).

Phase 3: Data collection. After the MIPQ was revised and IRB approval was again obtained, data collection took place. All data was collected and managed by the principal investigator. Three research assistants, who were included on the IRB, each assisted during one day of data collection to provide extra support during recruitment, such as answering parents' questions and distributing survey packets. All data are kept in a locked office in a locked file cabinet, consistent with HIPAA regulations. 


\section{Participants}

Participants were recruited through daycare centers, after-school and extracurricular programs, and a private university in South Florida. Criteria for inclusion in this study were: (a) being a parent of a child between the ages of 2- to 16-years-old and (b) English as a primary language. Due to the content of the items, parents who only had an infant (younger than 2 years) or a youth older than 16 years were not eligible. Parents who had multiple children in this age range were asked to focus on one child between the ages of 2- to 16-years old while completing the survey packet (referred to as the "target child"), and to list this child's age first on the demographics form (see Appendix B).

Overall, two-hundred and three parents of children ages 2 to 16 years participated in the study. One-hundred sixty-eight $(82.8 \%)$ of the participants were female, and parents' ages ranged from 19 to 63 years. The sample was diverse, with $37.4 \%$ of the participants identifying themselves as Black/African American, 33.4\% of the sample identifying as White/Caucasian, and $20.7 \%$ identifying as Hispanic. The majority of the sample was employed (85.7\%). Analysis of participants' income revealed a bimodal distribution, with $32.5 \%$ of the sample reporting a household income less than $\$ 30,000$, and $28.6 \%$ of the sample reporting a household income of more than $\$ 100,000$. Level of education of the sample was also varied; while $24.1 \%$ of the sample completed 12 years of education or less, $47.3 \%$ of the parents in the sample completed 16 years of education. Over half $(56.2 \%)$ of the participants were married. Number of children ranged from 1 to 9. The average target child age was 6.1 years $(S D=3.8)$. Approximately half $(46.8 \%)$ of the participants reported engaging in mindfulness or a related activity (e.g., prayer, 
Table 6

Demographic Characteristics Across Samples

\begin{tabular}{|c|c|c|c|c|c|c|}
\hline Demographic Variable & $\begin{array}{c}\text { Sample } 1 \\
(n=44)\end{array}$ & $\begin{array}{l}\text { Sample } 2 \\
(n=62)\end{array}$ & $\begin{array}{c}\text { Sample } 3 \\
(n=58)\end{array}$ & $\begin{array}{c}\text { Sample } 4 \\
(n=23)\end{array}$ & $\begin{array}{c}\text { Sample } 5 \\
(n=16)\end{array}$ & $\begin{array}{c}\text { Total Sample } \\
(n=203)\end{array}$ \\
\hline $\mathrm{Age}^{\mathrm{a}}$ & $35.6(7.1)$ & $38.3(6.5)$ & $30.5(5.6)$ & $44.1(9.5)$ & $36.3(7.0)$ & $36.0(8.0)$ \\
\hline Sex (female) & $81.8 \%$ & $82.3 \%$ & $96.6 \%$ & $69.6 \%$ & $56.3 \%$ & $82.8 \%$ \\
\hline Race/Ethnicity & -- & -- & -- & -- & -- & -- \\
\hline White/Caucasian & $4.5 \%$ & $64.5 \%$ & $1.7 \%$ & $60.9 \%$ & $68.8 \%$ & $33.5 \%$ \\
\hline Black/African American & $52.3 \%$ & $4.8 \%$ & $81.0 \%$ & $8.7 \%$ & $6.3 \%$ & $37.4 \%$ \\
\hline Hispanic & $38.6 \%$ & $17.7 \%$ & $10.3 \%$ & $26.1 \%$ & $12.5 \%$ & $20.7 \%$ \\
\hline Caribbean Islander & $2.3 \%$ & $3.2 \%$ & $3.4 \%$ & $0.0 \%$ & $0.0 \%$ & $2.5 \%$ \\
\hline Asian & $0.0 \%$ & $6.5 \%$ & $0.0 \%$ & $0.0 \%$ & $0.0 \%$ & $2.0 \%$ \\
\hline Multiracial & $2.3 \%$ & $3.2 \%$ & $1.7 \%$ & $4.3 \%$ & $12.5 \%$ & $3.0 \%$ \\
\hline Other & $0.0 \%$ & $0.0 \%$ & $1.7 \%$ & $0.0 \%$ & $0.0 \%$ & $1.0 \%$ \\
\hline Household Income & -- & -- & -- & -- & -- & -- \\
\hline Under 30k & $47.7 \%$ & $3.2 \%$ & $62.1 \%$ & $8.7 \%$ & $31.3 \%$ & $33.0 \%$ \\
\hline $30-50 \mathrm{k}$ & $25.0 \%$ & $1.6 \%$ & $27.6 \%$ & $17.4 \%$ & $25.0 \%$ & $18.0 \%$ \\
\hline $50-70 \mathrm{k}$ & $15.9 \%$ & $3.2 \%$ & $6.9 \%$ & $4.3 \%$ & $6.3 \%$ & $7.5 \%$ \\
\hline $70-100 \mathrm{k}$ & $4.5 \%$ & $24.2 \%$ & $1.7 \%$ & $21.7 \%$ & $12.5 \%$ & $12.5 \%$ \\
\hline $100 \mathrm{k}+$ & $4.5 \%$ & $64.5 \%$ & $1.7 \%$ & $47.8 \%$ & $25.0 \%$ & $29.0 \%$ \\
\hline
\end{tabular}




\begin{tabular}{|c|c|c|c|c|c|c|}
\hline Demographic Variable & $\begin{array}{l}\text { Sample } 1 \\
(n=44)\end{array}$ & $\begin{array}{c}\text { Sample 2 } \\
(n=62)\end{array}$ & $\begin{array}{c}\text { Sample } 3 \\
(n=58)\end{array}$ & $\begin{array}{l}\text { Sample } 4 \\
(n=23)\end{array}$ & $\begin{array}{l}\text { Sample } 5 \\
(n=16)\end{array}$ & $\begin{array}{c}\text { Total Sample } \\
\quad(n=203)\end{array}$ \\
\hline Family Size $^{\mathrm{a}}$ & $3.98(1.3)$ & $3.7(0.8)$ & $4.1(1.6)$ & $3.8(1.4)$ & $3.9(1.2)$ & $3.9(1.3)$ \\
\hline 1 & $0.0 \%$ & $1.6 \%$ & $0.0 \%$ & $0.0 \%$ & $0.0 \%$ & $0.5 \%$ \\
\hline 2 & $6.8 \%$ & $1.6 \%$ & $15.5 \%$ & $8.7 \%$ & $12.5 \%$ & $8.4 \%$ \\
\hline 3 & $29.5 \%$ & $37.1 \%$ & $25.9 \%$ & $43.5 \%$ & $18.8 \%$ & $31.5 \%$ \\
\hline 4 & $38.6 \%$ & $51.6 \%$ & $22.4 \%$ & $21.7 \%$ & $43.8 \%$ & $36.5 \%$ \\
\hline 5 & $15.9 \%$ & $6.5 \%$ & $15.5 \%$ & $17.4 \%$ & $12.5 \%$ & $12.8 \%$ \\
\hline 6 & $0.0 \%$ & $1.6 \%$ & $12.1 \%$ & $4.3 \%$ & $12.5 \%$ & $5.4 \%$ \\
\hline 7 & $2.3 \%$ & $0.0 \%$ & $3.4 \%$ & $0.0 \%$ & $0.0 \%$ & $1.5 \%$ \\
\hline 8 & $4.5 \%$ & $0.0 \%$ & $3.4 \%$ & $4.3 \%$ & $0.0 \%$ & $2.5 \%$ \\
\hline Number of Children $^{\mathrm{a}}$ & $2.2(1.3)$ & $1.7(0.7)$ & $2.6(1.6)$ & $2.2(1.4)$ & $2.1(1.1)$ & $2.2(1.3)$ \\
\hline 1 & $36.4 \%$ & $37.1 \%$ & $27.6 \%$ & $34.8 \%$ & $37.5 \%$ & $34.0 \%$ \\
\hline 2 & $29.5 \%$ & $54.8 \%$ & $34.5 \%$ & $30.4 \%$ & $31.3 \%$ & $38.9 \%$ \\
\hline 3 & $20.5 \%$ & $6.5 \%$ & $12.1 \%$ & $26.1 \%$ & $18.8 \%$ & $14.3 \%$ \\
\hline 4 & $6.8 \%$ & $0.0 \%$ & $15.5 \%$ & $4.3 \%$ & $12.5 \%$ & $7.4 \%$ \\
\hline 5 & $4.5 \%$ & $1.6 \%$ & $5.2 \%$ & $0.0 \%$ & $0.0 \%$ & $3.0 \%$ \\
\hline 6 & $2.3 \%$ & $0.0 \%$ & $3.4 \%$ & $0.0 \%$ & $0.0 \%$ & $1.5 \%$ \\
\hline 7 & $0.0 \%$ & $0.0 \%$ & $0.0 \%$ & $4.3 \%$ & $0.0 \%$ & $0.5 \%$ \\
\hline 8 & $0.0 \%$ & $0.0 \%$ & $0.0 \%$ & $0.0 \%$ & $0.0 \%$ & $0.0 \%$ \\
\hline 9 & $0.0 \%$ & $0.0 \%$ & $1.7 \%$ & $0.0 \%$ & $0.0 \%$ & $0.5 \%$ \\
\hline Marital Status & -- & -- & -- & -- & -- & \\
\hline Single & $43.2 \%$ & $4.8 \%$ & $63.8 \%$ & $17.4 \%$ & $31.3 \%$ & $33.5 \%$ \\
\hline Married & $40.9 \%$ & $91.9 \%$ & $27.6 \%$ & $60.9 \%$ & $56.3 \%$ & $56.2 \%$ \\
\hline Separated & $4.5 \%$ & $0.0 \%$ & $3.4 \%$ & $4.3 \%$ & $0.0 \%$ & $2.5 \%$ \\
\hline Divorced & $11.4 \%$ & $1.6 \%$ & $5.2 \%$ & $13.0 \%$ & $12.5 \%$ & $6.9 \%$ \\
\hline Widowed & $0.0 \%$ & $1.6 \%$ & $0.0 \%$ & $0.0 \%$ & $0.0 \%$ & $0.5 \%$ \\
\hline Partnered & $0.0 \%$ & $0.0 \%$ & $0.0 \%$ & $4.3 \%$ & $0.0 \%$ & $0.5 \%$ \\
\hline Employed & $97.7 \%$ & $90.3 \%$ & $82.8 \%$ & $69.6 \%$ & $68.8 \%$ & $85.7 \%$ \\
\hline
\end{tabular}




\begin{tabular}{lcccccc}
\hline Demographic Variable & $\begin{array}{c}\text { Sample 1 } \\
(n=44)\end{array}$ & $\begin{array}{c}\text { Sample 2 } \\
(n=62)\end{array}$ & $\begin{array}{c}\text { Sample 3 } \\
(n=58)\end{array}$ & $\begin{array}{c}\text { Sample 4 } \\
(n=23)\end{array}$ & $\begin{array}{c}\text { Sample 5 } \\
(n=16)\end{array}$ & $\begin{array}{c}\text { Total Sample } \\
(n=203)\end{array}$ \\
\hline Educational Attainment & -- & -- & -- & -- & -- & -- \\
$<12$ & $27.3 \%$ & $0.0 \%$ & $17.2 \%$ & $8.7 \%$ & $6.3 \%$ & $12.3 \%$ \\
12 /GED & $15.9 \%$ & $3.2 \%$ & $22.4 \%$ & $8.7 \%$ & $0.0 \%$ & $11.8 \%$ \\
13 & $15.9 \%$ & $4.8 \%$ & $12.1 \%$ & $0.0 \%$ & $6.3 \%$ & $8.9 \%$ \\
14 & $22.7 \%$ & $1.6 \%$ & $15.5 \%$ & $17.4 \%$ & $6.3 \%$ & $12.3 \%$ \\
15 & $0.0 \%$ & $1.6 \%$ & $5.2 \%$ & $13.0 \%$ & $0.0 \%$ & $3.4 \%$ \\
16 & $18.2 \%$ & $87.1 \%$ & $17.2 \%$ & $47.8 \%$ & $6.3 \%$ & $47.3 \%$ \\
\hline
\end{tabular}

${ }^{\mathrm{a}}$ Mean and standard deviation 
meditation, yoga) regularly. Sample-specific demographics are reported below and are summarized in Table 6.

Sample 1. Parents from Sample $1(n=44)$ were recruited from staff of a large, multi-site after-school program. The mean age of parents in this sample was 35.6 years old $(S D=7.1)$, and $81.8 \%$ of the parents were female. Parents comprising this sample were largely of minority and of low socio-economic status. Approximately half $(52.3 \%)$ of the sample identified as Black or African American, and $38 \%$ of the sample identified as Hispanic. Nearly half of the sample (48.8\%) reported an annual household income of less than $\$ 30,000$, with a mode family size $(38.6 \%)$ of $4(M=3.9, S D=1.3)$. Forty-three percent of the parents identified themselves as single parents, $40.9 \%$ reported being married, and $15.9 \%$ were divorced or separated. This entire sample was employed. Educational attainment appeared to be bimodal, with $27.3 \%$ of the sample completing less than 12 years of schooling, and $40.9 \%$ completing more than 14 years.

Sample 2. Participants from Sample $2(n=62)$ were recruited from a private early childhood/preschool program. Age and gender demographics for this sample was similar to Sample 1 , with a mean age of 38.29 years $(S D=6.5)$, and $82.3 \%$ female. This sample identified as predominantly Caucasian (64.5\%), and of a high socio-economic status. Two-thirds (64.5\%) of the parents in Sample 2 reported an annual household income of more than $\$ 100,000$, with $88.7 \%$ of the sample reporting an annual household income of at least $\$ 70,000$. Ninety percent of parents were employed. Similar to Sample 1, the most common family size in Sample 2 was $4(51.6 \% ; M=3.7, S D=0.8)$. Nearly $100 \%$ of the parents in this sample were married (91.9\%). Parents in this sample were highly educated, with $87 \%$ of the sample completing at least 16 years of school. 
Sample 3. Parents from Sample $3(n=57)$ were recruited from an early childhood educational program. Parents in Sample 3 were predominately women (96.6\%) and were younger than the other samples $(M=30.5, S D=5.6)$. This sample was largely Black/African American (81.0\%) and had a low socio-economic status. Eighty-two percent of the parents were employed and $62.1 \%$ of the annual household incomes fell below $\$ 30,000$. Average household size was $4.1(S D=1.6)$, and $63.8 \%$ of the parents in this sample were single. Educational attainment was highly variable; $17.2 \%$ did not complete high school, $22.4 \%$ of parents reported their highest level of education to be high school/GED, while $17.2 \%$ completed 16 years of schooling.

Sample 4. Sample 4 consisted of 23 parents who were recruited through an extracurricular after-school program. Parents in Sample 4 were older than the other samples, with an average age of 44.1 years $(S D=9.5)$. Seventy percent were female. Over half of the parents in Sample 4 identified as White/Caucasian (60.9\%), almost one-third identified as Hispanic (26.1\%). Seventy percent of the parents were employed and nearly half of the parents reported an annual household income of more than $\$ 100,000$. Average household size was $3.8(S D=1.7)$, with a mode of 3 . Sixty-one percent of the parents in Sample 4 were married, $17.4 \%$ were single, and $13.0 \%$ were divorced. Half of the parents completed 16 years of education, with $78.2 \%$ of the sample completing at least 14 years of schooling.

Sample 5. Parents were also recruited from fliers posted around a large private university campus $(n=16)$. Approximately half of these parents were fathers $(43.8 \%)$. Average age of the sample was $36.3(S D=7.0)$. The majority of the parents identified as White/Caucasian (68.8\%). Two-thirds were employed (68.8\%). The distribution of 
income was bimodal, with $31.3 \%$ of the sample reporting an annual household income of less than $\$ 30,000$, and $25.0 \%$ reporting an income of more than $\$ 100,000$. Average household size was $3.9(S D=1.2)$. Fifty-six percent of Sample 5 was married, $31.3 \%$ were single, and $12.5 \%$ reported being divorced. The majority of parents in this sample completed at least 16 years of education $(81.3 \%)$.

\section{Measures}

Refer to Appendix B for measures used in the study.

Demographic Questionnaire. Parents completed a brief demographic form that included information regarding the parent's age, sex, race/ethnicity, household income, education, household family size, employment status, marital status, number of children and the children's ages. Additionally, parents were asked about their experience with mindfulness, meditation, or related activities (e.g., prayer, yoga, tai-chi, etc.).

Parental Authority Questionnaire-Revised (PAQ-R). The PAQ-R (Reitman, et al., 2002) is a 30 item measure of parenting style. Parents respond using a 4-point Likert-type rating scale (strongly disagree to strongly agree). In a sample of ethnically and socioeconomically diverse families, the PAQ-R was found to have a three factor structure, i.e., Authoritarian, Authoritative, and Permissive parenting styles. Each of the three subscales have demonstrated adequate to modest internal consistency across samples (Authoritarian $\alpha=.72-.76$; Permissive $\alpha=.73-.74$; Authoritative $\alpha=.56$ .77). The Authoritarian and Permissive subscales of the PAQ-R demonstrated construct validity through correlations with subscales of the Parenting Scale (e.g., Laxness and Overreactivity $[r=.26]$; Authoritarian and Overreactivity $[r=.4])$ and the Parent-Child Relationship Inventory (e.g., Permissive and Limit Setting [ $r=-.30]$; Authoritative and 
Communication $[r=.34])$. The PAQ-R has been utilized with parents of kindergarten children through adolescents (Reitman et al., 2002; Williams \& Wahler, 2010). In the current study, the three PAQ-R scales exhibited adequate internal consistency, similar to previous studies (see Table 7).

Parenting Scale (PS). The PS (Arnold, et al., 1993) is a measure of dysfunctional parenting behavior that was initially created and validated for mothers of children 18 - to 48-months-old. Thirty items are scored using a 7-point response format with polar anchor points of less adequate parenting at one end (e.g., when my child misbehaves...I raise my voice or yell) and more adequate parenting at the other end (e.g., when my child misbehaves...I speak to my child calmly). It consists of three factors, Laxness, Overreactivity, and Verbosity. The PS has demonstrated good test-retest reliability $(r=$ .84) and construct validity through a relation with observed parenting behaviors (Arnold et al., 1993).

In more recent studies investigating the PS with parents of older children, researchers found a two factor solution: Overreactivity and Laxness (Collett, Gimpel, Greenson, \& Gunderson, 2001; Harvey, Danforth, Ulazek, \& Eberhardt, 2001; Irvine, Biglan, Smolkowski, \& Ary, 1999). In the first study to evaluate the psychometrics of the PS in a non-Caucasian sample, Reitman et al. (2001) found a two factor solution and retained only 10 items. In 2005, Steele, Nesbitt-Daly, Daniel, and Forehand attempted to replicate Reitman et al. by evaluating the PS with a primarily low-income African American sample of parents with pre-adolescent and adolescent youth. Authors reported their results to be consistent with Reitman's findings, confirming the 10-item, two factor solution (Steele et al., 2005). The current study utilized the 10-item two-factor PS as 
identified in Reitman et al. (2001). Reliability estimates for the PS obtained in the current study can be found in Table 7.

Recently, Lorber, Xu, Slep, and Bulling (2014) conducted an Item Response Theory investigation of the Overreactivity and Laxness subscales in the original PS and shorter versions of the PS (i.e., Reitman et al., 2000; Rhoades \& O’Leary, 2007), including a "most informative 5" set derived from an IRT analysis of the original PS. Overall, analysis of factor structure and stability and concurrent validity supported the subscales. Results also revealed better discrimination for parents at the mid to upper reaches of each construct. Information was greater for the Laxness subscale than for the Overreactivity. Further, shorter versions of the PS (e.g., Reitman et al., 2001) resulted in loss of precision (in particular, a reduction in test information curves for the Overreactivity scale at higher levels of the construct), and lower stability and concurrent validity correlations (Lorber et al., 2014). Specifically, women's Overreactivity (ZPF = $2.10, p=.036)$ and men's Laxness $(Z P F=3.44, p<.001)$ scores based on the original PS exhibited significantly greater 6 month stability than Reitman and colleague's PS.

Regarding concurrent validity, the original PS Overreactivity scale was more strongly associated with child externalizing behavior than Reitman et al.'s version for both women $(Z=3.50, p<.001)$ and men $(Z=3.43, p<.001)$. There were also significant differences between the quality of marriage (Quality of Marriage Index; QMI) and Laxness, and the QMI and Overreactivity associations in men between the original and short version of the PS (see Lorber et al., 2014). Last, differences in reliability between the original PS (.83 and .81 for women and men, respectively, for Overreactivity; .89 and .87 for women and men, respectively, for Laxness) and shorter 
versions (i.e., Reitman et al., 2001) were also noted (.77 and .75 for women and men, respectively, on Overreactivity; .77 for both men and women on Laxness).

Mindful Attention and Awareness Scale (MAAS). The MAAS (Brown \& Ryan, 2003 ) is a 15 -item unidimensional measure of intrapersonal mindfulness in adults. Parents respond to items using a 6 point likert-type rating scale (Almost Always to Almost Never). Its psychometrics have been evaluated in samples of college students (Brown \& Ryan, 2003; MacKillop \& Anderson, 2007), adults from the general populations (Brown \& Ryan, 2003), and cancer patients (Brown \& Ryan, 2003; Carlson \& Brown, 2005), and has been translated into French, Dutch, and Swedish versions (Hansen, Lundh, Homman, \& Wangby-Lundh, 2009; Jermann et al., 2009; Schroevers, Nyklick, \& Topman, 2008). The MAAS has demonstrated adequate internal consistency $(\alpha=.82-.87)$, high test-retest reliability (4 weeks; $\alpha=.81$ ), convergent (i.e., openness to experience, social anxiety, rumination, etc.) and discriminant validity (i.e., aesthetics, private self-consciousness, self-reflectiveness, self-monitoring), predictive validity (i.e., predicts relapse/recurrence in MDD; Michalak, Heidenreich, Meibert, \& Schulte, 2008), known-groups validity (i.e., discriminates between general public and Zen Buddhist practitioners; Brown \& Ryan, 2003), and incremental validity in predicting anhedonic depressive symptoms and wellbeing (Brown \& Ryan, 2003; Zvolensky et al., 2006). Further, mindfulness scores on the MAAS have been found to relate to brain activity; specifically, higher MAAS scores are associated with enhanced prefrontal cortical regulation of affect through labeling of negative affective stimuli (Creswell, Way, Eisenberger, \& Lieberman, 2007). The MAAS exhibited excellent internal consistency in the current study (Table 7). 
Mindfulness in Parenting Questionnaire (MIPQ). The MIPQ administered during Phase 3 included 61 items. It required parents to respond using a 5-point likert scale (Never to Almost Always) to describe whether each item is true for them over the past two weeks (see Appendix B).

\section{Statistical Analyses}

Although several authors provide guidelines for measure development according to IRT procedures (e.g., Linacre, 2013), measure development is an idiographic datadriven process and no specific analytic plan is appropriate for all measures. However, there are several key components of an IRT instrument development project, and each of these components is discussed below.

\section{Table 7}

Reliability Estimates of Study Measures

\begin{tabular}{lccc}
\hline & Cronbach's Alpha & Mean & SD \\
\hline PAQR: Authoritarian & .776 & 2.745 & .539 \\
PAQR: Authoritative & .732 & 1.972 & .228 \\
PAQR: Permissive & .742 & 3.511 & .378 \\
PS: Overreactivity & .730 & 5.157 & .771 \\
PS: Laxness & .818 & 5.429 & .404 \\
MAAS & .917 & 4.680 & .361 \\
\hline
\end{tabular}

Note. These data were obtained using raw scores, not reverse-coded scoring

Rating scale performance can be assessed by examining Rasch-Andrich thresholds, which indicate the extent to which the response options are discriminating individuals in an expected way (e.g., 5-point ordered category responses; $1=$ Never, $2=$ Rarely, 3=Sometimes, $4=$ Often, $5=$ Almost Always). These categories are ordered such that endorsement of higher values should be indicative of higher levels of the underlying trait being measured. Disordered threshold estimates suggest that the response categories 
are not ordered in a way that reflects increasing levels of the latent trait. They could also represent confusion. In addition to examining thresholds, WINSTEPS provides graphical representations of probability curves for each item. These probability curves can be visually inspected to assess the usefulness of the response categories across each item. Additionally, the frequency in which each response option is endorsed should also be examined in WINSTEPS. If no or very few participants endorse "never," then this response option is not useful (i.e., this item is too "easy" and it does not assist in discriminating between persons). Adjustment of the response options, such as collapsing categories, may be considered under certain circumstances (e.g., disordered thresholds, lack of endorsement) in order to improve consistent discrimination of individuals along the measure.

When constructing a Rasch model with polytomous data (e.g., likert-type rating scale), the measure developer has a choice of parameterization between different rating scale models. For example, a Partial Credit Model (PCM; Masters, 1982) and a Rasch Rating Scale Model (RSM; Andrich, 1978) can be employed to examine the psychometric properties of the MIPQ. The PCM is expressed as

$$
\operatorname{Pr}\left\{X_{i j}=x\right\}=\frac{e^{\sum_{k=0}^{x}\left(\theta_{j}-\tau_{k i}\right)}}{\sum_{x=0}^{m} e^{\sum_{k=0}^{x}\left(\theta_{j}-\tau_{k i}\right)}}
$$

where $\theta_{j}$ is a person's $(j)$ ability level, $\beta_{i}$ is the difficulty level of an item $(i)$, and $\tau_{k i}$ is the threshold $(k)$ of the rating scale of item $(i)$. Importantly, the RSM varies from the PCM because the RSM restricts thresholds across items to be equal, specifying that the items all share the same rating scale structure. That is, the RSM is a more parsimonious model (Wright, 1998). This model is expressed as 


$$
\operatorname{Pr}\left\{X_{i j}=x\right\}=\frac{e^{\sum_{k=0}^{x}\left[\theta_{j}-\left(\beta_{i}-\tau_{k}\right)\right]}}{\sum_{x=0}^{m} e^{\sum_{k=0}^{x}\left[\theta_{j}-\left(\beta_{i}-\tau_{k}\right)\right]}}
$$

where $\theta_{j}$ is a person's $(j)$ ability level, $\beta_{i}$ is the difficulty level of an item $(i)$, and $\tau_{k}$ is the threshold $(k)$, which is common to all items. These models were employed using specialized software for Rasch models, WINSTEPS version 3.74.0.

Item fit is assessed by examining item outfit and infit statistics in WINSTEPS. Item infit is an "inlier-pattern-sensitive fit-statistic" (Bond \& Fox, 2007; Linacre, 2013). Specifically, it is the "square of the model standard deviation of the observation about its Rasch expected value" (Bond \& Fox, 2007, p. 238). That is, the higher the infit value, the greater the difference between an items' expected and observed performance. Because residuals are weighted by their individual variance, performances of persons closer to the item value more strongly influence the infit statistic. Item outfit is an "outlier-sensitive fit statistic" (Linacre, 2013). It is the unweighted average of standardized residual variance across persons and items; consequently it is sensitive to unexpected responses far from a person's or item's measure (e.g., a person answers an item correctly with difficulty that is much higher than the individual's ability level). According to Linacre (2013), high outfit may be the result of a few random responses by low performers. The expected value of mean-square infit and outfit is 1.0. Chi-square fit statistics greater than 1.33 may suggest nonconformity and may be considered for removal.

Dimensionality can be evaluated by performing an unrotated PCA on probability scale residuals obtained from the model. Specifically, if the percent of the variance explained by the first contrast is greater than $15 \%$ or the residual variance of the $1^{\text {st }}$ contrast is larger than 2.0, the measure is likely multidimensional (Linacre, 2013). Said 
differently, a significant amount of residual variance clustering together suggests the presence of a second factor.

The person-to-item map provides information regarding bandwidth and hierarchy of the items. Specifically, items that are deemed to require higher person ability level to endorse should reflect this difficulty level on the person-to-item map. Further, the personto-item map can provide visual support for the precision of the measure to detect differences between persons of similar ability across individuals at higher, moderate, and low levels of the construct.

An item's discrimination is the item's ability to differentiate persons of high and low ability levels as expected given its difficulty. The ideal discrimination value is 1 . Discrimination values below 1 indicates that the item discriminates between high and low performers less than expected, while a value higher than 1 means that the item discriminates more than expected. However, high item discrimination can indicate item dependence and may be problematic. In traditional CTT, internal consistency, or Cronbach's alpha is used to evaluate reliability. The greater the correlation among items, the greater the test's reliability. However, this emphasis on achieving high internal consistency can lead to an attenuation paradox. Take, for instance, a test that contains 10 identical items. Although this measure would have a reliability of 1.0, each item would not provide meaningful information independent from the others. Further, validity would be reduced (i.e., the attenuation paradox; Andrich, 1985). During Rasch model analysis, this issue is taken into account by evaluating item difficulty and dependence. Specifically, it is assumed that items should vary in their ability to discriminate and in their difficulty. That is, while low discrimination may suggest multidimensionality, 
discrimination that is too high is viewed as an indicator of possible response dependence. Rasch modeling also includes measures of person separation and reliability, and item separation and reliability. Person separation and reliability that is below 2 and .8, respectively, suggest that the instrument is not sensitive enough to distinguish between high and low performers. Person reliability is most similar to Cronbach's alpha in CTT. However, Cronbach's alpha tends to overestimate reliability, which is computed assuming the data match assumptions (Linacre, 2013). Conversely, item separation is related to the item hierarchy or construct validity of the instrument. Item separation and reliability values that are below 3 and .9 , respectively, suggest that the sample is not large enough to confirm the item hierarchy, or locate the items on the latent variable.

In order to examine convergent and discriminant validity (hypotheses A-D), correlations between MIPQ factor scores (obtained from WINSTEPS) and other variables were examined in SPSS. 


\section{CHAPTER IV}

\section{Results}

The analyses presented here generally follow recommendations for measurement development from an IRT perspective (Linacre, 2013), but deviate somewhat from these guidelines as measure modification is a partially data-driven and iterative process. The multi-step approach presented here was primarily exploratory, and results should be considered preliminary, given the sample size $(n=203)$.

Descriptive statistics for the 61 MIPQ items are provided in Table 8. Less than $2 \%$ of the MIPQ items (218 out of 12,383) were missing, as parents were instructed to leave items blank if they chose not to answer (e.g., felt uncomfortable answering the item, felt it did not apply to them, etc.). Upon initial examination of the items, it was noted that negatively worded items (e.g., Did you become angry with your child and feel guilty afterwards) were not negatively correlated with positively worded items. Further, examination of dimensionality by running a PCM in WINSTEPS 3.74.0 revealed evidence for a multidimensional measure, where negatively worded and positively worded parenting items grouped together into factors. The first contrast, or first PCA component in the correlation matrix of the residuals, was 14.3 , and the unexplained variance in the first contrast was $23.5 \%$. That is, a significant amount of residual variance appeared to be clustering together, indicating the presence of a second factor composed of negatively worded items. Taken together, these results provide evidence that positively worded items (where endorsement of "almost always" suggests high levels of mindful parenting) and negatively worded items (where endorsement of "almost always" suggests 
Table 8

Descriptive Statistics for MIPQ Items

\begin{tabular}{|c|c|c|c|c|}
\hline MIPQ Item & Minimum & Maximum & $M$ & $S D$ \\
\hline 1. Did you carefully listen and tune into your child when you two were talking & 1 & 5 & 4.28 & .85 \\
\hline 2. Did you do other things while your child was talking to you & 1 & 5 & 2.82 & .84 \\
\hline $\begin{array}{l}\text { 3. Did you catch yourself thinking about something else when your child was } \\
\text { talking to you }\end{array}$ & 1 & 5 & 2.54 & .83 \\
\hline 4. Did you think "I don't have time to listen to my child's side of the story" & 1 & 5 & 1.63 & .86 \\
\hline $\begin{array}{l}\text { 5. Did you let your concerns about the future go when spending time with your } \\
\text { child }\end{array}$ & 1 & 5 & 3.12 & 1.23 \\
\hline 6. Did you watch your child and not let other obligations distract you & 1 & 5 & 3.70 & 1.07 \\
\hline 7. Did you start saying something to your child, but forgot what your point was & 1 & 5 & 2.05 & .87 \\
\hline 8. Did you become distracted from your main goals of parenting & 1 & 5 & 1.91 & .82 \\
\hline $\begin{array}{l}\text { 9. Did you actively bring your attention back to your child when you noticed } \\
\text { you had become distracted }\end{array}$ & 1 & 5 & 3.98 & 1.05 \\
\hline 10. Could you tell what your child was thinking, even when they didn't tell you & 1 & 5 & 3.83 & .90 \\
\hline 11. Could you tell how your child felt by looking at them & 1 & 5 & 4.24 & .88 \\
\hline 12. Did you recognize when your child was "up to something" by their behavior & 1 & 5 & 4.28 & .86 \\
\hline $\begin{array}{l}\text { 13. Did you accurately predict in advance how your child would react to a } \\
\text { situation }\end{array}$ & 1 & 5 & 3.97 & .90 \\
\hline 14. Did you notice the way your emotions affected your child & 1 & 5 & 4.08 & .94 \\
\hline 15. Did you feel that your child's mood changes were unpredictable & 1 & 5 & 2.51 & 1.06 \\
\hline 16. Did you feel “in-tune” with your child's feelings & 1 & 5 & 4.18 & .78 \\
\hline
\end{tabular}




\begin{tabular}{|c|c|c|c|c|}
\hline 17. Did you notice the way that your child responded to your behavior & 1 & 5 & 4.12 & .87 \\
\hline 18. Did you find yourself thinking, "I cannot figure my child out" & 1 & 5 & 1.97 & .96 \\
\hline 19. Did you understand your child's motives for their behavior & 1 & 5 & 3.87 & .85 \\
\hline 20. Did you understand why your child acted the way they did & 1 & 5 & 3.80 & .91 \\
\hline $\begin{array}{l}\text { 21. Did you believe that the way you were parenting was consistent with best } \\
\text { parenting practices }\end{array}$ & 1 & 5 & 3.83 & .86 \\
\hline 22. Did you have fun and act goofy with your child & 1 & 5 & 4.17 & .81 \\
\hline 23. Did you accept your child exactly how he/she is & 1 & 5 & 4.47 & .82 \\
\hline 24. Did you fail to live up to your own expectations as a parent & 1 & 5 & 2.25 & .99 \\
\hline 25. Did you wish you parented differently & 1 & 5 & 2.25 & .99 \\
\hline 26. Did you wish your child acted differently & 1 & 5 & 2.22 & .93 \\
\hline 27. Did you find yourself comparing your child's abilities to other children & 1 & 5 & 2.16 & 1.06 \\
\hline 28. Did you wish your child was more like another child & 1 & 5 & 1.49 & .80 \\
\hline 29. Did you find yourself thinking, "parenting can be challenging at times" & 1 & 5 & 3.26 & 1.02 \\
\hline 30. Did you feel confident in your ability to handle difficult parenting situations & 1 & 5 & 3.91 & .94 \\
\hline 31. Did you judge your child & 1 & 4 & 1.83 & .89 \\
\hline 32. Did you wish you weren't so critical of your child & 1 & 5 & 2.19 & 1.03 \\
\hline 33. Did others tell you that you were too critical of your child & 1 & 5 & 1.56 & .83 \\
\hline $\begin{array}{l}\text { 34. Did arguments escalate with your child and spin out of control before you } \\
\text { knew what had happened }\end{array}$ & 1 & 5 & 1.57 & .81 \\
\hline 35. Did you react too quickly or harshly to your child out of frustration & 1 & 5 & 2.05 & .87 \\
\hline 36. Did your patience run out with your child & 1 & 5 & 2.21 & .93 \\
\hline 37. Did you consider your feelings before disciplining your child & 1 & 5 & 3.01 & 1.12 \\
\hline 38. Did you consider your child's feelings before disciplining your child & 1 & 5 & 3.63 & .97 \\
\hline
\end{tabular}




\begin{tabular}{|c|c|c|c|c|}
\hline 39. Did you notice when your child's behavior was making you upset & 1 & 5 & 3.69 & .99 \\
\hline 40. Were you able to calm yourself down when your child was making you upset & 1 & 5 & 4.00 & .91 \\
\hline 41. Were you surprised at the way you reacted to your child & 1 & 5 & 2.32 & .94 \\
\hline 42. Were you yelling at your child before you knew it & 1 & 5 & 2.26 & .93 \\
\hline 43. Did you notice your thoughts about your child's behavior before reacting & 1 & 5 & 3.46 & .97 \\
\hline 44. Did you watch your child doing something without reacting to him/her & 1 & 5 & 2.98 & .87 \\
\hline $\begin{array}{l}\text { 45. Did you let your child know when they were doing something that bothered } \\
\text { you }\end{array}$ & 1 & 5 & 4.04 & .86 \\
\hline $\begin{array}{l}\text { 46. Did you immediately have to tell someone when something was bothering } \\
\text { you about your child }\end{array}$ & 1 & 5 & 2.26 & 1.06 \\
\hline $\begin{array}{l}\text { 47. Did you find yourself becoming emotional while thinking about your child's } \\
\text { misbehavior }\end{array}$ & 1 & 5 & 2.22 & 1.14 \\
\hline 48. Did you feel guilty or upset when punishing your child & 1 & 5 & 2.60 & 1.08 \\
\hline $\begin{array}{l}\text { 49. Did you find yourself saying things to your child that you didn't mean } \\
\text { because you were upset }\end{array}$ & 1 & 5 & 2.04 & .95 \\
\hline 50. Did you take a moment to think before punishing your child & 1 & 5 & 3.67 & .97 \\
\hline $\begin{array}{l}\text { 51. Did you choose to do what was best for your child long-term, even when } \\
\text { something different would have been easier }\end{array}$ & 1 & 5 & 3.97 & .88 \\
\hline 52. Did you ask your child's opinion & 1 & 5 & 3.62 & 1.02 \\
\hline 53. Did you take time to think about your parenting & 1 & 5 & 3.85 & .98 \\
\hline $\begin{array}{l}\text { 54. Did you consider multiple reasons for why your child behaved the way } \\
\text { he/she did }\end{array}$ & 1 & 5 & 3.57 & 1.01 \\
\hline 55. Did you become angry with your child and feel guilty afterwards & 1 & 5 & 2.49 & .96 \\
\hline 56. Did you have trouble filtering what you said to your child & 1 & 5 & 2.06 & .97 \\
\hline 57. Were you aware of the skills you need to practice to be a better parent & 1 & 5 & 3.62 & 1.04 \\
\hline
\end{tabular}




\begin{tabular}{lllll}
\hline $\begin{array}{l}\text { 58. Did you try to slow down your reactions in order to accomplish your goals as } \\
\text { a parent }\end{array}$ & 1 & 5 & 3.56 & .96 \\
\hline 59. Did you let your child know why they were being punished & 1 & 5 & 4.50 & .83 \\
\hline 60. Did you find yourself trying to solve your child's problems for them & 1 & 5 & 3.02 & 1.00 \\
\hline 61. Did you let your child know when they were wrong and you were right & 1 & 5 & 3.66 & 1.19 \\
\hline
\end{tabular}


"mindless" parenting) may be two separate constructs, and are not necessarily extremes on either end of the continuum. Stated differently, lack of mindful parenting is not necessarily "mindless" parenting, and vice versa. This concept is well-supported in other areas of psychology; for example, happiness is not the absence of depression (e.g., Joseph, Linley, Harwood, Lewis, \& McCollam, 2004). Taken together, “mindless" parenting items appeared to be distorting the results and data supported the removal of "mindless" parenting items from further analysis. After removing the 28 negatively worded items, 33 items were retained.

\section{Refinement of the Rating Scale}

Examination of response categories. Rating scale performance was evaluated by running a Partial Credit Model (PCM) in WINSTEPS. Examination of thresholds revealed low frequency of endorsement of category 1 ("never") and 2 ("sometimes"), as well as disordered averages for categories 1 and 2 . That is, parents appeared to be having a difficult time differentiating between response options 1 and 2, and that the difference between these categories is not meaningful. Further, endorsing "rarely" did not require a substantially higher level of mindful parenting to endorse than "never." Consequently, categories 1 and 2 were collapsed to create a new response category of "infrequently." A PCM with the new response categories (i.e., "infrequently, sometimes, often, almost always") revealed an improvement in rating scale fit (see Table 9). However, five items (i.e., 1, 9, 37, 59, and 61) continued to evidence disordered thresholds between categories 1 and 2. Examination of item fit for these items suggested appropriate infit and outfit (less than 1.33), with the exception of item 61. This item evidenced infit and outfit values of 1.68 and 2.06, respectively. Due to disordered thresholds and poor item fit, item 61 
Table 9

Summary of Rating Scale Performance

\begin{tabular}{|c|c|c|c|}
\hline Item & Response Categories & Observed Count & Observed Average \\
\hline \multirow{4}{*}{ MIPQ 1} & 1 & 6 & .11 \\
\hline & 2 & 22 & $-.36^{*}$ \\
\hline & 3 & 79 & .46 \\
\hline & 4 & 94 & 1.04 \\
\hline \multirow{4}{*}{ MIPQ 5} & 1 & 57 & .38 \\
\hline & 2 & 61 & .38 \\
\hline & 3 & 53 & .82 \\
\hline & 4 & 29 & 1.24 \\
\hline \multirow{4}{*}{ MIPQ 6} & 1 & 24 & -.05 \\
\hline & 2 & 49 & .27 \\
\hline & 3 & 78 & .65 \\
\hline & 4 & 47 & 1.21 \\
\hline \multirow{4}{*}{ MIPQ 9} & 1 & 16 & .34 \\
\hline & 2 & 32 & $-.07 *$ \\
\hline & 3 & 80 & .45 \\
\hline & 4 & 71 & 1.20 \\
\hline \multirow{4}{*}{ MIPQ 10} & 1 & 12 & -.13 \\
\hline & 2 & 52 & .24 \\
\hline & 3 & 87 & .70 \\
\hline & 4 & 46 & 1.25 \\
\hline \multirow{4}{*}{ MIPQ 11} & 1 & 8 & -.65 \\
\hline & 2 & 20 & .07 \\
\hline & 3 & 83 & .37 \\
\hline & 4 & 90 & 1.11 \\
\hline \multirow{4}{*}{ MIPQ 12} & 1 & 7 & -.73 \\
\hline & 2 & 23 & -.06 \\
\hline & 3 & 75 & .40 \\
\hline & 4 & 96 & 1.07 \\
\hline \multirow{4}{*}{ MIPQ 13} & 1 & 9 & -.20 \\
\hline & 2 & 44 & -.09 \\
\hline & 3 & 85 & .57 \\
\hline & 4 & 61 & 1.34 \\
\hline \multirow{4}{*}{ MIPQ 14} & 1 & 11 & -.12 \\
\hline & 2 & 33 & .05 \\
\hline & 3 & 81 & .41 \\
\hline & 4 & 77 & 1.22 \\
\hline \multirow{4}{*}{ MIPQ 16} & 1 & 3 & -.73 \\
\hline & 2 & 30 & -.21 \\
\hline & 3 & 93 & .44 \\
\hline & 4 & 73 & 1.27 \\
\hline
\end{tabular}




\begin{tabular}{|c|c|c|c|}
\hline \multirow{4}{*}{ MIPQ 17} & 1 & 5 & -.16 \\
\hline & 2 & 41 & -.09 \\
\hline & 3 & 75 & .45 \\
\hline & 4 & 77 & 1.25 \\
\hline \multirow{4}{*}{ MIPQ 19} & 1 & 5 & .11 \\
\hline & 2 & 67 & .24 \\
\hline & 3 & 77 & .54 \\
\hline & 4 & 53 & 1.30 \\
\hline \multirow{4}{*}{ MIPQ 20} & 1 & 11 & -.78 \\
\hline & 2 & 60 & .23 \\
\hline & 3 & 84 & .63 \\
\hline & 4 & 47 & 1.47 \\
\hline \multirow{4}{*}{ MIPQ 21} & 1 & 12 & -.36 \\
\hline & 2 & 52 & .23 \\
\hline & 3 & 92 & .70 \\
\hline & 4 & 44 & 1.29 \\
\hline \multirow{4}{*}{ MIPQ 22} & 1 & 6 & -1.09 \\
\hline & 2 & 28 & .13 \\
\hline & 3 & 91 & .56 \\
\hline & 4 & 77 & 1.03 \\
\hline \multirow{4}{*}{ MIPQ 23} & 1 & 8 & -.92 \\
\hline & 2 & 16 & -.15 \\
\hline & 3 & 50 & .55 \\
\hline & 4 & 128 & .86 \\
\hline \multirow{4}{*}{ MIPQ 30} & 1 & 11 & -.20 \\
\hline & 2 & 47 & -.02 \\
\hline & 3 & 84 & .65 \\
\hline & 4 & 57 & 1.32 \\
\hline \multirow{4}{*}{ MIPQ 37} & 1 & 62 & .39 \\
\hline & 2 & 72 & $.35^{*}$ \\
\hline & 3 & 48 & .84 \\
\hline & 4 & 19 & 1.90 \\
\hline \multirow{4}{*}{ MIPQ 38} & 1 & 21 & -.14 \\
\hline & 2 & 67 & .25 \\
\hline & 3 & 73 & .74 \\
\hline & 4 & 40 & 1.51 \\
\hline \multirow{4}{*}{ MIPQ 39} & 1 & 19 & .09 \\
\hline & 2 & 59 & .38 \\
\hline & 3 & 79 & .54 \\
\hline & 4 & 42 & 1.42 \\
\hline \multirow{4}{*}{ MIPQ 40} & 1 & 11 & -.43 \\
\hline & 2 & 38 & -.12 \\
\hline & 3 & 88 & .61 \\
\hline & 4 & 65 & 1.28 \\
\hline
\end{tabular}




\begin{tabular}{|c|c|c|c|}
\hline \multirow{4}{*}{ MIPQ 43} & 1 & 22 & -.18 \\
\hline & 2 & 95 & .36 \\
\hline & 3 & 49 & .72 \\
\hline & 4 & 36 & 1.73 \\
\hline \multirow{4}{*}{ MIPQ 44} & 1 & 49 & .43 \\
\hline & 2 & 103 & .57 \\
\hline & 3 & 39 & .94 \\
\hline & 4 & 8 & 1.54 \\
\hline \multirow{4}{*}{ MIPQ 45} & 1 & 12 & -.42 \\
\hline & 2 & 31 & .29 \\
\hline & 3 & 92 & .53 \\
\hline & 4 & 65 & 1.11 \\
\hline \multirow{4}{*}{ MIPQ 50} & 1 & 21 & -.14 \\
\hline & 2 & 56 & .28 \\
\hline & 3 & 83 & .71 \\
\hline & 4 & 39 & 1.42 \\
\hline \multirow{4}{*}{ MIPQ 52} & 1 & 8 & -.69 \\
\hline & 2 & 47 & .20 \\
\hline & 3 & 80 & .58 \\
\hline & 4 & 59 & 1.24 \\
\hline \multirow{4}{*}{ MIPQ 53} & 1 & 17 & -.37 \\
\hline & 2 & 47 & .12 \\
\hline & 3 & 76 & .60 \\
\hline & 4 & 55 & 1.39 \\
\hline \multirow{4}{*}{ MIPQ 54} & 1 & 25 & .09 \\
\hline & 2 & 61 & .17 \\
\hline & 3 & 77 & .78 \\
\hline & 4 & 34 & 1.42 \\
\hline \multirow{4}{*}{ MIPQ 57} & 1 & 24 & .05 \\
\hline & 2 & 62 & .46 \\
\hline & 3 & 67 & .60 \\
\hline & 4 & 43 & 1.15 \\
\hline \multirow{4}{*}{ MIPQ 58} & 1 & 22 & .22 \\
\hline & 2 & 73 & .33 \\
\hline & 3 & 69 & .69 \\
\hline & 4 & 34 & 1.42 \\
\hline \multirow{4}{*}{ MIPQ 59} & 1 & 7 & -.29 \\
\hline & 2 & 19 & $-.45^{*}$ \\
\hline & 3 & 39 & .18 \\
\hline & 4 & 133 & .96 \\
\hline \multirow{4}{*}{ MIPQ 61} & 1 & 36 & .52 \\
\hline & 2 & 50 & $.40 *$ \\
\hline & 3 & 49 & .49 \\
\hline & 4 & 64 & .96 \\
\hline
\end{tabular}

Note. * Indicates disordered averages. 
(i.e., "Did you let your child know when they were wrong and you were right") was removed.

Comparison of model fit. After removing item 61, the new 32 item MIPQ with four response categories was evaluated through a PCM in WINSTEPS. Given that some of the items' thresholds appeared similar across items, the fit of a Rating Scale Model (RSM) was then conducted by restricting thresholds to be equivalent. The RSM is a more parsimonious model than the PCM, which allows thresholds to vary across items. A chisquare difference test was employed to examine the fit between the two models. The loglikelihood chi-square from the PCM model was 13206.38 with 6083 degrees of freedom, and the chi-square from the RSM model was 13363.25 with 6145 degree of freedom. Results indicated that the PCM fit significantly better than the RSM model ( $p<.001)$, and this model was used for further analysis.

\section{Examination of Item and Person Fit}

Next, item fit and person fit were examined in WINSTEPS 3.74.0. Examination of item fit revealed 2 items (items 5 and 44) with both an infit and outfit value above 1.33, suggesting they were degrading the measurement model (Linacre, 2013). As measurement refinement is an iterative process, item 5 (infit MNSQ $=1.42$, outfit MNSQ $=1.50 ;$ Did you let your concerns about the future go when spending time with your child) was removed first. Reexamination of item fit statistics supported the removal of item 44 (infit MNSQ = 1.42, outfit MNSQ = 1.39; Did you let your child know when they were doing something that bothered you). After deleting items 5 and 44, item 57 emerged as a poorly fitting item (infit MNSQ $=1.34$, outfit $\mathrm{MNSQ}=1.48$; Were you aware of the skills that you needed to practice to be a better parent) and was subsequently removed. 
The remaining 29 items revealed acceptable infit and outfit statistics (i.e., they did not evidence both infit and outfit statistics above the 1.33 cutoff), and were retained for further analyses (see Table 10).

Examination of person fit revealed $13(6.4 \%)$ persons with an infit or output value above 2.00 , and $49(24.1 \%)$ of the sample to have an infit or outfit statistic above 1.33 . However, given the preliminary nature of the current investigation with a limited sample size ( $n=203)$, persons were not eliminated based on fit statistics.

\section{Examination of Dimensionality}

Unexplained variance in the first contrast (3.1 and 10.7\%) suggested multidimensionality. Preliminary analysis of the contrast plot suggested that 13 items (i.e., items 50, 38, 51, 37, 58, 54, 53, 39, 59, 52, 40, 21 and 43) loaded onto the first factor, while 11 items (i.e., items 13, 11, 12, 16, 17, 10, 14, 19, 9, 20, and 22) loaded onto a second factor (see Figure 1 and Table 11).

Examination of item content was used to determine factor labels, or the latent factor which the items reflect (see Table 11). The primary investigator arrived at factor labels by consulting with consulting with dissertation committee members who are familiar with the construct of mindfulness in clinical and research contexts. Items comprising the first factor were parent-focused, and content reflected nonreactivity in parenting, parenting awareness, and goal-focused parenting. Overall, this factor appeared to represent parental self-efficacy. Conversely, factor 2 appeared to represent a childfocused facet of mindful parenting, which included present-centered attention, empathic understanding of the child, and acceptance. This factor was titled Being in the Moment with the Child. 
Table 10

Item Infit and Outfit

\begin{tabular}{|c|c|c|}
\hline Item & Infit MNSQ & Outfit MNSQ \\
\hline MIPQ 37 & 1.29 & 1.38 \\
\hline MIPQ 58 & 1.27 & 1.32 \\
\hline MIPQ 39 & 1.22 & 1.21 \\
\hline MIPQ 6 & 1.17 & 1.3 \\
\hline MIPQ 9 & 1.17 & 1.3 \\
\hline MIPQ 45 & 1.11 & 1.2 \\
\hline MIPQ 52 & 1.11 & 1.19 \\
\hline MIPQ 10 & 1.09 & 1.08 \\
\hline MIPQ 54 & 1.08 & 1.08 \\
\hline MIPQ 50 & 1.07 & 1.1 \\
\hline MIPQ 19 & 1.06 & 1.16 \\
\hline MIPQ 21 & 1.02 & 1.02 \\
\hline MIPQ 14 & 1.02 & 0.95 \\
\hline MIPQ 22 & 0.99 & 1.06 \\
\hline MIPQ 1 & 0.96 & 1.05 \\
\hline MIPQ 38 & 0.95 & 0.93 \\
\hline MIPQ 51 & 0.95 & 0.94 \\
\hline MIPQ 11 & 0.93 & 0.95 \\
\hline MIPQ 23 & 0.9 & 1.09 \\
\hline MIPQ 30 & 0.89 & 0.89 \\
\hline MIPQ 12 & 0.88 & 0.9 \\
\hline MIPQ 59 & 0.87 & 0.74 \\
\hline MIPQ 43 & 0.85 & 0.87 \\
\hline MIPQ 53 & 0.85 & 0.86 \\
\hline MIPQ 17 & 0.83 & 0.78 \\
\hline MIPQ 13 & 0.83 & 0.81 \\
\hline MIPQ 20 & 0.82 & 0.85 \\
\hline MIPQ 40 & 0.81 & 0.78 \\
\hline MIPQ 16 & 0.79 & 0.75 \\
\hline
\end{tabular}




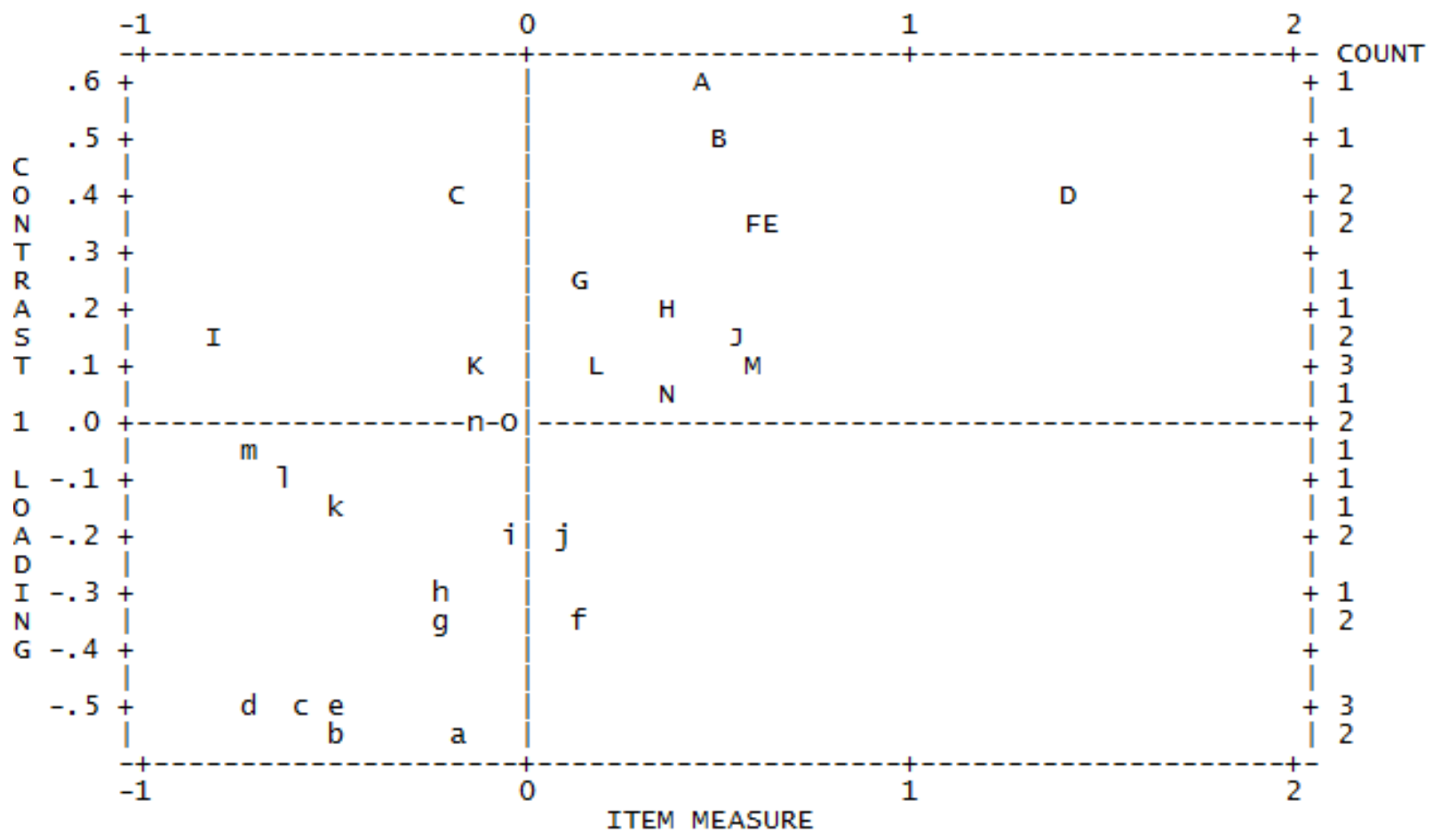

Figure 1. Standardized Residual Contrast Plot 
Table 11

Standardized Residual Loadings for Item

\begin{tabular}{|c|c|c|c|c|}
\hline Contrast & Loading & $\begin{array}{l}\text { Entry } \\
\text { Number }\end{array}$ & $\begin{array}{c}\text { Item } \\
\text { Number }\end{array}$ & Item Content \\
\hline 11 & .58 & $\mathrm{~A}$ & MIPQ50 & Did you take a moment to think before punishing your child \\
\hline 11 & .51 & $\mathrm{~B}$ & MIPQ38 & Did you consider your child's feelings before disciplining your child \\
\hline 11 & .40 & $\mathrm{C}$ & MIPQ51 & $\begin{array}{l}\text { Did you choose to do what was best for your child long-term, even when something } \\
\text { different would have been easier }\end{array}$ \\
\hline 11 & .40 & $\mathrm{D}$ & MIPQ37 & Did you consider your feelings before disciplining your child \\
\hline 11 & .36 & $\mathrm{E}$ & MIPQ58 & Did you try to slow down your reactions in order to accomplish your goals as a parent \\
\hline 11 & .34 & $\mathrm{~F}$ & MIPQ54 & Did you consider multiple reasons for why your child behaved the way he/she did \\
\hline 11 & .26 & $\mathrm{G}$ & MIPQ53 & Did you take time to think about your parenting \\
\hline 11 & .21 & $\mathrm{H}$ & MIPQ39 & Did you notice when your child's behavior was making you upset \\
\hline 11 & .16 & I & MIPQ59 & Did you let your child know why they were being punished \\
\hline 11 & .13 & $\mathbf{J}$ & MIPQ52 & Did you ask your child's opinion \\
\hline 11 & .11 & $\mathrm{~K}$ & MIPQ40 & Were you able to calm yourself down when your child was making you upset \\
\hline 11 & .10 & $\mathrm{~L}$ & MIPQ21 & $\begin{array}{l}\text { Did you believe that the way you were parenting was consistent with best parenting } \\
\text { practices }\end{array}$ \\
\hline 11 & .10 & M & MIPQ43 & Did you notice your thoughts about your child's behavior before reacting \\
\hline 11 & .07 & $\mathrm{~N}$ & MIPQ6 & Did you watch your child and not let other obligations distract you \\
\hline 11 & .02 & $\mathrm{O}$ & MIPQ30 & Did you feel confident in your ability to handle difficult parenting situations \\
\hline 12 & -.54 & a & MIPQ13 & Did you accurately predict in advance how your child would react to a situation \\
\hline 12 & -.53 & $\mathrm{~b}$ & MIPQ11 & Could you tell how your child felt by looking at them \\
\hline 12 & -.49 & $\mathrm{c}$ & MIPQ12 & Did you recognize when your child was "up to something" by their behavior \\
\hline 12 & -.49 & $\mathrm{~d}$ & MIPQ16 & Did you feel "in-tune" with your child's feelings \\
\hline
\end{tabular}




\begin{tabular}{llll}
\hline 12 & -.48 & $\mathrm{e}$ & MIPQ17 Did you notice the way that your child responded to your behavior \\
12 & -.37 & $\mathrm{f}$ & MIPQ10 Could you tell what your child was thinking, even when they didn't tell you \\
12 & -.33 & $\mathrm{~g}$ & MIPQ14 Did you notice the way your emotions affected your child \\
12 & -.32 & $\mathrm{~h}$ & MIPQ19 Did you understand your child's motives for their behavior \\
12 & -.20 & $\mathrm{I}$ & MIPQ9 Did you actively bring your attention back to your child when you noticed you had become \\
distracted
\end{tabular}


Several items, including items 6, 30, 1, 23, and 45, exhibited substantial crossloading. As item assignment is a data- and theory-driven process (Embretson \& Reise, 2000), theory was used to guide the decision as to which factor these items would load. Following item assignment, Factor 1 consisted of 15 items (i.e., items 21, 30, 37, 38, 39, 40, 43, 45, 50, 51, 52, 53, 54, 58, and 59), while Factor 2 consisted of 14 items (i.e., items $1,6,9,10,11,12,13,14,16,17,19,20,22$, and 23; see Table 12). Factor scores obtained through WINSTEPS revealed the two factors to be moderately correlated ( $r=$ $.674)$.

\section{Examination of Factor 1: Parental Self-Efficacy}

Factor 1 was further examined through a PCM in WINSTEPS. Each of the 15 parental self-efficacy items evidenced acceptable item fit (see Table 12). The factor appeared to be unidimensional (i.e., a standardized residual in the first contrast of 1.9 and $12.7 \%$ unexplained variance in the first contrast), and explained $42.3 \%$ of the variance. This model produced a person separation of 2.29 and a reliability of .84 . That is, this factor is sensitive enough to distinguish between persons who are both high and low in mindful parenting. Item separation (4.90) and reliability (.96) suggest that the sample was large enough to confirm the item hierarchy, supporting the factor's construct validity.

\section{Examination of Factor 2: Being in the Moment with the Child}

Factor 2 was then examined in WINSTEPS. Item 6 (Did you watch your child and not let other obligations distract you) exhibited an infit MNSQ of 1.38 and outfit MNSQ of 1.61, and was removed from the model. After this item was removed, none of the remaining items $(n=13)$ exhibited an infit and outfit above 1.33 (see Table 12). Further, 
Table 12

Item Fit by Factor and Discrimination

\begin{tabular}{|c|c|c|c|}
\hline Item & $\begin{array}{l}\text { Item } \\
\text { Infit }\end{array}$ & $\begin{array}{l}\text { Item } \\
\text { Outfit }\end{array}$ & $\begin{array}{c}\text { Item } \\
\text { Discrim. }\end{array}$ \\
\hline \multicolumn{4}{|l|}{ Factor 1: Parental Self-Efficacy } \\
\hline $\begin{array}{l}\text { 39. Did you notice when your child's behavior was making you } \\
\text { upset }\end{array}$ & 1.22 & 1.19 & .73 \\
\hline 37. Did you consider your feelings before disciplining your child & 1.20 & 1.20 & .71 \\
\hline $\begin{array}{l}\text { 45. Did you let your child know when they were doing something } \\
\text { that bothered you }\end{array}$ & 1.18 & 1.30 & .75 \\
\hline $\begin{array}{l}\text { 58. Did you try to slow down your reactions in order to } \\
\text { accomplish your goals as a parent }\end{array}$ & 1.18 & 1.21 & .74 \\
\hline 52. Did you ask your child's opinion & 1.11 & 1.21 & .79 \\
\hline $\begin{array}{l}\text { 21. Did you believe that the way you were parenting was } \\
\text { consistent with best parenting practices }\end{array}$ & 1.10 & 1.17 & .86 \\
\hline $\begin{array}{l}\text { 54. Did you consider multiple reasons for why your child behaved } \\
\text { the way he/she did }\end{array}$ & 1.02 & 1.02 & .98 \\
\hline $\begin{array}{l}\text { 30. Did you feel confident in your ability to handle difficult } \\
\text { parenting situations }\end{array}$ & .96 & .96 & 1.06 \\
\hline 50. Did you take a moment to think before punishing your child & .91 & .90 & 1.14 \\
\hline $\begin{array}{l}\text { 40. Were you able to calm yourself down when your child was } \\
\text { making you upset }\end{array}$ & .87 & .85 & 1.18 \\
\hline $\begin{array}{l}\text { 51. Did you choose to do what was best for your child long-term, } \\
\text { even when something different would have been easier }\end{array}$ & .87 & .95 & 1.17 \\
\hline $\begin{array}{l}\text { 43. Did you notice your thoughts about your child's behavior } \\
\text { before reacting }\end{array}$ & .86 & .87 & 1.17 \\
\hline 59. Did you let your child know why they were being punished & .85 & .67 & 1.14 \\
\hline $\begin{array}{l}\text { 38. Did you consider your child's feelings before disciplining } \\
\text { your child }\end{array}$ & .82 & .79 & 1.28 \\
\hline 53. Did you take time to think about your parenting & .81 & .81 & 1.29 \\
\hline \multicolumn{4}{|l|}{ Factor 2: Being in the Moment with the Child } \\
\hline $\begin{array}{l}\text { 9. Did you actively bring your attention back to your child when } \\
\text { you noticed you had become distracted }\end{array}$ & 1.22 & 1.70 & .73 \\
\hline 22. Did you have fun and act goofy with your child & 1.15 & 1.24 & .77 \\
\hline $\begin{array}{l}\text { 10. Could you tell what your child was thinking, even when they } \\
\text { didn't tell you }\end{array}$ & 1.14 & 1.16 & .81 \\
\hline 23. Did you accept your child exactly how he/she is & 1.12 & 1.59 & .82 \\
\hline
\end{tabular}




\begin{tabular}{|c|c|c|c|}
\hline $\begin{array}{l}\text { 1. Did you carefully listen and tune into your child when you two } \\
\text { were talking }\end{array}$ & 1.11 & 1.21 & .86 \\
\hline 19. Did you understand your child's motives for their behavior & 1.08 & 1.11 & .88 \\
\hline 14. Did you notice the way your emotions affected your child & 1.06 & 1.07 & .96 \\
\hline 20. Did you understand why your child acted the way they did & .89 & .89 & 1.14 \\
\hline $\begin{array}{l}\text { 12. Did you recognize when your child was "up to something" by } \\
\text { their behavior }\end{array}$ & .88 & .94 & 1.13 \\
\hline 11. Could you tell how your child felt by looking at them & .88 & .88 & 1.14 \\
\hline $\begin{array}{l}\text { 17. Did you notice the way that your child responded to your } \\
\text { behavior }\end{array}$ & .81 & .75 & 1.28 \\
\hline $\begin{array}{l}\text { 13. Did you accurately predict in advance how your child would } \\
\text { react to a situation }\end{array}$ & .78 & .77 & 1.29 \\
\hline 16. Did you feel "in-tune" with your child's feelings & .76 & .74 & 1.30 \\
\hline
\end{tabular}

Note. Discrim= Discrimination. 
this factor appeared to be unidimensional; unexplained variance in the first contrast was $14.7 \%$ and the $1^{\text {st }}$ contrast in the residual variance was less than $2(1.9)$. This factor explained $43.4 \%$ of the variance, and produced a person separation of 2.13 and a person reliability of .82 . These values suggest that this factor is sensitive enough to discriminate between parents who are both high and low in their mindful parenting. However, item separation (2.90) and item reliability (.89) were slightly below the standard "cut off" points, suggesting that the sample may not be large enough to confirm the item difficulty hierarchy. Consequently, the item hierarchy for this second factor should be interpreted with caution (see below).

\section{Item Hierarchy}

Based on information provided in the item hierarchies (see Figures 2 and 3), it appears that the items were generally sequential as expected. From factor 1, items 37 (Did you consider your feelings before disciplining your child) and 43 (Did you notice your thoughts about your child's behavior before reacting) required the highest levels of mindful parenting (i.e., parental self-efficacy) to endorse, while item 59 was easiest to endorse (Did you let your child know why they were being punished). From factor 2, items 10 (Could you tell what your child was thinking, even when they didn't tell you) and 20 (Did you understand why your child acted the way they did) required the highest levels of child-focused mindful parenting to endorse, while items 16 (Did you feel "intune" with your child's feelings) and 23 (Did you accept your child exactly how he/she is) were easiest to endorse. 


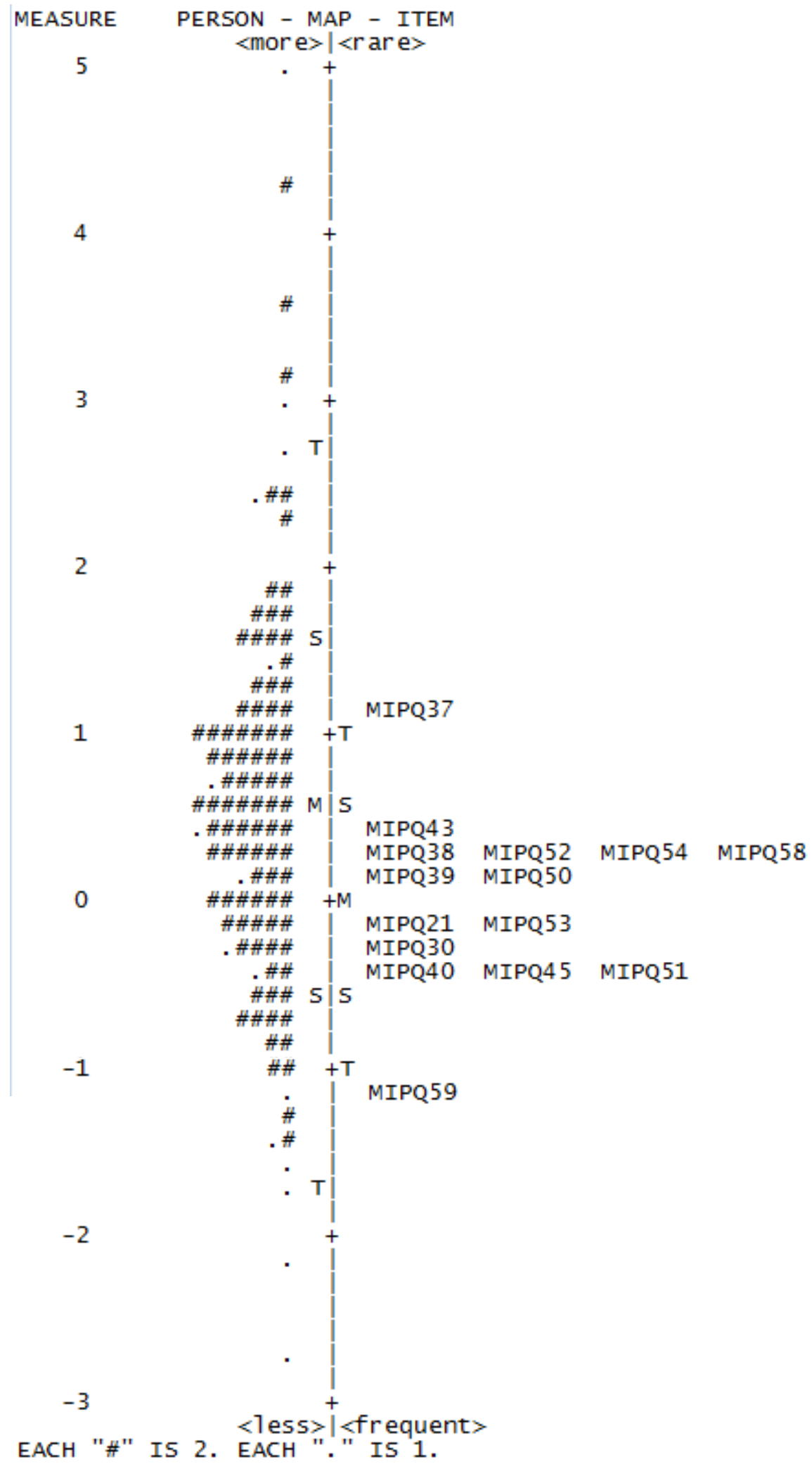

Figure 2. Person to Item Map for Factor 1. 


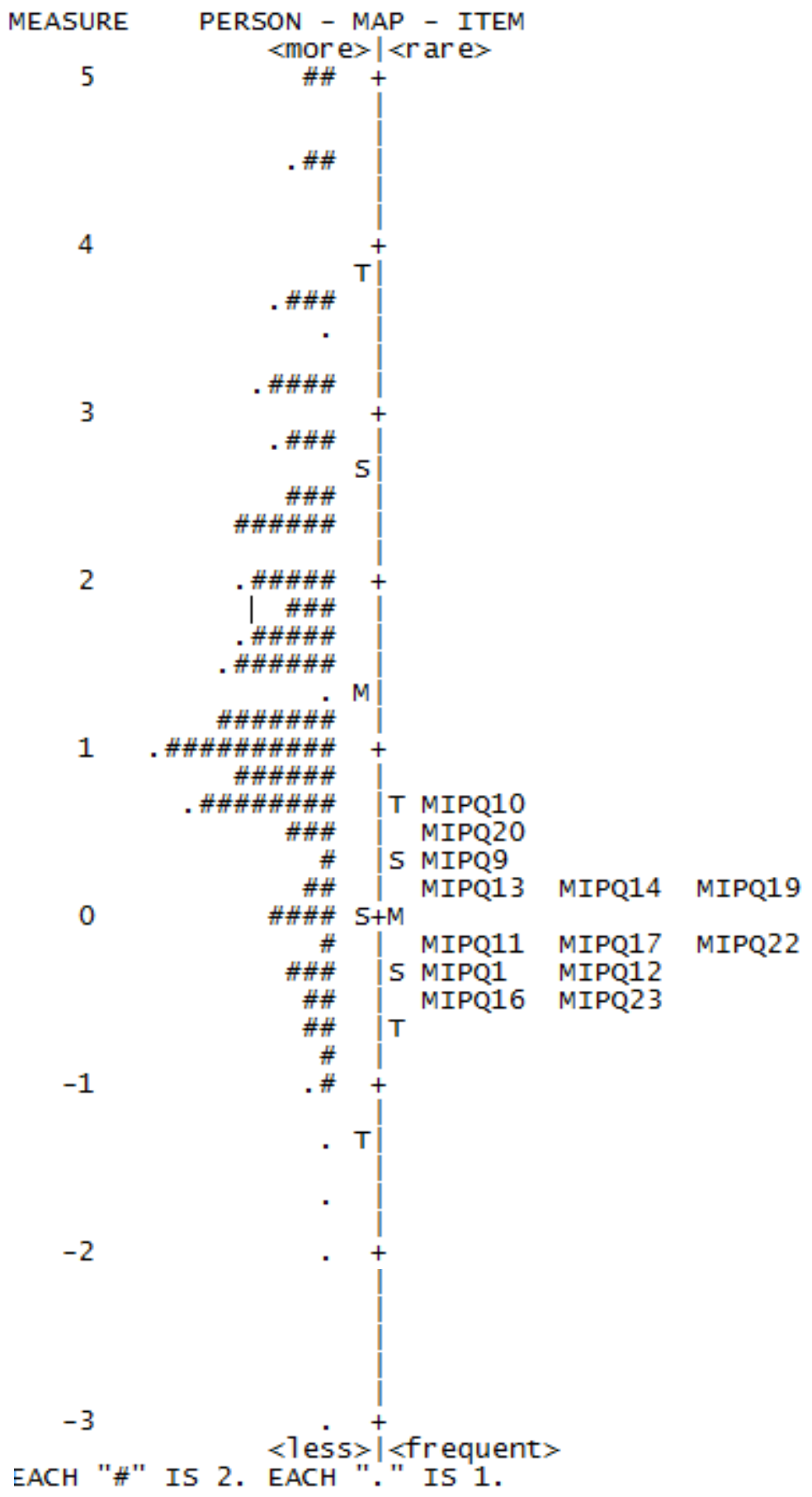

Figure 3. Person to Item Map for Factor 2. 


\section{Item Discrimination}

A discrimination of 1.0 suggests that the item is discriminating between high and low performers as expected given its difficulty. Item discrimination for factor 1 ranged from .71 to 1.29 , while item discrimination for factor 2 ranged from .73 to 1.30 . See Table 12 for information about item specific discrimination values. According to Uher et al., (2008), these items provide moderate levels of discrimination (i.e., they are between 0.65 and 1.34). Items with the highest levels of discrimination include $38,53,13,16$, and 17.

\section{Convergent and Discriminant Validity}

Validity was examined by examining Pearson Correlations between the two MIPQ factors and other psychological and demographic variables. Factor scores for the MIPQ items were obtained through WINSTEPS. Regarding convergent validity, it was hypothesized that both MIPQ factors would be distinct but positively related (a moderate positive correlation) to interpersonal mindfulness as measured by the MAAS, as well as meditation experience. This hypothesis was generally supported (see Table 13). Results indicated that the MIPQ factors were positively related to the MAAS (Factor $1 r=.23, p$ $=.001$; Factor $2 r=.17, p=.014)$. According to Cohen (1988), these correlations represent a small to medium (.10 to .30) effect size. While Factor 2, Being in the Moment with the Child, was significantly related to endorsement of mindfulness practice $(F(1$, $198)=5.05, p=.026)$, Factor1, Parental Self-Efficacy, neared significance $(F(1,198)=$ $3.64, p=.058)$. Prayer was the most frequently reported $(n=54)$, with yoga $(n=30)$, meditation $(n=14)$, exercise $(n=10)$, reading $(n=3)$, and mindfulness $(n=2)$ being 
reported less frequently. Thirteen percent of parents reported engaging in more than one of these activities.

To further establish convergent validity, it was also expected that the MIPQ factors would be positively related to an authoritative parenting style, as measured by the PAQ-R, and negatively related to authoritarian and permissive parenting styles.

Additionally, the MIPQ factors were predicted to be negatively related to both laxness and overreactivity in parents' discipline practices, as measured by the PS. This hypothesis was also largely supported. MIPQ factors were significantly positively related to an authoritative parenting style (Factor $1 r=.37, p<.001$; Factor $2 r=.40, p<.001$ ), and were negatively related to permissive parenting style (Factor $1 r=-.19, p=.009$; Factor 2 $r=-.21, p=.003)$. Results indicated a significant negative correlation between MIPQ Factor 1 and the PAQ-R's Authoritarian scale $(r=-.17, p=.016)$, and a negative, but nonsignificant relationship between MIPQ Factor 2 and authoritarian parenting style. Similarly, overreactivity, as measured by the PS, was also significantly negatively related to the two MIPQ factors (Factor $1 r=-.33, p<.001 ; r=-.23 p<.001$ ). Laxness was significantly negatively related to MIPQ factor $2(r=-.19, p=.010)$, although the relation between laxness and MIPQ factor 1 was not significant.

Next, discriminant validity of the MIPQ was evaluated. To establish discriminant validity, it was hypothesized that mindful parenting would not be related to socioeconomic status (employment status, educational attainment, and household income) or ethnicity. MIPQ factors were not related to employment status or educational attainment (Table 14). To examine the relation between income and mindful parenting, 
Table 13

Convergent Validity Evidence

\begin{tabular}{lcc}
\hline \multicolumn{1}{c}{ Measure } & $\underline{\text { Factor } 1}$ & $\underline{\underline{r(p)}}$ \\
\hline MAAS & $.24(.001)^{* *}$ & $.18(.010)^{*}$ \\
\hline PS: Overreactivity & $-.33(.000)^{* *}$ & $-.23(.001)^{* *}$ \\
\hline PS: Laxness & $-.09(.216)$ & $-.19(.010)^{*}$ \\
\hline PAQR: Authoritarian & $-.17(.016)^{*}$ & $-.09(.199)$ \\
\hline PAQR: Authoritative & $.37(.000)^{* *}$ & $.40(.000)^{* *}$ \\
\hline PAQR: Permissive & $-.19(.009)^{* *}$ & $-.21(.003)^{* *}$ \\
\hline
\end{tabular}

$* p<.05,{ }^{* *} p<.01$.

income was recoded from five $(<\$ 30,000,30,000-50,000,50,000-70,000,70,000-$

$100,000,>100,000)$ into three income groups $(<\$ 30,000,30-100,000,>100,000)$. This

recoding was conducted in order to correct an assumption of the ANOVA model, homogeneity of variance (Levene statistic $(4,195)=2.440, p=.048)$. Levene's test suggested that the variances across the three income levels were not significantly different for either Factor 1 (Levene Statistic $(2,197)=1.732, p=.180)$ or Factor 2 $($ Levene Statistic $(2,197)=2.062, p=.130)$. Results did not suggest differences in MIPQ's Factor 1, Parental Self-Efficacy, across parents of different income levels. However, an ANOVA yielded a significant difference in Being in the Moment with the Child (MIPQ Factor 2) across parents with different household incomes $(F(2,197)=6.69$, $p=.002)$. Post-hoc analyses indicated that parents who reported a household income of less than $\$ 30,000$ were significantly less mindful within the parent-child relationship than parents who made $\$ 30,000$ to $\$ 100,000(p=.001)$. There was not a significant difference between parents who made less than $\$ 30,000$ and parents who made more than $\$ 100,000$, or between parents who made between $\$ 30,000$ and $\$ 100,000$ and those who made more than $\$ 100,000$. 
Next, differences in mindful parenting were examined across Black/African American $(n=76)$, Caucasian $(n=68)$, and Hispanic $(n=42)$ parents. Caribbean Islander $(n=5)$, Asian $(n=4)$, multiracial $(n=6)$, and "other" $(n=2)$ were selected out during these analyses. ANOVA results suggested significant differences in MIPQ factors across parents' race/ethnicity $($ Factor $1 F(2,183)=7.75, p=.001$; Factor $2 F(2,183)=11.17, p$ $<.001$ ), such that Black/African American parents (Factor $1 M=.17, S D=1.07$, Factor 2 $M=.86, S D=1.43$ ) reported significantly lower MIPQ scores than White/Caucasian (Factor $1 M=.66, S D=1.06, p=.022$; Factor $2 M=1.55, S D=1.15, p=.008$ ) and Hispanic (Factor $1 M=.94, S D=1.04, p=.001$; Factor $2 M=2.04, S D=1.50 ; p<.001$ ) parents.

Table 14

Discriminant Validity of the MIPQ

\begin{tabular}{lcc}
\hline & $\frac{\text { Factor } 1}{\underline{F(p)}}$ & $\frac{\underline{\text { Factor } 2}}{\underline{F(p)}}$ \\
\hline Demographic Characteristic & $0.09(.868)$ & $0.06(.802)$ \\
Education & $1.70(.135)$ & $1.35(.244)$ \\
Income & $3.04(.050)$ & $6.69(.002)^{* *}$ \\
Sex & $0.04(.835)$ & $0.48(.488)$ \\
Race/Ethnicity & $7.75(.001)^{* *}$ & $11.17(<.001)^{* *}$ \\
\hline
\end{tabular}
$* p<.05, * * p<.01$.

There was not a significant relationship between mindful parenting and parental age (Factor $1 r=.11, p=.112$, Factor $2 r=-.00, p=.972$ ) or sex (Table 14). The final 28 -item MIPQ is presented in Appendix C. 


\section{CHAPTER V}

\section{Discussion}

The primary aim of the current study was to develop a measure of mindful parenting for mothers and fathers of both children and adolescents, ranging in age from 2- to 16-years-old. An Item Response Theory approach was adopted to guide measure development and psychometric evaluation, as it provides a more accurate and reliable approach to measure development (e.g., An \& Yung, 2014). Indeed, IRT approaches have become increasingly popular in the field of psychology over the past decade; over 2,000 published studies related to IRT can be found on PsychINFO from 2010 to 2015. The field of Education has been utilizing IRT approaches for decades to improve accuracy, reliability, and efficiency of testing, and all major educational tests, such as the GRE, are developed from IRT and Rasch modeling approaches. Classical test theory approaches are limited in that they rely on the assumptions that true scores and error scores are uncorrelated, the average error score in the population of examinees is zero, and error scores on parallel tests are uncorrelated. Often, these assumptions do not hold true, resulting in tests with different psychometric properties across samples, including unstable factor structures. That is, the factor sizes and loadings are "rarely" reproduced across samples (Bond \& Fox, 2007, p. 252). Further, although a factor structure is typically considered "confirmed" once it is reproduced, the confirmation procedures do not provide fit statistics (Wright, 1996, as cited in Bond \& Fox, 2007). Conversely, in IRT, item and person parameters are sample independent, meaning that both the person characteristics are independent of test items and item parameters are independent of the set of examinees and their ability levels (Hambleton, Swaminathan, \& Rogers, 1991). 
IRT approaches also provide test information as opposed to a single reliability estimate, because a test may provide better information at particular trait levels than others (Crocker \& Algina, 2008). For these reasons, IRT modeling was employed. However, if the assumptions of classical test theory hold true, CTT and IRT approaches yield similar results. According to Lorber and colleagues (2014), CFA and IRT analyses may not arrive at the same set of items for various reasons; for example, an item that discriminates differentially at various ability levels may be dropped in CFA because it does not exhibit a strong loading.

While a comparison of CTT and IRT approaches was not a central focus of this study, data were subject to a factor analysis and results are presented in Appendix D. A Principal Components Analysis (PCA) of the 33 MIPQ positively worded items using a Promax rotation and suppressing coefficients below .30, reveals 9 eigenvalues above 1.0 (see Appendix D). The first factor exhibited an eigenvalue of 9.49 and explained $28.77 \%$ of the variance. Three more components explained more than $5 \%$ of additional variance. Based on these statistics, without exploration of item content, results may suggest a four factor solution. Cronbach's alpha of the 33 positively worded MIPQ items was strong (.908).

\section{The Structure of Mindful Parenting}

As part of the measure development process, an important goal of the present study was to explore the structure of mindful parenting empirically using IRT. Duncan originally hypothesized a three factor structure, although results from her dissertation suggested a 4 factor model (2007). In 2009, she theorized that mindful parenting was comprised of 5 dimensions (Duncan et al., 2009), while factor analysis of the Dutch IM-P 
in 2012 revealed a 6 factor structure (de Bruin et al., 2012). These two empirical studies utilized different samples; Duncan originally developed the IEM-P for use with parents of at-risk adolescents (10-14 years), while the Dutch IM-P was validated with a general population sample of Dutch mothers of adolescents (12-15 years) and mothers of adolescents with diabetes mellitus. Unfortunately, both of these studies relied on CTT approaches, which are sample-dependent. Consequently, differences between these two studies may suggest actual differences in mindful parenting across populations, or reflect error associated with the measures (e.g., content coverage of the item, non-interval level data, differences in item severity or difficulty across measures, correlated error between items, etc.) or people (e.g., sampling parents who were low or high on mindfulness, acquiescent responding, parents' lack of understanding of item content, response rating scale, or directions, etc.).

Results from the current study using IRT approaches revealed a two factor measure of mindful parenting. Specifically, Items comprising the first factor, termed Parental Self-Efficacy, were parent-focused, and item content reflected nonreactivity in parenting (e.g., did you consider your feelings before disciplining your child, did you try to slow down your reactions in order to accomplish your goals as a parent, did you notice when your child's behavior was making you upset, did you take a moment to think before punishing your child), parenting awareness (e.g., did you take time to think about your parenting), and goal-focused parenting (e.g., did you believe the way you were parenting was consistent with best parenting practices, did you choose to do what was best for your child long-term, even when something different would have been easier). Conversely, the second factor, Being in the Moment with the Child, represented a child-focused facet of 
mindful parenting, which included present-centered attention (e.g., did you carefully listen and tune into your child when you two were talking, did you actively bring your attention back to your child when you noticed you had become distracted), empathic understanding of the child (e.g., did you understand your child's motives for their behavior, could you tell what your child was thinking, even when they didn't tell you) and acceptance (e.g., did you accept your child exactly how he/she is, did you have fun and act goofy with your child). These dimensions are similar to mindful parenting factors suggested from other research. For example, de Bruin and colleagues' factor analyses of the Dutch IM-P revealed three dimensions that appear relatively similar in content to the first MIPQ parent-focused factor, Parenting Self-Efficacy. These factors include Emotional Awareness of the Self, Emotional Non-reactivity in Parenting, and Nonjudgmental Acceptance of Parental Functioning. The other three factors that were identified by de Bruin et al. (2012) were Compassion for the Child, Emotional Awareness of the Child, and Listening with Full Attention, which appear comparable to the MIPQ's child-focused factor, Being in the Moment with the Child. Although Duncan's theoretical model of mindful parenting is comprised of 5 dimensions which were not empirically supported by de Bruin and colleagues (2012), her dimensions include content which is very similar to content on the MIPQ. For example, Duncan identifies Listening with Full Attention and Self-Regulation in the Parenting Relationship as two dimensions of mindful parenting. These dimensions include parenting behaviors such as correctly discerning the child's behavioral cues, emotion regulation in the parenting context, and parenting in accordance with goals and values. This content is captured by MIPQ items, such as "Did you consider your feelings before disciplining your child," "Were you able 
to calm yourself down when your child was making you upset," "Did you believe that the way you were parenting was consistent with best parenting practices," "Did you recognize when your child was "up to something" by their behavior," "Did you accurately predict in advance how your child would react to a situation," and "Did you notice the way that your child responded to your behavior." Duncan also included dimensions related to nonjudgmental acceptance, emotional awareness, and compassion (i.e., Nonjudgmental Acceptance of Self and Child, Emotional Awareness of Self and Child, Compassion for Self and Child); however, she did not separate these facets across the parent and child, which appears to be empirically supported in both the current study and in de Bruin and colleagues' study.

Following the first two phases of MIPQ development, the original 83 and 61 item MIPQs created from phase 1 and phase 2 contained both positively and negatively worded items. However, these 28 items were removed from the MIPQ because they appeared to be distorting the measurement model. That is, the negatively worded items were not negatively correlated with positively worded items, and examination of dimensionality in WINSTEPS indicated that the negatively and positively worded items were grouping together into factors, suggesting correlated error. It is possible that "mindless" parenting is a separate construct from "mindful" parenting, as opposed to extremes on either end of a continuum. Additionally, the possibility that negatively worded items are inappropriate for measuring mindfulness is supported by previous research (van Dam et al., 2009; van Dam et al., 2010) For instance, negatively and positively worded items did not function similarly across meditators and nonmeditators, so that non-meditators were more likely than meditators to reject (i.e., rate lower on a 
Likert scale) negatively-worded items than accept (i.e., rate highly) positively-worded items. Said differently, negatively worded items regarding mindfulness may require a certain level of mindfulness in order to respond accurately, as it requires metacognitive awareness of awareness (Schooler, 2002). These results also call into question differential item function (DIF) of the IM-P, which includes both negatively and positively worded items.

Examination of the item hierarchy suggested that the addition of more "difficult" (i.e., more difficult to endorse because they require a high amount of mindful parenting ability) items to the second MIPQ factor, Being in the Moment with the Child, would improve its item-to-person targeting. Specifically, this would improve the MIPQ's ability to measure and differentiate parents who are high on mindful parenting.

\section{Construct Validity of the MIPQ}

Convergent validity. In addition to creating a measure of mindful parenting and exploring the structure of the mindful parenting construct, the construct validity of the MIPQ was examined. Specifically, it was hypothesized that mindful parenting would be distinct, but positively related to intrapersonal mindfulness. Indeed, results yielded a significant, yet modest correlation between the MAAS and the two MIPQ factors, Parental Self-Efficacy and Being in the Moment with the Child. Similarly, De Bruin and colleagues (2012) found that the Dutch IM-P total score was positively and significantly correlated with the Freiburg Mindfulness Inventory and the Five-Facet Mindfulness Questionnaire (FFMQ).

It was also hypothesized that parents' MIPQ scores would be positively related to self-report of current practice of mindfulness or meditation. Specifically, parents were 
asked "Do you practice mindfulness or meditation, or participate in a related activity? (e.g., prayer, yoga, tai-chi, etc.)." While Being in the Moment with the Child was significantly related to the endorsement of mindfulness practice, Parental-Self-Efficacy did not reach significance. It is possible that engaging in intrapersonal mindfulness or meditation exercises, such as prayer or yoga, does not increase parents' self-efficacy in the parenting role. The relation between self-report of mindfulness and engaging in mindfulness practice has been inconsistent in previous research. For example, Singh and colleagues (2006) found that mothers' self-report of mindfulness actually decreased following a mindful parenting intervention. Further, the ways in which engaging in intrapersonal mindfulness exercises, such as prayer or meditation, may be related to mindfulness within interpersonal relationships is unclear. It is possible that parents who are higher on mindful parenting seek out more mindfulness-related activities than parents who are less mindful. For example, a mother who is high on mindful parenting may recognize when her stress level is increasing and how it is impacting her reactivity in her relationship with her child, and seek out yoga or other mindfulness related activities in order to reduce her reactivity. Alternatively, engaging in intrapersonal mindfulness related activities may also increase parents' interpersonal mindfulness skills.

It should be noted that in the current study, parents were not asked about the frequency in which they were engaging in mindfulness-related activities, and no checks were made to determine if parents were "correctly" engaging in mindfulness or meditation exercises. That is, the relation between the "dose" of intrapersonal mindfulness-related activities that a parent received and their amount of mindful 
parenting is unknown. Future research is needed to elucidate the relationship between mindful parenting the practice of mindfulness-related activities.

It was also hypothesized that parents' MIPQ scores would be positively related to an authoritative parenting style, and negatively related to permissive and authoritarian parenting, as measured by the PAQ-R. As anticipated, Parental Self-Efficacy was negatively related to authoritarian and permissive parenting, and positively related to authoritative parenting. The second MIPQ factor, Being in the Moment with the Child, was also negatively related to permissive parenting and positively related to authoritative parenting. Although Being in the Moment with the Child was negatively related to Authoritarian parenting, this relationship was not significant. These findings are relatively consistent with previous research (Williams \& Wahler, 2010), which found negative correlations between mothers' intrapersonal mindfulness (MAAS) and Authoritarian parenting, and positive correlations with Authoritative parenting (PAQ-R). Williams and Wahler (2010) explain that when a mother notices how her style impacts her child's behavior, she will choose more authoritative interactions. Thus, "the authoritative mother, who enacts responsible dialogue, combined with appropriate control of her child's behavior, might already have developed periodic states of mindfulness" ( $p$. 231). However, authors found that the Permissive scale did not correlate with the other measures and demonstrated poor internal consistency.

Interestingly, examination of the MAAS and PAQ-R data collected during the current study did not yield the same results as Williams and Wahler (2010). Although MIPQ scores were positively related to Authoritative items and negatively related to Authoritarian items, MAAS scores were not related to Authoritarian or Authoritative 
parenting. However, MAAS scores were negatively related to Permissive parenting ( $r=$ $0.228, p=0.001)$. Overall, results from the current study suggest that intrapersonal mindfulness, at least as measured using the MAAS, is not related to parenting style, while mindful parenting is correlated with Authoritative parenting. These results highlight the importance of targeting mindfulness within the parent-child relationship during mindfulness-based behavioral parent training interventions, as opposed to providing parents' with intrapersonal mindfulness training.

The hypothesis that mindful parenting would be negatively related to both laxness and overreactive parenting practices was also largely supported. Parental Self-Efficacy from the MIPQ was negatively related to the PS Overreactivity scale. However, the negative correlation between Parental Self-Efficacy and the PS Laxness scale did not reach significance. The relationship between Being in the Moment with the Child was significantly and negatively related to both overreactive and lax parenting. The nonsignificant relation between Parental Self-Efficacy and lax parenting was unexpected, and is not supported in other research. For example, de Bruin found that the Dutch IM-P total score was negatively correlated with the PS total score, as well as Laxness, Overreactivity, and Verbosity scales. However, a different form of the PS was used in this study, and perhaps the 10-item short form used in the current study did not adequately capture lax parenting in this sample. A recent IRT evaluation of the PS (Lorber et al., 2014) found that the 10-item version of the PS was less reliable than the original 30-item version. Future research should re-examine the relation between parenting practices and mindful parenting using the 30 -item PS and MIPQ. 
Discriminant validity. To evaluate the MIPQ's discriminant validity, it was hypothesized that the MIPQ would not be significantly related to parent's socioeconomic status or race/ethnicity. MIPQ scores were not related to parents' employment status or educational attainment. However, MIPQ factors were significantly related to parents' household income. That is, parents who reported a household income less than $\$ 30,000$ had lower MIPQ Being in the Moment with the Child scores than parents who made $\$ 30,000$ to $\$ 100,000$. It is possible that parents with significant financial stressors have a more difficult time being mindful within the parent-child relationship than other parents. The current study is the first to examine mindful parenting in relation to socioeconomic status. Further research is needed to explore this finding.

Additionally, a significant difference in mindful parenting was found across parents of different races and ethnicities, such that Black/African American parents reported being significantly less mindful on both MIPQ factors than Caucasian and Hispanic parents. Given the relationship between mindful parenting and Authoritative parenting style elucidated by the current study, it is not surprising that Black/African American parents may be lower on mindful parenting. Further, the majority of Black/African American parents who participated in the current study reported a household income of less than $\$ 30,000$ (61\%), and $88 \%$ of Black/African American parents in the sample reported an income less than $\$ 50,000$. Consequently, the relationship between mindful parenting, income, and race/ethnicity is unclear. This problem is common in psychological research, where socioeconomic status and ethnicity/race are often confounded and difficult to disentangle (e.g., Hill, 2006). Importantly, previous research suggests that an Authoritarian parenting style in low SES 
Black/African American families is related to positive child outcomes (e.g., Spera, 2005). Consequently, further research should examine whether reporting lower levels of mindful parenting is necessarily problematic for parents of certain SES or ethnic/racial groups.

Although no apriori hypothesis regarding the relation between mindful parenting and parents' gender was made, results revealed a nonsignificant relation between MIPQ scores and gender. De Bruin and colleagues (2012) found that the Dutch IM-P was significantly related to parental age, and controlled for parent's age during one of their studies using partial correlations. However, authors did not hypothesize as to why this correlation occurred, and did not predict this finding apriori.

Overall, the MIPQ appears to be a promising measure of mindful parenting. However, one important limitation of the current study is that only 203 parents participated. Having more participants would have increased the power and robustness of statistical tests. With more parents, DIF analyses between mothers and fathers, as well as parents of different racial/ethnic groups could have been conducted. Despite this limitation, the MIPQ fills an important gap in the research. With the MIPQ, researchers will have the ability to study specific intervention components and their impact on parents' level of mindful parenting, ultimately aiding in intervention development. Further, the MIPQ can be used to investigate the relation between mindful parenting and various parenting styles and behaviors, parental psychopathology, etc., further elucidating the dynamic relationship between parental factors and child well-being. 


\section{References}

An, X. \& Yung, Y. (2014). Item Response Theory: What it is and how you can use the IRT procedure to apply it. Retrieved from http://support.sas.com/resources/papers/proceedings

Andrich, D. (1985). A latent trait model for items with response dependencies: Implications for test construction and analysis. In S. Embretson (Ed.), Test design: Contributions from psychology, education and psychometrics. Academic Press, New York

Arnold, D. S., O’Leary, S. G., Wolff, L. S., \& Acker, M. M. (1993). The Parenting Scale: A measure of dysfunctional parenting in discipline situations. Psychological Assessment, 5(2), 137-144.

Avery, L. M., Russell, D. J. Raina, P. S., Walter, S. D., \& Rosenbaum, P. L. (2003). Rasch analysis of the gross motor function measure: Validating the assumptions of the Rasch model to create an interval level measure. Archives of Physical Medicine and Rehabilitation, 84(5), 697-705. doi:10.1016/S0003-9993(03)048967

Baer, R. A. (2003). Mindfulness training as a clinical intervention: A conceptual and empirical review. Clinical Psychology: Science and Practice, 10(2), 125-143. doi:10.1093/clipsy.bpg015

Baer, R. A., Smith, G. T., Hopkins, J., Krietemeyer, J., \& Toney, L. (2006). Using selfreport assessment methods to explore facets of mindfulness. Assessment, 13(1), 27-45. doi:10.1177/1073191105283504 
Baer, R. A., Walsh, E., \& Lykins, E. L. (2009). Assessment of mindfulness. In F.

Didonna (Ed.). Clinical handbook of mindfulness (pp. 153-168). New York, NY: Springer.

Beer, M., Ward, L., \& Moar, K. (2013). The relationship between mindful parenting and distress in parents of children with an autism spectrum disorder. Mindfulness, 4(2), 102-112. doi: 10.1007/s12671-012-0192-4

Benn, R., Akiva, T., Arel, S., \& Roeser, R. W. (2012). Mindfulness training effects for parents and educators of children with special needs. Developmental Psychology, 48(5), 1476-1487. doi: 10.1037/a0027537

Bergomi, C., Tschacher, W., \& Kupper, Z. (2012). Measuring mindfulness: First steps towards the development of a comprehensive mindfulness scale. Mindfulness. doi: $10.1007 / \mathrm{s} 12671-012-0102-9$

Bishop, S. R., Lau, M., Shapiro, S., Carlson, L., Anderson, N. C., Carmody, J....Devins, G. (2004). Mindfulness: A proposed operational definition. Clinical Psychology: Science and Practice, 11(3), 230-241. doi:10.1093/clipsy/bph077

Blackledge, J. T., \& Hayes, S. C. (2006). Using acceptance and commitment training in the support of parents of children diagnosed with autism. Child and Family Behavior Therapy, 28(1), 1-18. doi:10.1300/J019v28n01_01

Block-Lerner, J., Salters-Pednault, K., \& Tull, M. T. (2005). Assessing mindfulness and experiential acceptance: Attempts to capture inherently elusive phenomena. In S. M. Orsillo \& L. Roemer (Eds.), Acceptance and mindfulness-based approaches to anxiety: Conceptualization and treatment (pp. 71-100). NY: Springer. 
Bluth, K., \& Wahler, R. G. (2011). Does effort matter in mindful parenting? Mindfulness, 2(3), 175-178. doi: 10.1007/s12671-011-0056-3

Bond, T. \& Fox, C. (2007). Applying the Rasch model: Fundamental measurement in the human sciences (2nd). Mahwah, NJ: LEA.

Bogels, S., Hoogstad, B., van Dun, L., de Schutter, S., \& Restifo, K. (2008). Mindfulness training for adolescents with externalizing disorders and their parents.

Behavioural and Cognitive Psychotherapy, 26(2), 193-209. doi:

$10.1017 / \mathrm{S} 1352465808004190$

Bogels, S.M., Lehtonen, A., \& Restifo, K. (2010). Mindful parenting in mental health care. Mindfulness, 1(2), 107-120. doi: 10.1007/s12671-010-0014-5

Brown, K. W. \& Ryan, R. M. (2004). Perils and promise in defining and measuring mindfulness: Observations from experience. Clinical Psychology: Science and Practice, 11(3), 242-248. doi:10.1093/clipsy.bph078

Brown, K. W., \& Ryan, R. M. (2003). The benefits of being present: Mindfulness and its role in psychological wellbeing. Journal of Personality and Social Psychology, $84,822-848$

Brown, K. W., Ryan, R. M., \& Creswell, J. D. (2007). Mindfulness: Theoretical foundations and evidence for its salutary effects. Psychological Inquiry, 18(4), 211237. doi:10.1080/10478400701598298

Brown, K. W., West, A. M., Loverich, T. M., \& Biegel, G. M. (2011). Assessing adolescent mindfulness: Validation of an adapted Mindful Attention Awareness 
Scale in adolescent normative and psychiatric populations. Psychological Assessment, 23(4), 1023-1033. doi: 10.1037/a0021338

Burke, C.A. (2010). Mindfulness-based approaches with children and adolescents: A preliminary review of current research in an emergent field. Journal of Child and Family Studies, 19(2), 133-144. doi: 10.1007/s10826-009-9282-x

Carlson, L. E., \& Brown, K. W. (2005). Validation of the Mindful Attention Awareness Scale in a cancer population. Journal of Psychosomatic Research, 58(1), 29-33. doi:10.1016/j.jpsychores.2004.04.366

Coatsworth, J. D., Duncan, L. G., Greenberg, M. T., \& Nix, R. L. (2009). Changing parent's mindfulness, child management skills and relationship quality with their youth: Results form a randomized pilot intervention trial. Journal of Child and Family Studies, 19(2), 203-217. doi: 10.1007/s10826-009-9304-8

Collett, B. R., Gimpel, G. A., Greenson, J. N., \& Gunderson, T. L. (2001). Assessment of discipline styles among parents of preschool through school-age children. Journal of Psychopathology and Behavioral Assessment, 23, 163-170.

Coyne, L. W., \& Wilson, K. G. (2004). The role of cognitive fusion in impaired parenting: An RFT analysis. International Journal of Psychology and Psychological Therapy, 4, 469-486.

Creswell, J.D., Way, B.M., Eisenberger, N.I., \& Lieberman, M.D. (2007). Neural correlates of dispositional mindfulness during affect labeling. Psychosomatic Medicine, 69(6), 560-565. doi:10.1097/PSY.0b013e3180f6171f

Crocker L., \& Algina, J. (2008). Introduction to classical and modern test theory $\left(7^{\text {th }}\right.$ ed.). Mason, $\mathrm{OH}$ : Cengage Learning. . 
Cullen, M., \& Wallace, L. (2010). Stress Management and Relaxation Techniques in Education (SMART) training manual. Unpublished manual, Impact Foundation: Aurora, Colorado.

Dawe, S., \& Harnett, P. (2007). Reducing potential for child abuse among methadonemaintained parents: Results from a randomized controlled trial. Journal of Substance Abuse Treatment, 32(4), 381-390. doi:10.1016/j.jsat.2006.10.003

Dawe, S., Harnett, P. H., Rendalls, V., \& Staiger, P. (2003). Improving family functioning and child outcome in methadone maintained families: The parents under pressure programme. Drug and Alcohol Review, 22(3), 299-307. doi:10.1080/0959523031000154445

De Bruin, E. I., Zijlstra, B. J. H., Geurtzen, N., van Zundert, R. M. P., van de WeijerBergsma, ...Bogels, S. M. (2012). Mindful parenting assessed further: Psychometric properties of the Dutch version of the Interpersonal Mindfulness in Parenting scale (IM-P). Mindfulness. doi: 10.1007/s12671-012-0168-4

Dimidjian, S., \& Linehan, M. (2003). Defining an agenda for future research on the clinical application of mindfulness practice. Clinical Psychology: Science and Practice, 10(2), 166-171. doi:10.1093/clipsy.bpg019

Dishion, T. J., Burraston, B., \& Li, F. (2003). A multimethod and multitrait analysis of family management practices: Convergent and predictive validity. In B. Bukoski $\&$ Z. Amsel (Eds.), Handbookfor drug abuse prevention theory, science, and practice. New York: Plenum. 
DiStefano, C., \& Motl, R. W. (2009). Personality correlates of method effects due to negatively worded items on the Rosenberg self-esteem scale. Personality and Individual Differences, 46(3), 309-313. doi:10.1016/j.paid.2008.10.020

Dumas, J. (2005). Mindfulness-based parent training: Strategies to lessen the grip of automaticity in families with disruptive children. Journal of Clinical Child and Adolescent Psychology, 34(4), 779-791.doi:10.1207/s15374424jccp3404_20

Duncan, L. G. (2007). Assessment of mindful parenting among parents of early adolescents: Development and validation of the Interpersonal Mindfulness in Parenting scale. Unpublished dissertation.

Duncan, L.G., \& Bardacke, N. (2010). Mindfulness-based childbirth and parenting education: Promoting family mindfulness during the prenatal period. Journal of Child and Family Studies, 19(2), 190-202.

Duncan, L.G., Coatsworth, J. D., \& Greenberg, M.T. (2009a). A model of mindful parenting: Implications for parent-child relationships and prevention research. Clinical Child \& Family Psychology Review, 12(3), 255-270. doi: 10.1007/s10567-009-0046-3

Duncan, L. G., Coatsworth, J. D., \& Greenberg, M. T. (2009b). Pilot study to gauge acceptability of a mindfulness-based, family focused preventive intervention. Journal of Primary Prevention, 30(5), 605-618. doi:10.1007/s10935-009-0185-9

Dunn, C., Hanieh, E., Roberts, R., \& Powrie, R. (2012) Mindful pregnancy and childbirth: effects of a mindfulness-based intervention on women's psychological distress and well-being in the perinatal period. Archives of Women's Mental Health, 15(2), 139-143. doi:10.1007/s00737-012-0264-4 
Embretson, S. E., \& Reise, S. P. (2000). Item response theory for psychologists.

Mahwah, NJ: Erlbaum Publishers.

Eyberg, S. M., \& Graham-Pole, J. R. (2005). Mindfulness and behavioral parent training: Commentary. Journal of Clinical Child and Adolescent Psychology, 34(4), 792794. doi: 10.1207/s15374424jccp3404_21

Ferraioli, S. J., \& Harris, S. L. (2012). Comparative effects of mindfulness and skillsbased parent training programs for parents of children with Autism: Feasibility and preliminary outcome data. Mindfulness, 4(2), doi: 10.1007/s12671-012-00990

Fraley, R.C., Waller, N. G., \& Brennan, K. A. (2000). An item response theory analysis of self-report measures of adult attachment. Journal of Personality and Social Psychology, 78(2), 350-365. doi: 10.1037//0022-3514.78.2.350

Frye, S., \& Dawe, S. (2008). Interventions for women prisoners and their children in the post-release period. Clinical Psychology, 12(3), 99-108. doi: $10.1080 / 13284200802516522$

Galla, B., Hale, T. S., Shrestha, A., Loo, S. K., Smalley, S.L. (2012). The disciplined mind: Associations between the Kentucky Inventory of Mindfulness Skills and attention control. Mindfulness, 3(2), 95-103. doi: 10.1007/s12671-011-0083-0

Grossman, P., Niemann, L., Schmidt, S., \& Walach, H. (2004). Mindfulness-based stress reduction and health benefits: A metaanalysis. Journal of Psychosomatic Research, 57, 35-43. 
Hambleton, R. K., \& Jones, R. W. (1993). Comparison of classical test theory and item response theory and their applications to test development. Instructional Topics in Educational Measurement: Issues and Practice, 12(3), 38-47.

Hambleton, R. K., Swaminathan, H., \& Rogers, H. J. (1991). Fundamentals of item response theory. Newbury Park, CA: Sage.

Hansen, E., Lundh, L. G., Homman, A., \& Wangb-Lundh, M. (2009). Measuring mindfulness: Pilot studies with the Swedish versions of the Mindful Attention Awareness Scale and Kentucky Inventory of Mindfulness Skills. Cognitive Behaviour Therapy, 38(1), 2-15. doi: 10.1080/16506070802383230

Harnett, P. H., \& Dawe, S. (2008). Reducing child abuse potential in families identified by social services: Implications for assessment and treatment. Brief Treatment and Crisis Intervention, 8(3), 226-235. doi:10.1093/brief-treatment/mhn010

Harnett, P. H., \& Dawe, S. (2012). Review: The contribution of mindfulness-based therapies for children and families and proposed conceptual integration. Child and Adolescent Mental Health, 17(4), 195-208. doi:10.1111/j.14753588.2011.00643.x

Harvey, E., Danforth, J. S., Ulaszek, W. R., \& Eberhardt, T. L. (2001). Validity of the Parenting Scale for parents of children with attention-deficit/hyperactivity disorder. Behaviour Research and Therapy, 39(6), 731-743. doi:10.1016/S00057967(00)00052-8

Hayes, S. C. (2004). Acceptance and commitment therapy, relational frame theory, and the third wave of behavioral and cognitive therapies. Behavior Therapy, 35(4), 639-665. doi:10.1016/S0005-7894(04)80013-3 
Hayes, S. C., Follette, V. M., \& Linehan, M. M. (Eds.). (2004). Mindfulness and acceptance: Expanding the cognitive-behavioral tradition. New York: Guilford Press.

Hayes, S. C., Strosahl, K., \& Wilson, K. G. (1999). Acceptance and commitment therapy: An experiential approach to behavior change. New York: Guilford Press.

Hayes, S. C., \& Wilson, K. G. (2003). Mindfulness: Method and process. Clinical Psychology: Science and Practice, 10(2), 161-165. doi: 10.1093/clipsy/bpg018

Hill, N. E. (2006). Disentangling ethnicity, socioeconomic status and parenting: Interactions, influences and meaning. Vulnerable Children and Youth Studies, 1(1), 114-124. doi:10.1080/17450120600659069

Irvine, A. B., Biglan, A., Smolkowski, K., Metzler, C. W., \& Ary, D. V. (1999). The effectiveness of a parenting skills program for parents of middle school students in small communities. Journal of Consulting and Clinical Psychology, 67(6), 811825.

Jermann, F., Billieux, J., Laroi, F., d'Argembeau, A., Bondolfi, G.,...van der Linden. (2009). Mindful attention awareness scale (MAAS): Psychometric properties of the French translation and exploration of its relation with emotion regulation strategies. Psychological Assessment, 21(4), 506-514. doi: 10.1037/a0017032

Jha, A., Krompinger, J., \& Baime, M. (2007). Mindfulness training modifies subsystems of attention. Cognitive, Affective \& Behavioural Neuroscience, 7(2), 109-119. doi: 10.3758/CABN.7.2.109

Jobe, J. B. (2003). Cognitive psychology and self-reports: Models and methods. Quality of Life Research, 12, 219-227. 
Joseph, S., Linley, P. A., Harwood, J., Lewis, C. A., \& McCollam, P. (2004). Rapid assessment of well-being: The Short Depression-Happiness Scale (SDHS). Psychology and Psychotherapy, 77(4), 463-478. doi:10.1348/1476083042555406

Kabat-Zinn, J. (1990). Full catastrophe living: Using the wisdom of your body and mind to face stress, pain and illness. New York, NY: Delacorte.

Kabat-Zinn, J. (1994). Wherever you go, there you are: Mindfulness meditation in everyday life. New York: Hyperion.

Kabat-Zinn, J. (2003). Mindfulness-based interventions in context: Past, present and future. Clinical Psychology: Science and Practice, 10(2), 144-156. doi:10.1093/clipsy.bpg016

Kabat-Zinn, J. (2005). Full catastrophe living: Using the wisdom of your body and mind to face stress, pain, and illness. New York, NY: Bantam Dell.

Kabat-Zinn, M. \& Kabat-Zinn, J. (1997). Everyday blessings: The inner work of mindful parenting. New York, NY: Hyperion Books.

Langer, E.J., \& Moldoveanu, M. C. (2000). The construct of mindfulness. Journal of Social Issues, 56(1), 1-9. doi:10.1111/0022-4537.00148

Lane, R. D., Quinlan, D. M., Schwartz, G. E., Walker, P. A., \& Zeitlin, S. B. (1990). The levels of emotional awareness scale: A cognitive-developmental measure of emotion. Journal of Personality Assessment, 55(1), 124-134.

Linacre, J. M. (2013). Rasch-Model Computer Program Manual. Chicago, IL: MESA Press.

Linehan, M. M., (1993). Cognitive-behavioral treatment of borderline personality disorder. New York: Guilford. 
Linehan, M. M., Armstrong, H. E., Suarez, A., Allmon, D., \& Heard, H. L. (1991). Cognitive-behavioral treatment of chronically parasuicidal borderline patients. Archives of General Psychiatry, 48(12), 1060-1064. doi:10.1001/archpsyc.1991.01810360024003

Lorber, M. F., Xu, S., Slep, A. M., Bulling, L., \& O’Leary, S. G. (2014). A new look at the psychometrics of the parenting scale through the lens of item response theory. Journal of Clinical Child and Adolescent Psychology, 43(4), 613-626. doi: $10.1080 / 15374416.2014 .900717$

MacDonald, E. E., \& Hastings, R. P. (2010). Mindful parenting and care involvement of fathers of children with intellectual disabilities. Journal of Child and Family Studies, 19(2), 236-240. doi: 10.1007/s10826-008-9243-9

MacKillop, J., \& Anderson, E. J. (2007). Further psychometric validation of the Mindful Attention Awareness Scale (MAAS). Journal of Psychopathology and Behavioral Assessment, 29(4), 289 -293. doi:10.1007/s10862-007-9045-1

Masters, G.N. (1982). A Rasch model for partial credit scoring. Psychometrika, 47(2), 149. doi:10.1007/BF02296272

Michalak, J., Heidenreich, T., Meibert, P., \& Schulte, D. (2008). Mindfulness predicts relapse/recurrence in major depressive disorder after mindfulness-based cognitive therapy. Journal of Nervous \& Mental Disease, 196(8), 630-633. doi: 10.1097?NMD.0b013e31817d0546

Miners, R. (2008). Collected and connected: Mindfulness and the early adolescent. Dissertations Abstracts International: Section B. The Sciences and Engineering, $68,9$. 
Minor, H. G., Carlson, L. E., Mackenzie, M. J., Zernicke, K., \& Jones, L. (2006). Evaluation of a mindfulness-based stress reduction (MBSR) program for caregivers of children with chronic conditions. Social Word in Health Care, 43(1), 91-109. doi.org/10.1300/J010v43n01_06

Naranjo, C., \& Ornstein, R. E. (1971). On the psychology of meditation. New York: Viking Press.

O’Brien, K.M., Larson, C.M., \& Murrell, A. R. (2008). Third-wave behavior therapies for children and adolescents: Progress, challenges, and future directions. In L. A. Greco \& S. C. Hayes (Eds.), Acceptance and mindfulness treatments for children and adolescents: A practitioner's guide (pp. 15-35). Oakland, CA: New Harbinger Publications, Inc.

Ortner, S., Kilner, S., \& Zelazo, P. (2007). Mindfulness meditation and reduced emotional interference on a cognitive task. Motivation and Emotion, 31(4), 271283. doi:10.1007/s11031-007-9076-7

Perez-Blasco, J., Viguer, P., \& Rodrigo, M. F. (2013). Effects of a mindfulness-based intervention on psychological distress, well-being, and maternal self-efficacy in breast feeding mothers: Results of a pilot study. Archives of Women's Mental Health, 16(3), 227-236. doi: 10.1007/s00737-013-0337-z

Reise, S. P. \& Waller, N. G. (2009). Item Response Theory and Clinical Measurement. Annual Review of Clinical Psychology, 5(1), 27-48. doi:10.1146/annurev.clinpsy.032408.153553

Reitman, D., Currier, R. O., Hupp, S. D. A., Rhode, P. C., Murphy, M. A., \& O'Callaghan, P. M. (2001). Psychometric characteristics of the Parenting Scale in 
a Head Start population. Journal of Clinical Child \& Adolescent Psychology, 30(4), 514-524. doi:10.1207/S15374424JCCP3004_08

Reitman, D., Rhode, P. C., Hupp, S. D. A., \& Altobello, C. (2002). Development and validation of the parental authority questionnaire - revised. Journal of Psychopathology and Behavioral Assessment, 24(2), 119-127. doi:10.1207/S15374424JCCP3004_08

Rhoades, K. A., \& O'Leary, S. G. (2007). Factor structure and validity of the Parenting Scale. Journal of Clinical Child \& Adolescent Psychology, 36(2), 137. doi: $10.1080 / 15374410701274157$

Saltzman, A., \& Goldin, P. (2009). Mindfulness-Based Stress Reduction for school-age children. In L. A. Greco \& S. C. Hayes (Eds.), Acceptance and mindfulness treatments for adolescents and children: A practitioner's guide (pp. 139-161). Oakland, CA: New Harbinger Publications.

Schooler, J. W. (2002). Re-representing consciousness: Dissociations between experience and meta-consciousness. TRENDS in Cognitive Sciences, 6(8), 339-344. doi:10.1016/S1364-6613(02)01949-6

Schroevers, M., Nykliek, I., \& Topman, R. (2008). Validatie van de nederlandstalige versie van de Mindful Attention Awareness Scale (MAAS). Gedragstherapie, 4193, 225-240.

Segal, Z. V., Williams, J. M. G., \& Teasdale, J. D. (2002). Mindfulness-based cognitive therapy for depression: A new approach to relapse prevention. New York: The Guildford Press. 
Siegel, D.J., \& Hartzell, M. (2003). Parenting from the inside out: How a deeper understanding can help you raise children who thrive. New York: The Guilford Press.

Singh, N. N, Lancioni, G. E., Manikam, R., Winton, A. S. W., ...Singh, A. D. A. (2011). A mindfulness-based strategy for self-management of aggressive behavior in adolescents with autism. Research in Autism Spectrum Disorders, 5(3), 11531158. doi:10.1016/j.rasd.2010.12.012

Singh, N. N., Lancioni, G. E., Singh, A. D. A., Winton, A. S. W., Singh, A. N. A., \& Singh, J. (2011). Adolescents with Asperger syndrome can use a mindfulnessbased strategy to control their aggressive behavior. Research in Autism Spectrum Disorders, 5(3), 1103-1109. doi:10.1016/j.rasd.2010.12.006

Singh, N. N., Lancioni, G. E., Singh Joy, S. D., Winton, A. S. W., Sabaawi, M., Wahler, R. G., \& Singh, J. (2007). Adolescents with conduct disorder can be mindful of their aggressive behavior. Journal of Emotional and Behavioral Disorders, 15(1), 56-63. doi:10.1177/10634266070150010601

Singh, N. N., Singh, A. N., Lancioni, G. E., Singh, J., Winton, A. S. W., \& Adkins, A. D. (2009). Mindfulness training for parents and their children with ADHD increases the child's compliance. Journal of Child and Family Studies, 19, 157-166. DOI $10.1007 / \mathrm{s} 10826-009-9272-\mathrm{z}$

Singh, N., Lancioni, G., Winton, A., Fisher, B. C., Curtis, W., Wahler, R.,...Sabaawi, M. (2006). Mindful parenting decreases aggression, noncompliance, and self-injury in children with autism. Journal of Emotional and Behavioral Disorders, 14(3), 169-177. doi: $10.1177 / 10634266060140030401$ 
Singh, N. N., Singh, A. N., Lancioni, G. E., Singh, J., Winton, A. S. W., Singh, J.,...Wahler, R. G. (2010). Mindfulness training for parents and their children with ADHD increases the children's compliance. Journal of Child and Family Studies, 19(2), 157-174. doi:10.1007/s10826-009-9272-z

Spera, C. (2005). A review of the relationship among parenting practices, parenting styles, and adolescent school achievement. Educatioal Psychology review, 17(2), 125-146. doi: 0.1007/s10648-005-3950-1

Srivastava, M., Gupta, A., Talukdar, U., Kalra, B. P., \& Lahan, V. (2011). Effects of parental training in managing the behavioral problems of early childhood. Indian Journal of Pediatrics, 78(8), 973-978. doi: 10.1007/s12098-011-0401-5

Steele, R. G., Nesbitt-Daly, J. S., Daniel, R. C., \& Forehand, R. (2005). Factor structure of the Parenting Scale in a low-income African American sample. Journal of Child and Family Studies, 14(4), 535-549. doi: 10.1007/s10826-005-7187-x

Steinberg, L. (2004). The 10 basic principles of good parenting. New York: Simon \& Schuster.

Tang, Y. Y., Ma, Y., Wang, J., Fan, Y., Feng, S., Lu, Q.,...Posner, M. I. (2007). Shortterm meditation training improves attention and self-regulation. Proceedings of the National Academy of Sciences of the United States of America, 104(43), 17152-17156. doi:10.1073/pnas.0707678104

Uher, R., Farmer, A., Maier, W., Rietschel, M., Hauser, J., ...Aitchison, K.J. (2008). Measuring depression: Comparison and integration of three scales in the GENDEP study. Psychological Medicine, 38(2), 289-300. 
Valentine, E., \& Sweet, P. (1999). Meditation and attention: A comparison of the effects of concentrative and mindfulness meditation on sustained attention. Mental Health, Religion and Culture, 2(1), 59-70. doi:10.1080/13674679908406332

van Dam, N. T., Earleywine, M., \& Borders, A. (2010). Measuring mindfulness? An item response theory analysis of the mindful attention awareness scale. Personality and Individual Differences, 49(7), 805-801. doi:10.1016/j.paid.2010.07.020

van Dam, N. T., Earleywine, M., \& Danoff-Burg, S. (2009). Differential item function across meditators and non-meditators on the Five Facet Mindfulness Questionnaire. Personality and Individual Differences, 47(5), 516-521. doi:10.1016/j.paid.2009.05.005

van de Weijer-Bergsma, Formsma, A. R., de Bruin, E. I., \& Bogels, S. M. (2012). The effectiveness of mindfulness training on behavioral problems and attentional functioning in adolescents with ADHD. Journal of Child and Family Studies, 12(5), 775-787. doi: 10.1007/s10826-011-9531-7

van der Oord, S., Bogels, S. M., \& Peijnenburg, D. (2012). The effectiveness of mindfulness training for children with ADHD and mindful parenting for their parents. Journal of Child and Family Studies, 21(1), 139-147. doi:

$10.1007 / \mathrm{s} 10826-011-9457-0$

Vieten, C., \& Astin, J. (2008). Effects of a mindfulness-based intervention during pregnancy on prenatal stress and mood: results of a pilot study. Archives of Women's Mental Health, 11(1), 67-74. doi:10.1007/s00737-008-0214-3

Wahler, R., Rowinski, K., \& Williams, K. (2008). Mindful parenting: An inductive search process. In L. A. Greco \& S. C. Hayes (Eds.), Acceptance and mindfulness 
treatments for adolescents and children: A practitioner's guide (pp. 217-235).

Oakland, CA: New Harbinger Publications.

Weiss, D. J., \& Kingsbury, G.G. (1984). Application of computerized adaptive testing to educational problems. Journal of Educational Measurement, 21(4), 361-375. doi:10.1111/j.1745-3984.1984.tb01040.x

Williams, M., Teasdale, J., Segal, Z., \& Kabat-Zinn, J. (2007). The mindful way through depression: Freeing yourself from chronic unhappiness. New York, NY: Guilford Press.

Williams, K. L., \& Wahler, R. G. (2010). Are mindful parents more authoritative and less authoritarian? An analysis of clinic-referred mothers. Journal of Child and Family Studies, 19(2), 230-235. doi: 10.1007/s10826-009-9309-3

Wright, B. D., (1998). Model selection: Rating Scale Model (RSM) or Partial Credit Model (PCM)? Rasch Measurement Transactions, 12(3), 641-642.

Zvolensky, M. J., Solomon, S. E., McLeish, A. C., Cassidy, D., Bernstein, A., Bowman, C. J., \& Yartz, A. R. (2006). Incremental validity of mindfulness-based attention in relation to the concurrent prediction of anxiety and depressive symptomatology and perceptions of health. Cognitive Behaviour Therapy, 35(3), 148-158. doi: $10.1080 / 1650607060067408$ 


\section{APPENDICES}

\section{Appendix A: Initial MIPQ Created During Phase 1}

\section{MINDFULNESS IN PARENTING QUESTIONNIARE}

Please reflect on your parenting and interactions with your child over the last two weeks. Read each question carefully, and consider whether this item is true for you NEVER (1), RARELY (2), SOMETIMES (3), OFTEN (4), or ALMOST ALWAYS (5). Try your best to answer each question.

\begin{tabular}{|c|c|c|c|c|c|}
\hline OVER THE PAST TWO WEEKS, HOW OFTEN...? & $\begin{array}{c}1 \\
\text { Never }\end{array}$ & $\begin{array}{c}2 \\
\text { Rarely }\end{array}$ & $\begin{array}{c}3 \\
\text { Sometimes }\end{array}$ & $\begin{array}{c}4 \\
\text { Often }\end{array}$ & $\begin{array}{c}5 \\
\text { Almost } \\
\text { Always }\end{array}$ \\
\hline $\begin{array}{l}\text { 1. Did you carefully listen and tune into your child when you two we } \\
\text { talking }\end{array}$ & & & & & \\
\hline 2. Did you do other things while your child was talking to you & & & & & \\
\hline $\begin{array}{l}\text { 3. Did you catch yourself thinking about something else when your } \\
\text { child was talking to you }\end{array}$ & & & & & \\
\hline $\begin{array}{l}\text { 4. Did you think "I don't have time to listen to my child's side of the } \\
\text { story" }\end{array}$ & & & & & \\
\hline 5. Did you tune your child out when they were talking & & & & & \\
\hline 6. Did you worry about other things when spending time with your cl & & & & & \\
\hline $\begin{array}{l}\text { 7. Did you have difficulty focusing on your child because you were } \\
\text { planning for the future }\end{array}$ & & & & & \\
\hline $\begin{array}{l}\text { 8. Did you find yourself thinking about upcoming activities when } \\
\text { participating in an activity with your child }\end{array}$ & & & & & \\
\hline $\begin{array}{l}\text { 9. Did you let your concerns about the future go when spending time } \\
\text { with your child }\end{array}$ & & & & & \\
\hline 10. Did you watch your child and not let other obligations distract you & & & & & \\
\hline $\begin{array}{l}\text { 11. Did you start saying something to your child, but forgot what your } \\
\text { point was }\end{array}$ & & & & & \\
\hline
\end{tabular}




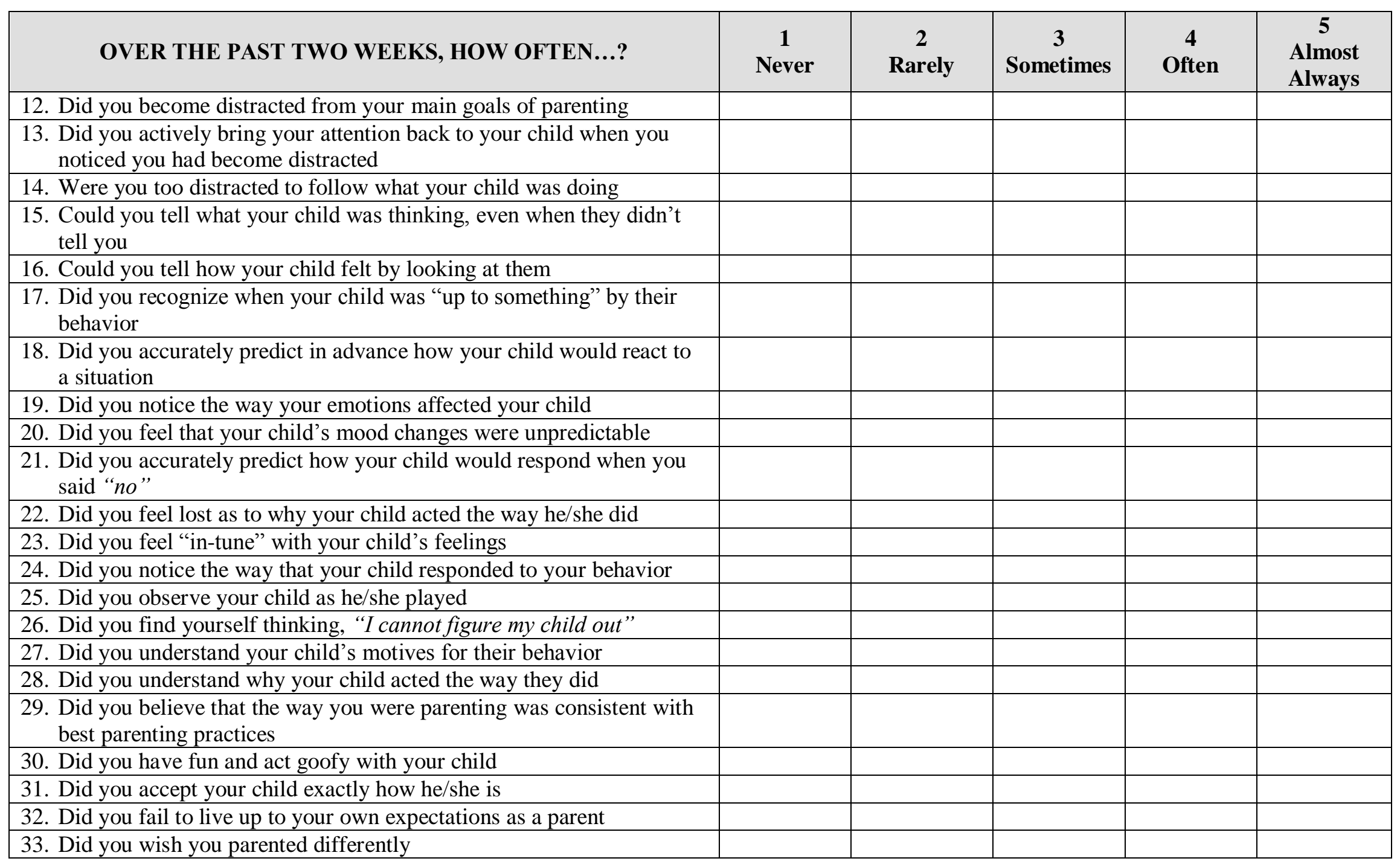




\begin{tabular}{|c|c|c|c|c|c|}
\hline OVER THE PAST TWO WEEKS, HOW OFTEN...? & $\begin{array}{c}1 \\
\text { Never }\end{array}$ & $\begin{array}{c}2 \\
\text { Rarely }\end{array}$ & $\begin{array}{c}3 \\
\text { Sometimes }\end{array}$ & $\begin{array}{c}4 \\
\text { Often }\end{array}$ & $\begin{array}{c}5 \\
\text { Almost } \\
\text { Always }\end{array}$ \\
\hline \multicolumn{6}{|l|}{ 34. Did you wish your child acted differently } \\
\hline \multicolumn{6}{|l|}{$\begin{array}{l}\text { 35. Did you find yourself comparing your child's abilities to other } \\
\text { children }\end{array}$} \\
\hline \multicolumn{6}{|l|}{ 36. Did you wish your child was more like another child } \\
\hline \multicolumn{6}{|l|}{$\begin{array}{l}\text { 37. Did you feel sympathetic for your child for having to grow up in } \\
\text { today's world }\end{array}$} \\
\hline \multicolumn{6}{|l|}{$\begin{array}{l}\text { 38. Did you find yourself thinking, "parenting can be challenging at } \\
\text { times" }\end{array}$} \\
\hline \multicolumn{6}{|l|}{$\begin{array}{l}\text { 39. Did you feel confident in your ability to handle difficult parenting } \\
\text { situations }\end{array}$} \\
\hline \multicolumn{6}{|l|}{ 40. Did you judge yourself for not being a better parent } \\
\hline \multicolumn{6}{|l|}{ 41. Did you wish you weren't so hard on yourself as a parent } \\
\hline \multicolumn{6}{|l|}{ 42. Did you judge your child } \\
\hline \multicolumn{6}{|l|}{ 43. Did you judge your child's behavior } \\
\hline \multicolumn{6}{|l|}{ 44. Did you wish you weren't so critical of your child } \\
\hline \multicolumn{6}{|l|}{ 45. Did others tell you that you were too critical of your child } \\
\hline \multicolumn{6}{|l|}{$\begin{array}{l}\text { 46. Did arguments escalate with your child and spin out of control before } \\
\text { you knew what had happened }\end{array}$} \\
\hline \multicolumn{6}{|l|}{ 47. Did you react too quickly or harshly to your child out of frustration } \\
\hline \multicolumn{6}{|l|}{ 48. Did you react strongly to your child } \\
\hline \multicolumn{6}{|l|}{ 49. Did your patience run out with your child } \\
\hline \multicolumn{6}{|l|}{ 50. Did you consider your feelings before disciplining your child } \\
\hline \multicolumn{6}{|l|}{ 51. Did you consider your child's feelings before disciplining your child } \\
\hline 52. Did you notice when your child's behavior was making you upset & & & & & \\
\hline
\end{tabular}




\begin{tabular}{|c|c|c|c|c|c|}
\hline OVER THE PAST TWO WEEKS, HOW OFTEN...? & $\begin{array}{c}1 \\
\text { Never }\end{array}$ & $\begin{array}{c}2 \\
\text { Rarely }\end{array}$ & $\begin{array}{c}3 \\
\text { Sometimes }\end{array}$ & $\begin{array}{c}4 \\
\text { Often }\end{array}$ & $\begin{array}{c}5 \\
\text { Almost } \\
\text { Always }\end{array}$ \\
\hline $\begin{array}{l}\text { 53. Were you able to calm yourself down when your child was making } \\
\text { you upset }\end{array}$ & & & & & \\
\hline 54. Were you surprised at the way you reacted to your child & & & & & \\
\hline 55. Were you yelling at your child before you knew it & & & & & \\
\hline $\begin{array}{l}\text { 56. Did you notice your thoughts about your child's behavior before } \\
\text { reacting }\end{array}$ & & & & & \\
\hline 57. Were you aware of your emotions when parenting your child & & & & & \\
\hline $\begin{array}{l}\text { 58. Did you sit with your feelings without reacting when something went } \\
\text { wrong with your child }\end{array}$ & & & & & \\
\hline $\begin{array}{l}\text { 59. Did you watch your child doing something without reacting to } \\
\mathrm{him} / \mathrm{her}\end{array}$ & & & & & \\
\hline $\begin{array}{l}\text { 60. Did you let your child know when they were doing something that } \\
\text { bothered you }\end{array}$ & & & & & \\
\hline $\begin{array}{l}\text { 61. Did you immediately have to tell someone when something was } \\
\text { bothering you about your child }\end{array}$ & & & & & \\
\hline $\begin{array}{l}\text { 62. Were you able to talk about your child's misbehavior to someone else } \\
\text { without becoming emotional }\end{array}$ & & & & & \\
\hline $\begin{array}{l}\text { 63. Did you find yourself becoming emotional while thinking about your } \\
\text { child's misbehavior }\end{array}$ & & & & & \\
\hline $\begin{array}{l}\text { 64. Were you able to talk to your child about their misbehavior without } \\
\text { becoming upset }\end{array}$ & & & & & \\
\hline 65. Did you feel guilty or upset when punishing your child & & & & & \\
\hline $\begin{array}{l}\text { 66. Did you find yourself saying things to your child that you didn't mean } \\
\text { because you were upset }\end{array}$ & & & & & \\
\hline 67. Did you take a moment to think before punishing your child & & & & & \\
\hline $\begin{array}{l}\text { 68. Did you choose to do what was best for your child long-term, even } \\
\text { when something different would have been easier }\end{array}$ & & & & & \\
\hline 69. Did you ask your child's opinion & & & & & \\
\hline 70. Did you take time to think about your parenting & & & & & \\
\hline
\end{tabular}




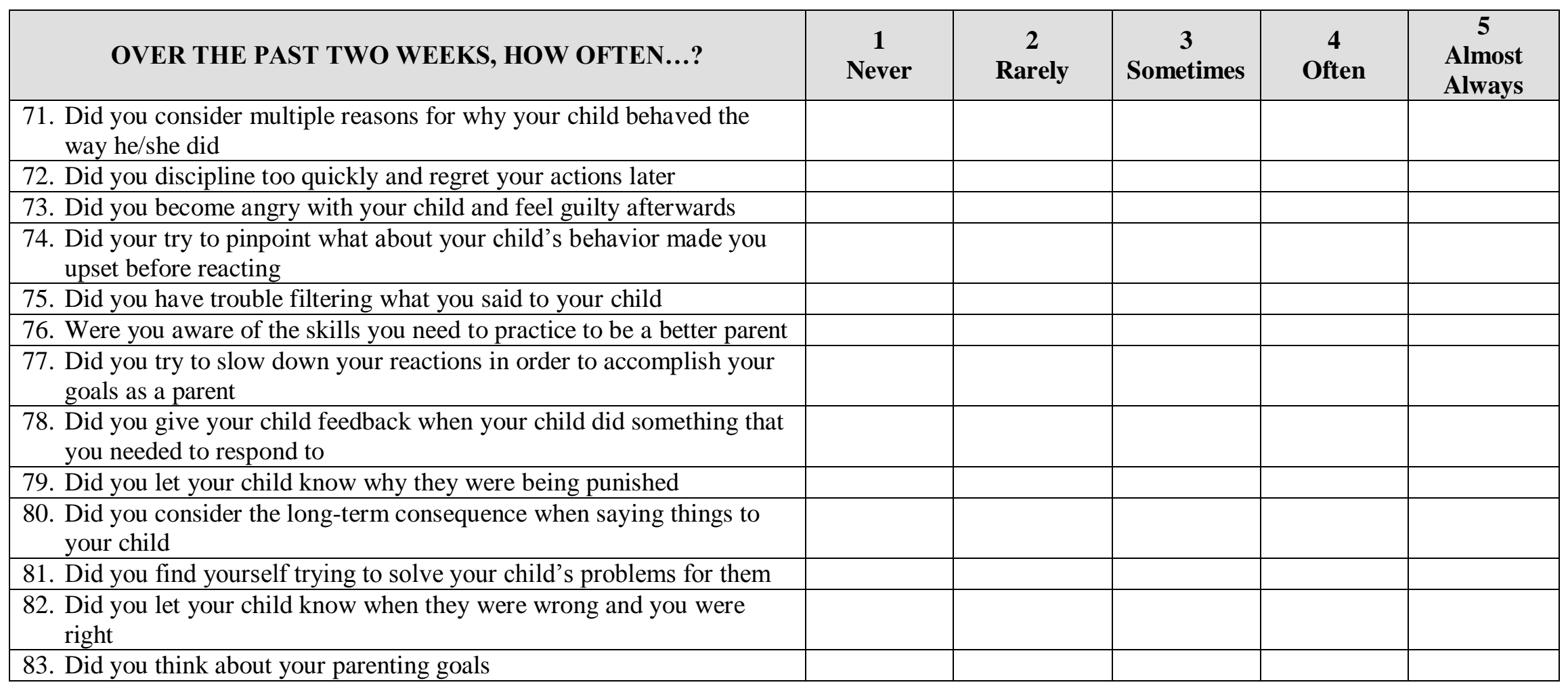




\section{Appendix B: Measures Used During Phase 3 \\ DEMOGRAPHICS QUESTIONNAIRE}

Remember all of your responses are confidential and protected to the fullest extent of the law.

Your responses will not be connected with your name or any identifying information.

About you:

1. Age:

2. Sex (circle):

Male

Female

3. Race/Ethnicity (circle):

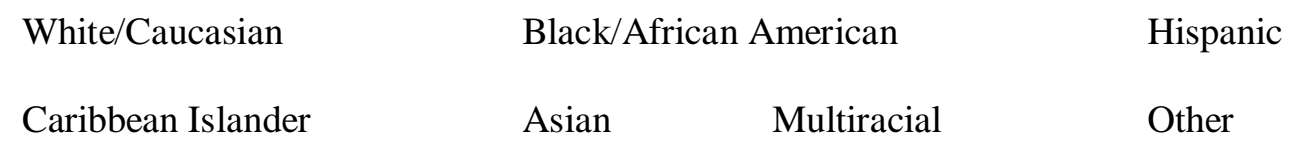

4. Annual Household Income (circle):

$$
\begin{array}{cc}
\text { Under } \$ 30,000 & \$ 30,000-\$ 50,000 \\
\$ 70,000-\$ 100,000 & \$ 50,000-\$ 70,000
\end{array}
$$

5. Education (in years): $<12 \quad 12 /$ GED $\quad 13 \quad 14 \quad 15 \quad 16+$

6. Household family size (including yourself):

$\begin{array}{llllllll}2 & 3 & 4 & 5 & 6 & 7 & 8+\end{array}$

7. Are you currently employed?

$$
\text { Yes No }
$$

8. Marital Status:

$$
\text { Single } \quad \text { MarriedSeparated Divorced }
$$

9. How many children do you have?

10. What are their ages?

11. Do you practice mindfulness or meditation, or participate in a related activity? (e.g., prayer, yoga, tai-chi, etc.)
Yes
No 


\section{If yes, please describe:}

\section{PARENTING SCALE}

(Arnold, O’Leary, Wolff, \& Acker, 1993)

At one time or another, all children misbehave or do things that could be harmful, that are "wrong", or that parents don't like. Examples include: hitting someone, whining or complaining, damaging things, forgetting homework, leaving things lying around, lying, being over-emotional, refusing to follow requests, breaking family rules, swearing, taking other people's things, staying out late.

Parents have many different ways or styles of dealing with these types of problems. Below are items that describe some styles of parenting. For each item, circle the number that best describes your style of parenting during the past 2 months with your child.

\section{Sample Item}

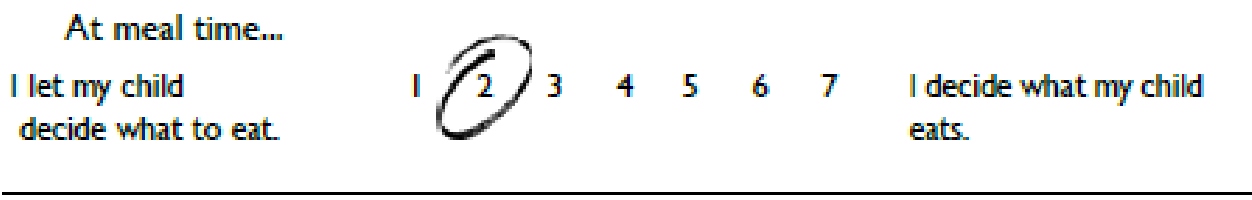

1. When I am upset or under stress...

$\begin{array}{ccccccccc}\text { I'm on my child's back } & 1 & 2 & 3 & 4 & 5 & 6 & 7 & \text { I am not more picky } \\ \text { than usual }\end{array}$

2. When my child misbehaves...

$\begin{array}{llllllll}\text { I usually get into a long } 1 & 2 & 3 & 4 & 5 & 6 & 7 & \text { I don't get into an argument }\end{array}$ argument with my child

3. When my child misbehaves...

$\begin{array}{lllllllll}\text { I raise my voice or yell } & 1 & 2 & 3 & 4 & 5 & 6 & 7 & \text { I speak to my child calmly }\end{array}$

4. When I want my child to stop doing something...

stop

$\begin{array}{lllllllll}\text { I coax or beg my child to } & 1 & 2 & 3 & 4 & 5 & 6 & 7 & \text { I firmly tell my child to }\end{array}$ stop

5. After there's been a problem with my child...
I often hold a grudge
1
3
$\begin{array}{llll}4 & 5 & 6 & 7\end{array}$
Things get back to
normal quickly 
6. When my child does something I don't like...

$\begin{array}{lllllllll}\text { I often let it go } & 1 & 2 & 3 & 4 & 5 & 6 & 7 & \text { I do something about it } \\ \text { every time it happens }\end{array}$

7. When there's a problem with my child...

$\begin{array}{llllllllll}\text { hand } & \begin{array}{l}\text { Things build up and I do } \\ \text { things I don't mean }\end{array} & 1 & 2 & 3 & 4 & 5 & 6 & 7 & \text { Things don't get out of } \\ & & & & & & & & \end{array}$

8. When my child won't do what I ask...

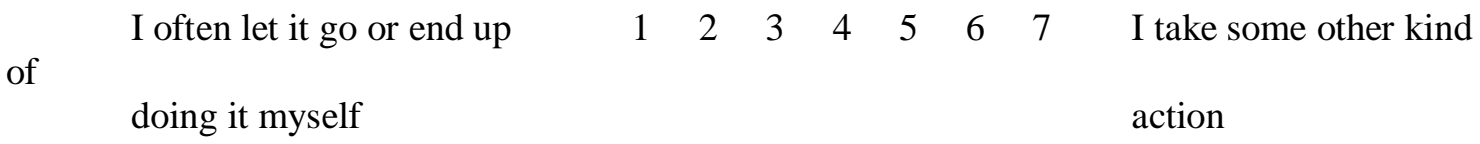

9. If saying "No" doesn't work...

$\begin{array}{llllllllll}\text { of } & \begin{array}{c}\text { I offer my child something } \\ \text { nice so he/she will behave }\end{array} & 1 & 2 & 3 & 4 & 5 & 6 & 7 & \text { I take some other kind } \\ & & & & & & & \text { action }\end{array}$

10. If my child gets upset when I say "No"...

$\begin{array}{llllllllll}\text { I back down and give in } & 1 & 2 & 3 & 4 & 5 & 6 & 7 & \text { I stick to what I said }\end{array}$ 


\section{PARENTAL AUTHORITY QUESTIONNAIRE-REVISED}

(Reitman, Rhode, Hupp, \& Antobello, 2002)

$P A Q-R$ Instructions: For each statement below circle the number that best describes your beliefs about parenting your child. There are no right or wrong answers. We are looking for your overall impression regarding each statement. In the right column, please CIRCLE your answer for each item: $\mathrm{SA}=$ Strongly Agree; $\mathbf{A}=$ Agree ; $\mathrm{N}=$ Neither Agree nor Disagree; $\mathrm{D}=$ Disagree; SD = Strongly Disagree.

There are no right or wrong answers. We are looking for your overall impression regarding each statement. In the right column, please CIRCLE your answer for each item: $\mathrm{SA}=$ Strongly Agree; $\mathrm{A}=\mathrm{Agree} ; \mathrm{N}=$ Neither Agree nor Disagree; Disagree; SD = Strongly Disagrec.

1. In a well-run home children should hove their way as often as porents do.

1. SA A N D SD

2. It is for my children's' own good to require them to do what I think is right, even if they don'l agree.

3. When I ask my chidren to do something. I expect it to be done immediately without questions.

4. Once family rules have been made, I discuss the reasons for the rules with my children.

5. I always encourage discussion when my children feel family rules and restrictions cre unfair.... 6. Children need to be free to make their own decisions obout activities, even if this disagrees with what a parent might want to do.

7. I do not allow my children to question the decisions that I make.

8. I drect the oclivities and decisions of my children by lalking with them and using rewards and punishments.

9. Other parents should use more force lo get their children to behove.

10. My children do not need to cbey rules simply becouse people in authorily have fold them to.

11. My children know what I expect from them, but feel free to tok with me if they feel $\mathrm{my}$ expectations gre unfair.

12. Smart porents should leach their children early exactly who is the boss in the family.

13. I usually don"t sel firm guidelines for my childrens" behavior.

14. Most of the time I do what my chiddren wont when making family decisions.

15. I lell my children what they should do, but I explain why I want them to do it.

16. I get very upset if my ehildien try to cisogree with me.

17. Most problems in soclety would be solved if porents would let their childten chopse their

activilies, make their own decisions, and follow their own desires when growing up.

18. I let my children know what behavior is expecled and if they don't lollow the fules they gel

punished.

19. I allow my children to decide most things for themsetves without a lot of help from me.

20. I Isten to my childten when making decisions, but I do not declde something simply because my children want it.

21. I do not think of myse f as responslble for telïng my children whot to do.

22 I have clear standards of behavior for my children. bul I am willing to change these standards to meet the needs of the child

23 I expect my children to follow my directions, but I am alwoys wiling to listen to their concems and discuss the rules with them.

24. I allow my childen to form their own opinions about family mallers and lel them

make their own decisions about those matters.

25. Most probiems in sociaty could be solved if parents were stricter when their children disobey......

26. I often tell my children exactly what I want them to do ond how I expect them to do it.

27. I set firm guidelines for my children but am understanding when they disagree with me

28 . I do not direct the behoviors, activities $\alpha$ desires of my children.

29. My children know what l expect of them and do what is asked simply out of respect for my authority.

30. If i moke a decision that hurts my children, $1 \mathrm{~cm}$ wiling to odmit that I mede a mistoke.

2. SA A N D SD

3. SA A N D SD

4. SA $A$ N D SD

5. SA A N D SD

6. SA A N D SD

7. SA A N D SO

8. SA A N D SO

9. SA A N D SO

10. SA A N D SD

11. SA A N D SD

12. $S A$ A $N$ D SD

13. SA A N D SD

14. SA A $N$ D SD

15. SA A N D SD

16. SA A N D SD

17. SA A N D SD

18. SA A N D SD

- 19. SA A N D SD

20. SA A N D SO

21. SA A N D SD

22. SA A N D SD

23. $5 A$ A $N$ D SD

24. SA A N D SO

25. SA A N D SD

26. SA A N D SD

27. SA A N D SD

28. 5A A $N$ D SD

29. SA A N D SO

30. SA A N D SD 


\section{MINDFUL ATTENTION AWARENESS SCALE}

(Brown \& Ryan, 2003)

Instructions: Below is a collection of statements about your everyday experience. Using the 1-6 scale below, please indicate how frequently or infrequently you currently have each experience. Please answer according to what really reflects your experience rather than what you think your experience should be. Please treat each item separately from every other item.

$\begin{array}{cccccc}1 & 2 & 3 & 4 & 5 & 6 \\ \text { Almost } & \text { Very } & \text { Somewhat } & \text { Somewhat } & \text { Very } & \text { Almost } \\ \text { Always } & \text { Frequently } & \text { Frequently } & \text { Infrequently } & \text { Infrequently } & \text { Never }\end{array}$

I could be experiencing some emotion and not be conscious of it until some time later.

I break or spill things because of carelessness, not paying attention, or thinking of something else.

I find it difficult to stay focused on what's happening in the present.

I tend to walk quickly to get where I'm going without paying attention to what I experience along the way.

I tend not to notice feelings of physical tension or discomfort until they really grab my attention.

I forget a person's name almost as soon as I've been told it for the first time.

It seems I am "running on automatic," without much awareness of what I'm doing.

I rush through activities without being really attentive to them.

I get so focused on the goal I want to achieve that I lose touch with what I'm doing right now to get there.

I do jobs or tasks automatically, without being aware of what I'm doing.

\begin{tabular}{|c|c|c|c|c|}
\hline 1 & 2 & 3 & 4 & 5 \\
\hline 1 & 2 & 3 & 4 & 5 \\
\hline 1 & 2 & 3 & 4 & 5 \\
\hline 1 & 2 & 3 & 4 & 5 \\
\hline 1 & 2 & 3 & 4 & 5 \\
\hline 1 & 2 & 3 & 4 & 5 \\
\hline 1 & 2 & 3 & 4 & 5 \\
\hline 1 & 2 & 3 & 4 & 5 \\
\hline 1 & 2 & 3 & 4 & 5 \\
\hline 1 & 2 & 3 & & 5 \\
\hline
\end{tabular}


I find myself listening to someone with one ear, doing something else at the same time.

I drive places on "automatic pilot" and then wonder why I went there.

I find myself preoccupied with the future or the past.

I find myself doing things without paying attention.

I snack without being aware that I'm eating. $\begin{array}{llllll}1 & 2 & 3 & 4 & 5 & 6\end{array}$

$\begin{array}{llllll}1 & 2 & 3 & 4 & 5 & 6\end{array}$

$\begin{array}{llllll}1 & 2 & 3 & 4 & 5 & 6\end{array}$

$\begin{array}{llllll}1 & 2 & 3 & 4 & 5 & 6\end{array}$

$\begin{array}{llllll}1 & 2 & 3 & 4 & 5 & 6\end{array}$ 


\section{MINDFULNESS IN PARENTING QUESTIONNAIRE}

Please reflect on your parenting and interactions with your child over the last two weeks. Read each question carefully, and consider whether this item is true for you NEVER (1), RARELY (2), SOMETIMES (3), OFTEN (4), or ALMOST ALWAYS (5). Try your best to answer each question.

\begin{tabular}{|c|c|c|c|c|c|}
\hline OVER THE PAST TWO WEEKS, HOW OFTEN...? & $\begin{array}{c}1 \\
\text { Never }\end{array}$ & $\begin{array}{c}2 \\
\text { Rarely }\end{array}$ & $\begin{array}{c}3 \\
\text { Sometimes }\end{array}$ & $\begin{array}{c}4 \\
\text { Often }\end{array}$ & $\begin{array}{c}5 \\
\text { Almost } \\
\text { Always }\end{array}$ \\
\hline $\begin{array}{l}\text { 1. Did you carefully listen and tune into your child when you two } \\
\text { were talking }\end{array}$ & & & & & \\
\hline 2. Did you do other things while your child was talking to you & & & & & \\
\hline $\begin{array}{l}\text { 3. Did you catch yourself thinking about something else when } \\
\text { your child was talking to you }\end{array}$ & & & & & \\
\hline $\begin{array}{l}\text { 4. Did you think "I don't have time to listen to my child's side of } \\
\text { the story" }\end{array}$ & & & & & \\
\hline $\begin{array}{l}\text { 5. Did you let your concerns about the future go when spending } \\
\text { time with your child }\end{array}$ & & & & & \\
\hline $\begin{array}{l}\text { 6. Did you watch your child and not let other obligations distract } \\
\text { you }\end{array}$ & & & & & \\
\hline $\begin{array}{l}\text { 7. Did you start saying something to your child, but forgot what } \\
\text { your point was }\end{array}$ & & & & & \\
\hline 8. Did you become distracted from your main goals of parenting & & & & & \\
\hline $\begin{array}{l}\text { 9. Did you actively bring your attention back to your child when } \\
\text { you noticed you had become distracted }\end{array}$ & & & & & \\
\hline $\begin{array}{l}\text { 10. Could you tell what your child was thinking, even when they } \\
\text { didn't tell you }\end{array}$ & & & & & \\
\hline 11. Could you tell how your child felt by looking at them & & & & & \\
\hline
\end{tabular}




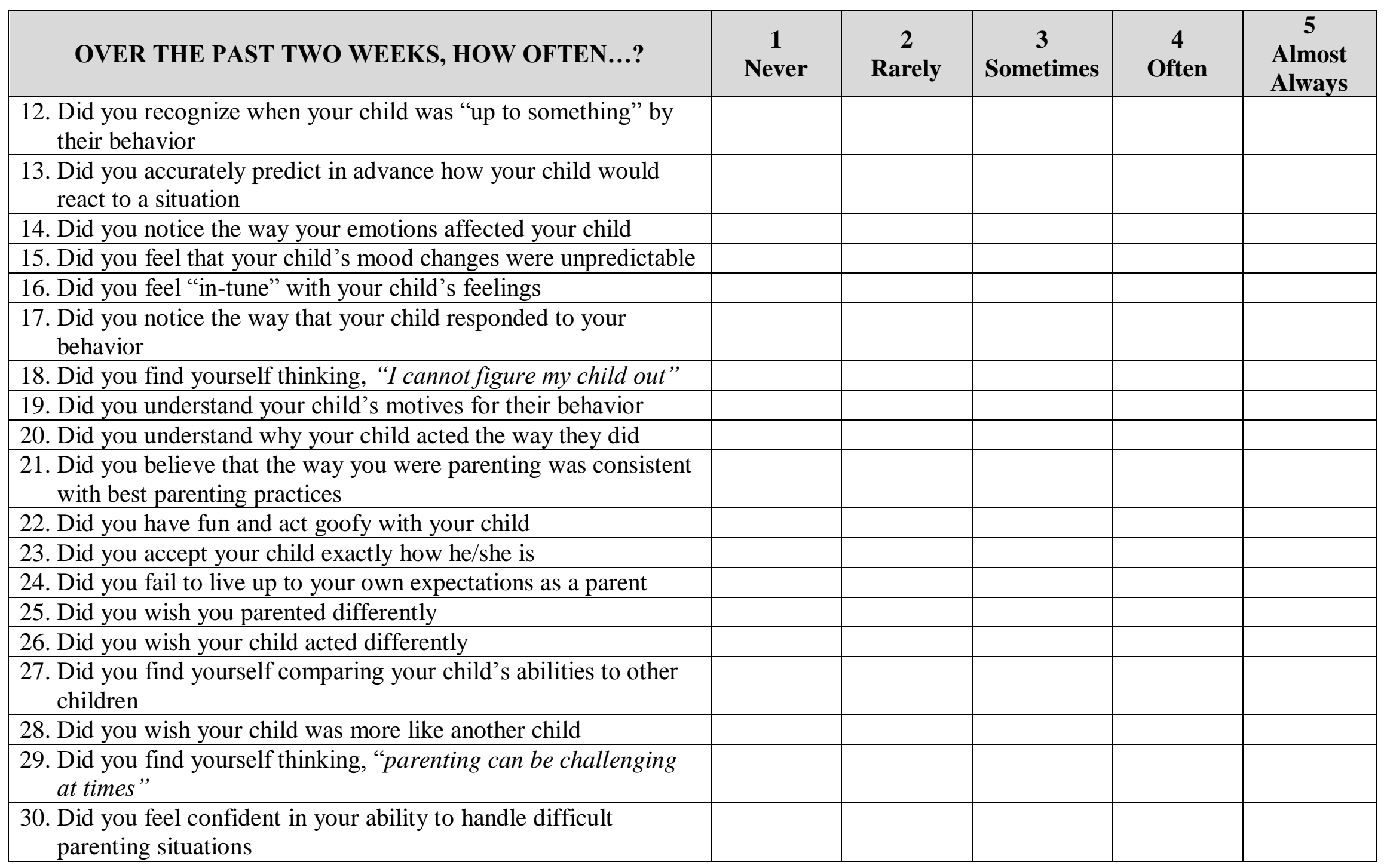




\begin{tabular}{|c|c|c|c|c|c|}
\hline OVER THE PAST TWO WEEKS, HOW OFTEN...? & $\begin{array}{c}1 \\
\text { Never }\end{array}$ & $\begin{array}{c}2 \\
\text { Rarely }\end{array}$ & $\begin{array}{c}3 \\
\text { Sometimes }\end{array}$ & $\begin{array}{c}4 \\
\text { Often }\end{array}$ & $\begin{array}{c}5 \\
\text { Almost } \\
\text { Always }\end{array}$ \\
\hline \multicolumn{6}{|l|}{ 31. Did you judge your child } \\
\hline \multicolumn{6}{|l|}{ 32. Did you wish you weren't so critical of your child } \\
\hline \multicolumn{6}{|l|}{ 33. Did others tell you that you were too critical of your child } \\
\hline \multicolumn{6}{|l|}{$\begin{array}{l}\text { 34. Did arguments escalate with your child and spin out of control } \\
\text { before you knew what had happened }\end{array}$} \\
\hline \multicolumn{6}{|l|}{$\begin{array}{l}\text { 35. Did you react too quickly or harshly to your child out of } \\
\text { frustration }\end{array}$} \\
\hline \multicolumn{6}{|l|}{ 36. Did your patience run out with your child } \\
\hline \multicolumn{6}{|l|}{ 37. Did you consider your feelings before disciplining your child } \\
\hline \multicolumn{6}{|l|}{$\begin{array}{l}\text { 38. Did you consider your child's feelings before disciplining your } \\
\text { child }\end{array}$} \\
\hline \multicolumn{6}{|l|}{$\begin{array}{l}\text { 39. Did you notice when your child's behavior was making you } \\
\text { upset }\end{array}$} \\
\hline \multicolumn{6}{|l|}{$\begin{array}{l}\text { 40. Were you able to calm yourself down when your child was } \\
\text { making you upset }\end{array}$} \\
\hline \multicolumn{6}{|l|}{ 41. Were you surprised at the way you reacted to your child } \\
\hline \multicolumn{6}{|l|}{ 42. Were you yelling at your child before you knew it } \\
\hline \multicolumn{6}{|l|}{$\begin{array}{l}\text { 43. Did you notice your thoughts about your child's behavior before } \\
\text { reacting }\end{array}$} \\
\hline \multicolumn{6}{|l|}{$\begin{array}{l}\text { 44. Did you watch your child doing something without reacting to } \\
\mathrm{him} / \mathrm{her}\end{array}$} \\
\hline \multicolumn{6}{|l|}{$\begin{array}{l}\text { 45. Did you let your child know when they were doing something } \\
\text { that bothered you }\end{array}$} \\
\hline \multicolumn{6}{|l|}{$\begin{array}{l}\text { 46. Did you immediately have to tell someone when something was } \\
\text { bothering you about your child }\end{array}$} \\
\hline \multicolumn{6}{|l|}{$\begin{array}{l}\text { 47. Did you find yourself becoming emotional while thinking about } \\
\text { your child's misbehavior }\end{array}$} \\
\hline 48. Did you feel guilty or upset when punishing your child & & & & & \\
\hline
\end{tabular}




\begin{tabular}{|c|c|c|c|c|c|}
\hline OVER THE PAST TWO WEEKS, HOW OFTEN...? & $\begin{array}{c}1 \\
\text { Never }\end{array}$ & $\begin{array}{c}2 \\
\text { Rarely }\end{array}$ & $\begin{array}{c}3 \\
\text { Sometimes }\end{array}$ & $\begin{array}{c}4 \\
\text { Often }\end{array}$ & $\begin{array}{c}5 \\
\text { Almost } \\
\text { Always }\end{array}$ \\
\hline \multicolumn{6}{|l|}{$\begin{array}{l}\text { 49. Did you find yourself saying things to your child that you didn't } \\
\text { mean because you were upset }\end{array}$} \\
\hline \multicolumn{6}{|l|}{ 50. Did you take a moment to think before punishing your child } \\
\hline \multicolumn{6}{|l|}{$\begin{array}{l}\text { 51. Did you choose to do what was best for your child long-term, } \\
\text { even when something different would have been easier }\end{array}$} \\
\hline \multicolumn{6}{|l|}{ 52. Did you ask your child's opinion } \\
\hline \multicolumn{6}{|l|}{ 53. Did you take time to think about your parenting } \\
\hline \multicolumn{6}{|l|}{$\begin{array}{l}\text { 54. Did you consider multiple reasons for why your child behaved } \\
\text { the way he/she did }\end{array}$} \\
\hline \multicolumn{6}{|l|}{$\begin{array}{l}\text { 55. Did you become angry with your child and feel guilty } \\
\text { afterwards }\end{array}$} \\
\hline \multicolumn{6}{|l|}{ 56. Did you have trouble filtering what you said to your child } \\
\hline \multicolumn{6}{|l|}{$\begin{array}{l}\text { 57. Were you aware of the skills you need to practice to be a better } \\
\text { parent }\end{array}$} \\
\hline \multicolumn{6}{|l|}{$\begin{array}{l}\text { 58. Did you try to slow down your reactions in order to accomplish } \\
\text { your goals as a parent }\end{array}$} \\
\hline \multicolumn{6}{|l|}{ 59. Did you let your child know why they were being punished } \\
\hline \multicolumn{6}{|l|}{$\begin{array}{l}\text { 60. Did you find yourself trying to solve your child's problems for } \\
\text { them }\end{array}$} \\
\hline $\begin{array}{l}\text { 61. Did you let your child know when they were wrong and you } \\
\text { were right }\end{array}$ & & & & & \\
\hline
\end{tabular}




\section{Appendix C: Mindfulness In Parenting Questionnaire}

Please reflect on your parenting and interactions with your child over the last two

weeks. Read each question carefully, and consider whether this item is true for you

NEVER (1), RARELY (2), SOMETIMES (3), OFTEN (4), or ALMOST ALWAYS

(5). Try your best to answer each question.

\begin{tabular}{|c|c|c|c|c|c|}
\hline $\begin{array}{l}\text { OVER THE PAST TWO WEEKS, } \\
\text { HOW OFTEN...? }\end{array}$ & $\begin{array}{c}1 \\
\text { Never }\end{array}$ & $\begin{array}{c}2 \\
\text { Rarely }\end{array}$ & $\begin{array}{c}3 \\
\text { Sometimes }\end{array}$ & $\begin{array}{c}4 \\
\text { Often }\end{array}$ & \begin{tabular}{|c|}
5 \\
Almost \\
Always
\end{tabular} \\
\hline $\begin{array}{l}\text { 1. Did you carefully listen and tune into } \\
\text { your child when you two were talking }\end{array}$ & 1 & 2 & 3 & 4 & 5 \\
\hline $\begin{array}{l}\text { 2. did you actively bring your attention } \\
\text { back to your child when you noticed you } \\
\text { had become distracted }\end{array}$ & 1 & 2 & 3 & 4 & 5 \\
\hline $\begin{array}{l}\text { 3. Could you tell what your child was } \\
\text { thinking, even when they didn't tell you }\end{array}$ & 1 & 2 & 3 & 4 & 5 \\
\hline $\begin{array}{l}\text { 4. Could you tell how your child felt by } \\
\text { looking at them }\end{array}$ & 1 & 2 & 3 & 4 & 5 \\
\hline $\begin{array}{l}\text { 5. Did you recognize when your child } \\
\text { was "up to something" by their behavior }\end{array}$ & 1 & 2 & 3 & 4 & 5 \\
\hline $\begin{array}{l}\text { 6. Did you accurately predict in advance } \\
\text { how your child would react to a situation }\end{array}$ & 1 & 2 & 3 & 4 & 5 \\
\hline $\begin{array}{l}\text { 7. Did you notice the way your emotions } \\
\text { affected your child }\end{array}$ & 1 & 2 & 3 & 4 & 5 \\
\hline $\begin{array}{l}\text { 8. Did you feel "in-tune" with your } \\
\text { child's feelings }\end{array}$ & 1 & 2 & 3 & 4 & 5 \\
\hline $\begin{array}{l}\text { 9. Did you notice the way that your child } \\
\text { responded to your behavior }\end{array}$ & 1 & 2 & 3 & 4 & 5 \\
\hline $\begin{array}{l}\text { 10. Did you understand your child's } \\
\text { motives for their behavior }\end{array}$ & 1 & 2 & 3 & 4 & 5 \\
\hline $\begin{array}{l}\text { 11. Did you understand why your child } \\
\text { acted the way they did }\end{array}$ & 1 & 2 & 3 & 4 & 5 \\
\hline $\begin{array}{l}\text { 12. Did you have fun and act goofy with } \\
\text { your child }\end{array}$ & 1 & 2 & 3 & 4 & 5 \\
\hline $\begin{array}{l}\text { 13. Did you accept your child exactly } \\
\text { how he/she is }\end{array}$ & 1 & 2 & 3 & 4 & 5 \\
\hline $\begin{array}{l}\text { 14. Did you believe that the way you } \\
\text { were parenting was consistent with best } \\
\text { parenting practices }\end{array}$ & 1 & 2 & 3 & 4 & 5 \\
\hline $\begin{array}{l}\text { 15. Did you feel confident in your ability } \\
\text { to handle difficult parenting situations }\end{array}$ & 1 & 2 & 3 & 4 & 5 \\
\hline $\begin{array}{l}\text { 16. Did you consider your feelings b } \\
\text { before disciplining your child }\end{array}$ & 1 & 2 & 3 & 4 & 5 \\
\hline
\end{tabular}




\begin{tabular}{|l|c|c|c|c|c|}
\hline $\begin{array}{l}\text { OVER THE PAST TWO WEEKS, } \\
\text { HOW OFTEN...? }\end{array}$ & $\begin{array}{c}\mathbf{1} \\
\text { Never }\end{array}$ & $\begin{array}{c}\mathbf{2} \\
\text { Rarely }\end{array}$ & $\begin{array}{c}\mathbf{3} \\
\text { Sometimes }\end{array}$ & $\begin{array}{c}\mathbf{4} \\
\text { Often }\end{array}$ & $\begin{array}{c}\mathbf{5} \\
\text { Almost } \\
\text { Always }\end{array}$ \\
\hline $\begin{array}{l}\text { 17. Did you consider your child's } \\
\text { feelings before disciplining your child }\end{array}$ & 1 & 2 & 3 & 4 & 5 \\
\hline $\begin{array}{l}\text { 18. Did you notice when your child's } \\
\text { behavior was making you upset }\end{array}$ & 1 & 2 & 3 & 4 & 5 \\
\hline $\begin{array}{l}\text { 19. Were you able to calm yourself } \\
\text { down when your child was making you } \\
\text { upset }\end{array}$ & 1 & 2 & 3 & 4 & 5 \\
\hline $\begin{array}{l}\text { 20. Did you notice your thoughts about } \\
\text { your child's behavior before reacting }\end{array}$ & 1 & 2 & 3 & 4 & 5 \\
\hline $\begin{array}{l}\text { 21. Did you let your child know when } \\
\text { they were doing something that bothered } \\
\text { you }\end{array}$ & 1 & 2 & 3 & 4 & 5 \\
\hline $\begin{array}{l}\text { 22. Did you take a moment to think } \\
\text { before punishing your child }\end{array}$ & 1 & 2 & 3 & 4 & 5 \\
\hline $\begin{array}{l}\text { 23. Did you choose to do what was best } \\
\text { for your child long-term, even when } \\
\text { something different would have been } \\
\text { easier }\end{array}$ & 1 & 2 & 3 & 4 & 5 \\
\hline 24. Did you ask your child's opinion & 1 & 2 & 3 & 4 & 5 \\
\hline $\begin{array}{l}\text { 25. Did you take time to think about } \\
\text { your parenting }\end{array}$ & 1 & 2 & 3 & 4 & 5 \\
\hline $\begin{array}{l}\text { 26. Did you consider multiple reasons } \\
\text { for why your child behaved the way } \\
\text { he/she did }\end{array}$ & 1 & 2 & 3 & 4 & 5 \\
\hline $\begin{array}{l}\text { 27. Did you try to slow down your } \\
\text { reactions in order to accomplish your } \\
\text { goals as a parent }\end{array}$ & 1 & 2 & 3 & 4 & 5 \\
\hline $\begin{array}{l}\text { 28. Did you let your child know why } \\
\text { they were being punished }\end{array}$ & 1 & 2 & 3 & 5 \\
\hline
\end{tabular}

Please review your responses to ensure that you answered each item. 


\section{Appendix D1: Eigenvalues from Factor Analysis}

\begin{tabular}{|c|c|c|c|}
\hline Component & Total & $\%$ of Variance & Cumulative \% \\
\hline 1 & 9.493 & 28.768 & 28.768 \\
\hline 2 & 2.430 & 7.364 & 36.132 \\
\hline 3 & 1.791 & 5.427 & 41.559 \\
\hline 4 & 1.677 & 5.081 & 46.639 \\
\hline 5 & 1.320 & 3.999 & 50.638 \\
\hline 6 & 1.264 & 3.831 & 54.469 \\
\hline 7 & 1.211 & 3.670 & 58.138 \\
\hline 8 & 1.091 & 3.305 & 61.443 \\
\hline 9 & 1.027 & 3.113 & 64.556 \\
\hline 10 & .936 & 2.836 & 67.392 \\
\hline 11 & .914 & 2.770 & 70.163 \\
\hline 12 & .855 & 2.592 & 72.754 \\
\hline 13 & .817 & 2.476 & 75.230 \\
\hline 14 & .731 & 2.216 & 77.446 \\
\hline 15 & .669 & 2.028 & 79.475 \\
\hline 16 & .657 & 1.991 & 81.466 \\
\hline 17 & .607 & 1.840 & 83.306 \\
\hline 18 & .598 & 1.812 & 85.118 \\
\hline 19 & .538 & 1.629 & 86.747 \\
\hline 20 & .496 & 1.504 & 88.251 \\
\hline 21 & .458 & 1.387 & 89.637 \\
\hline 22 & .414 & 1.255 & 90.893 \\
\hline 23 & .386 & 1.170 & 92.062 \\
\hline 24 & .358 & 1.086 & 93.149 \\
\hline 25 & .328 & .995 & 94.143 \\
\hline
\end{tabular}




\begin{tabular}{|l|c|c|c|}
\hline 26 & .308 & .934 & 95.077 \\
\hline 27 & .297 & .901 & 95.978 \\
\hline 28 & .282 & .854 & 96.832 \\
\hline 29 & .253 & .766 & 97.598 \\
\hline 30 & .240 & .727 & 98.325 \\
\hline 31 & .221 & .670 & 98.995 \\
\hline 32 & .176 & .535 & 99.530 \\
\hline 33 & .155 & .470 & 100.000 \\
\hline
\end{tabular}




\section{Appendix D2: Scree Plot of MIPQ Positively Worded Items following PCA}

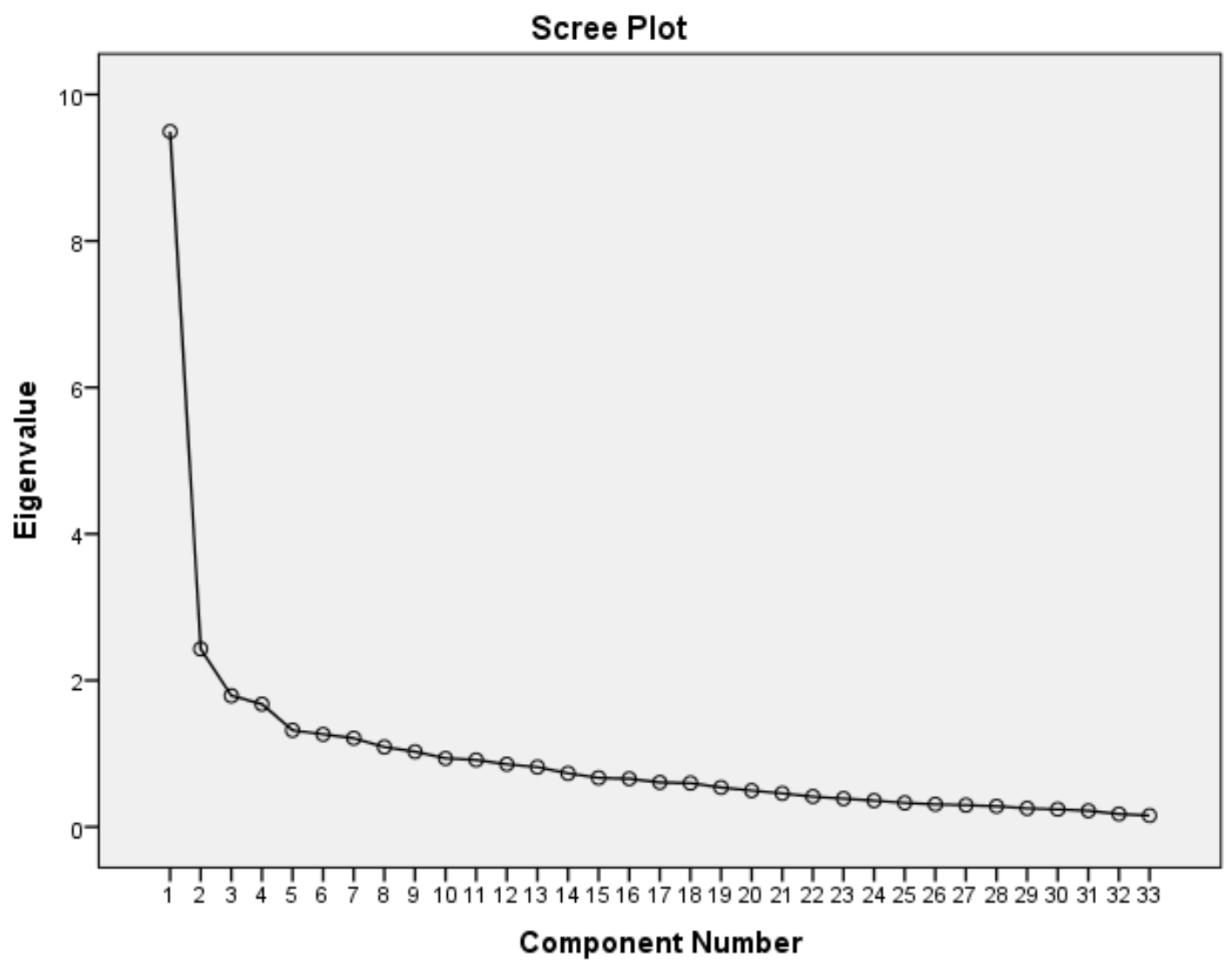

